\title{
\#LoveRugbyRespectWomen: An exploratory study of women's interactions with New Zealand rugby culture in the night- time economy
}

\author{
By \\ Genevieve Courtney
}

A thesis submitted to Victoria University of Wellington in fulfillment of the requirements for the degree of Master of Arts in Criminology 


\section{Abstract}

Following recent high-profile allegations of gender-based violence perpetrated by professional rugby players in contexts involving alcohol in New Zealand, concerns regarding the safety of women in the context of New Zealand rugby culture have emerged. Despite these concerns, no previous studies have explored how rugby culture is enacted in gendered environments where alcohol is consumed, nor has research considered how women in these environments perceive or experience rugby culture. This research addresses an important literature gap, by exploring how women working in licensed leisure venues perceive and experience New Zealand rugby culture. Applying a feminist lens, this qualitative study employed semi-structured interviews with fifteen women who had experience working in New Zealand's nighttime economy. This study found that experiences of violence, degradation, and sexual objectification were a routine and expected part of the women's interactions with rugby culture. These experiences profoundly impacted their ability to enjoy and participate in rugby, compromised their feelings of workplace safety and satisfaction, and contributed to a range of adverse mental health outcomes. While alcohol was considered to exacerbate antisocial behaviours within rugby culture, the participants identified multiple pathways to rugby-related violence, all of which can be linked to a 'Kiwi bloke' version of masculinity that prizes heterosexuality, toughness, and alcohol consumption. Based on these findings, this research concludes that in gendered environments that involve alcohol, New Zealand rugby culture cannot be considered a safe culture for women. This study therefore emphasises the need to prioritise ways of addressing attitudes, behaviours, and approaches to masculinity within rugby culture that may be conducive to gender-based violence and, given the cultural dominance of rugby in New Zealand, serves as an urgent call for further empirical research to inform the development of violence prevention and management strategies. 


\section{Acknowledgements}

This thesis would not have been possible without the support of many. Firstly, I would like to thank the women who participated in this research for taking the time to be interviewed and for trusting me with your stories. The insights and knowledge that you have provided is invaluable, and I am truly grateful for your participation.

Secondly, I would like to acknowledge the help of my supervisors, Lynzi Armstrong and Fiona Hutton. Thank you both for believing in my capabilities as a researcher, and for the time, feedback, guidance, encouragement, and emotional support that you have given me throughout. I could not have wished for better supervision.

Mum and Dad, no words can express my gratitude. Without you both, I would not have achieved what I have today. Thank you.

Bernie and Noel, thank you for welcoming me into your home, and for all that you have done for Kieran and I.

Kieran, thank you for always having my morning coffee ready for me, for watching countless episodes of Grand Design's with me, and for your unconditional love and patience.

Steph, Georgia, Reena, and Hannah - thank you for keeping my spirits up, for dealing with my self-doubt, and for giving me the reassurance I needed to complete this thesis.

Finally, I would like to acknowledge the support offered by the wonderful staff at NZPC. In particular, I would like to thank Catherine Healy for making me feel welcome at NZPC. It was a pleasure getting to know you and the team. 


\section{Contents}

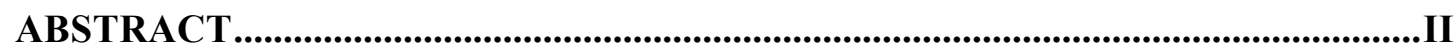

ACKNOWLEDGEMENTS _................................................................................................ III

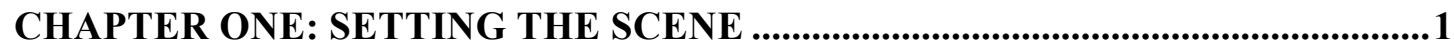

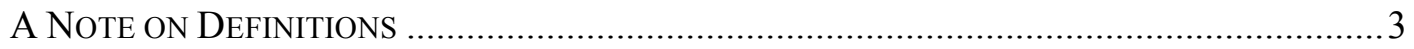

Gender-Based Violence - Against Women? ............................................................. 3

SPORT, MASCULINITY, AND VIOLENCE: AN INTRODUCTION.............................................

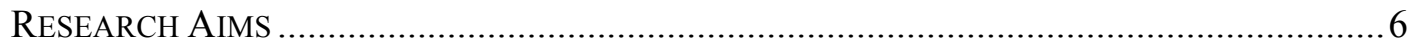

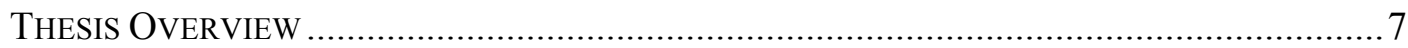

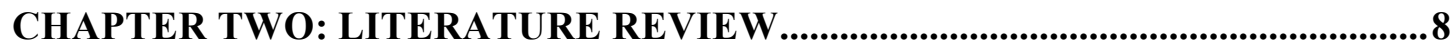

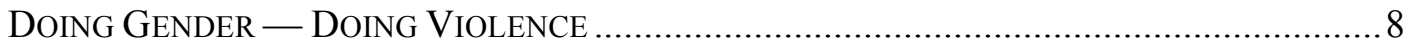

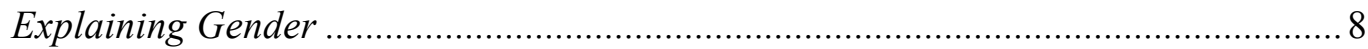

Theorising Gender-based Violence .................................................................... 10

DOING GENDER AND VIOLENCE IN THE NigHT-TIME ECONOMY..................................... 13

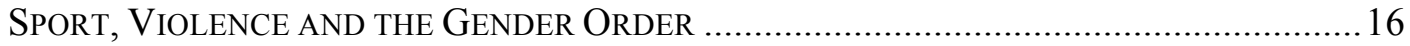

Sport as a Masculine Proving Ground ......................................................................... 16

The Sports Participation and Violence Against Women Debate.............................. 19

Alcohol Consumption and Sports-Related Violence …............................................22

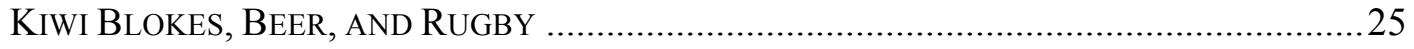

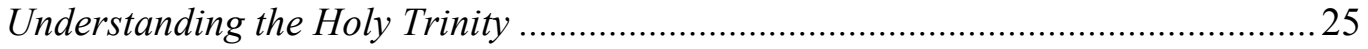

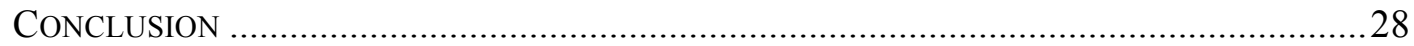

CHAPTER THREE: METHODOLOGICAL FRAMEWORK ...............................30

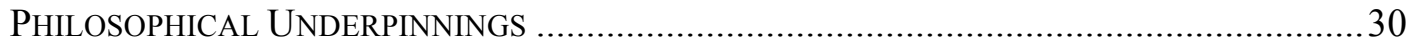

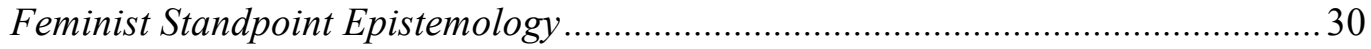

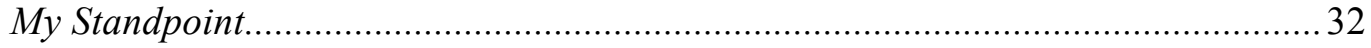

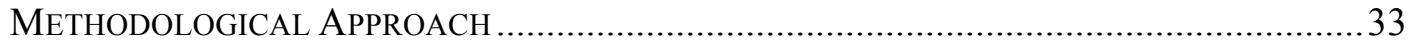

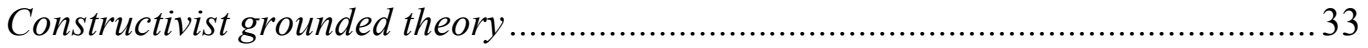

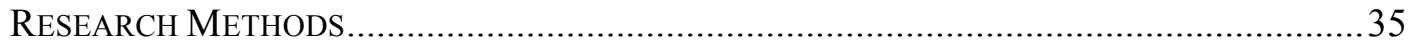

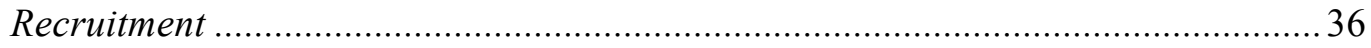

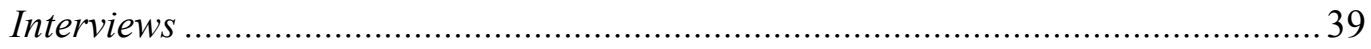

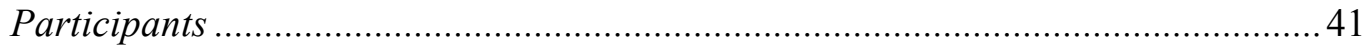

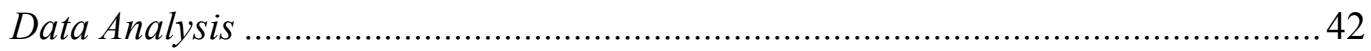

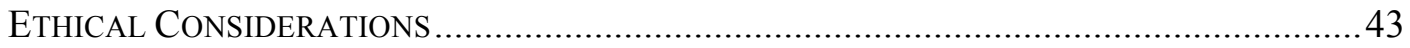


LIMITATIONS

NAVigating THE ReSEARCH PROCEss

\section{CHAPTER FOUR: EXPERIENCING RUGBY CULTURE IN THE NIGHT-TIME}

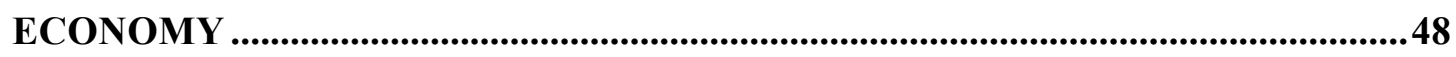

RUGBY AS A MASCULINIST CULTURE OF INTOXICATION ................................................. 48

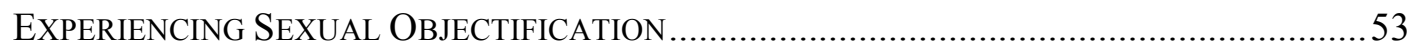

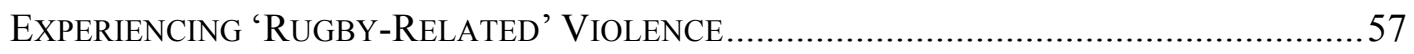

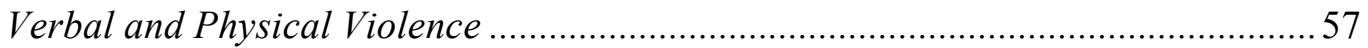

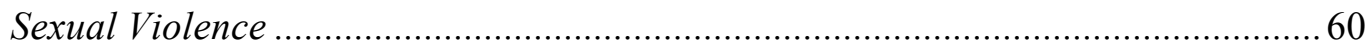

'Something about rugby culture is just different '.................................................... 64

EXPECTATION AND TOLERANCE OF RUGBY-RELATED ViOLENCE ...................................65

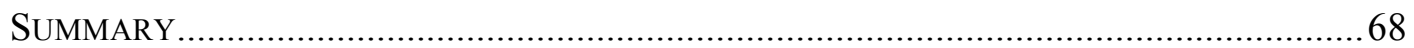

\section{CHAPTER FIVE: RATIONALISING INTERACTIONS WITH RUGBY}

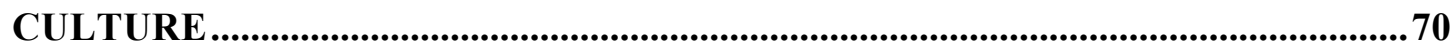

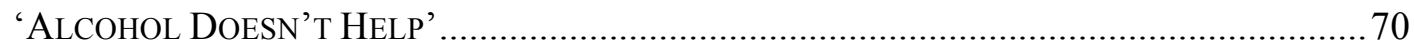

Rugby CUlture Membership AS An EnTITLEMENT To Power......................................76

A Perceived Pack Mentality and Code of Silence ..................................................... 82

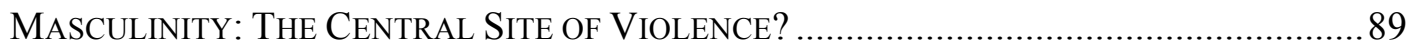

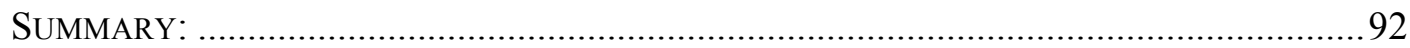

CHAPTER SIX: IMPACTS OF INTERACTIONS WITH RUGBY CULTURE.....93

PERCEPTIONS OF WOMEN AND FEMININITY AS 'VULNERABLE' ........................................93

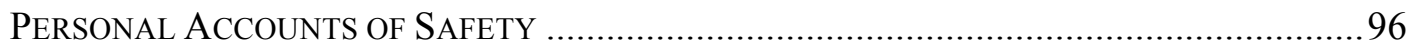

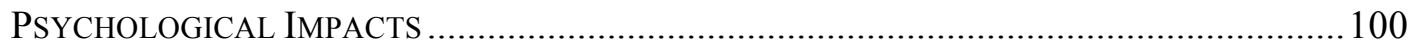

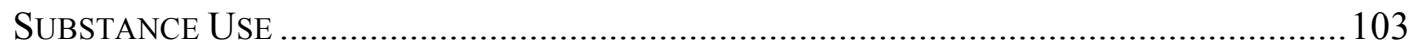

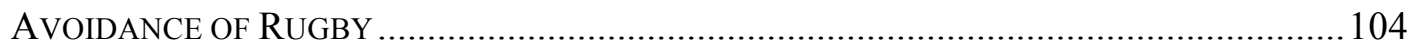

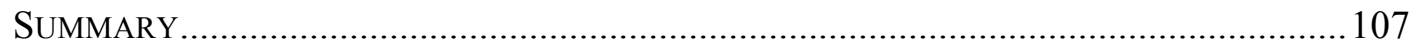

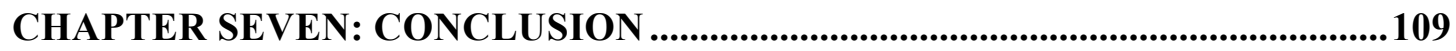

RugBy-Related Violence: Considering the EXTENT OF THE IsSUE..........................109

Possible Pathways to Violence AND theIR SignifiCANCE ................................... 111

Managing Risks, FeARs, AND Impacts of EnCOUnters with Rugby Culture...... 114

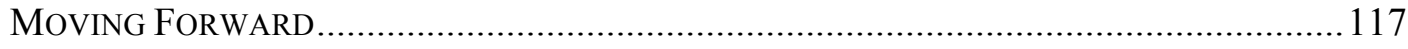

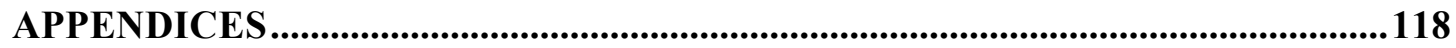

Appendix A: An Open LetTer to New Zealand Rugby ......................................... 118 


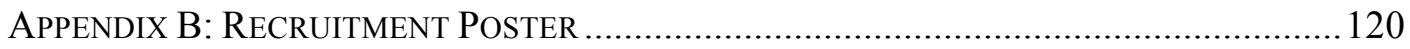

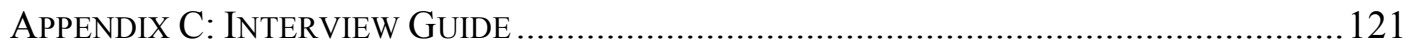

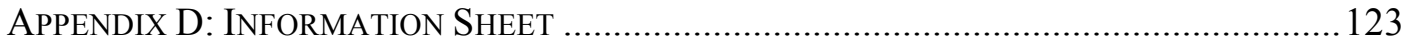

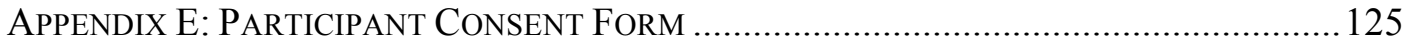

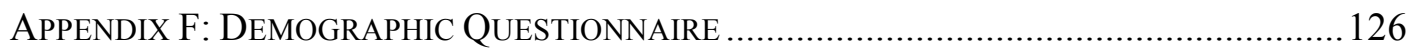

APPENDIX G: CONTACT LIST FOR SUPPORT SERVICES ................................................. 128

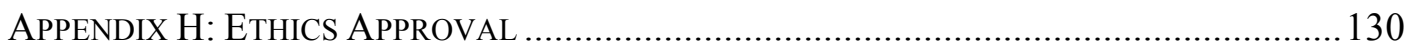

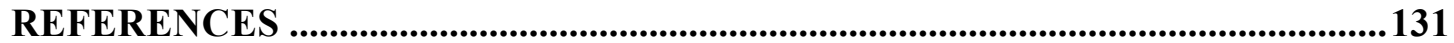




\section{Chapter One: Setting the Scene}

Rugby union has been described as both "a way of life" and "secular religion" in New Zealand (Pringle \& Markula, 2005: 472), where it is celebrated as a "unifying force" of benefit to society (Pringle, 2004: 113). As the country's national sport, rugby is said to be an important facet of New Zealand's cultural identity (Pringle, 2004). Due to its elevated societal position and history as a male-dominated sport, the results and achievements of men's rugby tend to dominate the New Zealand sports media (Pringle \& Markula, 2005). Paradoxically, extensive media coverage surrounding the alleged inappropriate conduct of rugby players has depicted a 'dark side' of New Zealand rugby, characterised by drunken and violent behaviour. Indeed, recent allegations of sexual and domestic violence perpetrated by professional rugby players have resulted in the resurgence of concerns regarding the potential impacts of New Zealand rugby on gender relations, and have encouraged perceptions of rugby as comprised of sexist subcultures in which drunken and disorderly conduct is celebrated (Flood \& Dyson, 2008).

One incident that received extensive media attention was the alleged sexual assault of a stripper in 2016 by members of the Waikato Chiefs. ${ }^{1}$ In the aftermath of this incident, the Human Rights Commission (2016) sent an open letter to New Zealand Rugby (NZR), which called for an urgent cultural shift within the sport (Appendix A). This letter, which was co-signed by 26 high-profile New Zealand women, claims that New Zealanders are questioning the culture that surrounds rugby, as well as "those in charge of it." The authors also articulated concerns that New Zealand rugby culture $(\mathrm{NZRC})^{2}$ may be harmful to women, stressing that "as much as New Zealanders love rugby, we need New Zealanders to respect women." These concerns were met with extensive public support, evidenced by an explosion of social media posts containing the hashtag '\#LoveRugbyRespectWomen.' In response to mounting public pressure to

\footnotetext{
1. The Waikato Chiefs are a professional New Zealand rugby union team. For more details about this incident see: https://www.stuff.co.nz/sport/rugby/super-rugby/82789997/Stripper-speaks-out-allegesChiefs-players-inappropriately-touched-her

2. This research broadly defines 'rugby culture' as the collective ideas, attitudes, customs, and behaviours of those involved in New Zealand rugby union, including players, spectators, and fans.
} 
take action, NZR committed to an independent 'respect and responsibility review' (RRR), which aimed to "support people within the rugby system to be better people" (Cockburn \& Atkinson, 2017a: 2). The RRR notes that rugby's history as a maledominated sport has created a culture that, in some situations, "is disrespectful towards women" (Cockburn \& Atkinson, 2017b: 112). The report also suggests that problems associated with New Zealand rugby tend to play out in gendered contexts that involve alcohol, such as the night-time economy (NTE). ${ }^{3}$

International literature echoes the concerns expressed in the RRR. Specifically, certain versions of masculinity found within male sporting cultures, including rugby, have been linked to the perpetration of off-field violence (see Messner, 1990; Anderson, 2008). As the NTE is found to provoke and intensify aspects of masculinity that are conducive to violence, the perpetration of violence is said to be a possible outcome of participation in the NTE for men involved in sports (Anderson, Daly, \& Rap, 2009). Indeed, the subcultural activities of some sporting codes, such as football in the UK, have been linked to the perpetration of violence in the NTE (Ayres $\&$ Treadwell, 2011). Pertinently, a video recently surfaced online of an incident in an English pub, where Sam Tomkins (who formerly played rugby league for the New Zealand Warriors) and his brother Joel Tomkins (also a professional rugby player) are observed physically pushing a barmaid after calling her a "fucking dickhead" and a "cunt." ${ }^{4}$ Despite growing concerns regarding the potential problems associated with NZRC in alcohol-focused settings, no previous studies have explored how rugby culture plays out in gendered environments where alcohol is consumed, nor have they considered how women in these environments perceive or experience this culture. This research seeks to address this literature gap and provide the first qualitative insight into how women working in the NTE perceive, experience, and navigate NZRC.

This introductory chapter further contextualises this research and outlines the key research aims. It begins by defining the key terms relating to this research. To locate the current study within the context of existing literature and further clarify the rationale for undertaking this research, this chapter then introduces the literature

\footnotetext{
3. The NTE consists primarily of alcohol-focused licensed leisure venues in urban city centers, and includes bars, pubs, nightclubs, strip-clubs, and brothels (Tierney \& Hobbs, 2003).

${ }^{4}$ See: https://www.youtube.com/watch?v=6MPww-IBzps
} 
exploring the nexus of sports, alcohol, masculinity, and violence, before outlining the key research objectives and providing an overview of the structure of this thesis.

\section{A Note on Definitions}

\section{Gender-Based Violence - Against Women?}

As concerns regarding the impacts of NZRC on intergender relations are influenced by allegations of 'violence against women' (VAW) involving professional rugby players, it is important to define this term and clarify the meaning of its use in this research. This thesis adopts the following definition of VAW, as outlined by the Declaration on the Elimination of Violence Against Women:

"Any act of gender-based violence that results in, or is likely to result in, physical, sexual or psychological harm or suffering to women, including threats of such acts, coercion, or arbitrary deprivation of liberty, whether occurring in public or in private life"(Watts \& Zimmerman, 2002: 1232).

Although broad, this definition is significant as it acknowledges VAW as acts that are rooted in gender inequality and intend to cause intentional harm and suffering to women (Watts \& Zimmerman, 2002). Yet, the focus on women as victims in this definition (and in this thesis more generally) does not disregard the fact that men experience violence too. However, since male-male violence tends to "differ in its aetiology and response strategies," it thereby warrants separate consideration (Watts \& Zimmerman, 2002: 1232). Echoing previous literature on VAW, the terms 'genderbased violence' and 'VAW' are used interchangeably in this research. Gender-based violence refers to harm that is inflicted upon women or men "because of their sex and/or socially constructed gender-roles" (Carpenter, 2006: 83). While this term emphasises the influence of gender-roles in the motivations underpinning certain acts of violence, it recognises that women and men can experience gender-based violence. However, as gender-based violence is overwhelmingly perpetrated by men and directed towards women, the use of this term in this research is intended to signify the relationship between the subordinate position of women in society and their increased vulnerability to violence (World Health Organisation [WHO], 2013).

\section{Sport, Masculinity, and Violence: An introduction}

Gender-based violence is a public health and human rights issue that has reached 
epidemic proportions in many societies (WHO, 2013). In New Zealand, it is estimated that one in four women will be sexually abused in their lifetime (Mayhew \& Reilly, 2007), while one in three will be physically assaulted by a male partner (Fanslow \& Robinson, 2011). These rates are significantly higher for Māori women, as research suggests that 57.6-percent of Māori women will experience physical or sexual violence in their lifetime (Fanslow, Robinson, Crengle, \& Perese, 2010). The costs of gender-based violence are severe and wide-ranging. As well as being a significant cause of death for women across the globe, gender-based violence is found to increase women's long-term risks of health problems including chronic pain, physical disability, substance abuse, depression, and anxiety (Heise, Ellsberg, \& Gottemoeller, 1999). It is thereby crucial that gender-based violence is acknowledged as a significant social problem.

The causes of gender-based violence have long been debated by social scientists (Jewkes, 2002). Underlying this debate is the fact that when measured with epidemiological criteria, evidence for causation is weak (Jewkes, 2002). Nevertheless, several well designed cross-sectional studies have identified variables associated with VAW that apply to multiple settings, as well as the mechanisms through which these variables contribute to gender-based violence (see Jewkes, Levin \& Penn-Kekana, 2002; Martin, Tsui, Maitra, \& Marinshaw 1999). These studies consistently identify one factor that appears to be central to acts of gender-based violence: the unequal (subordinate) position of women in society (Jewkes, 2002). As such, gender-based violence is widely accepted as a result of gender inequality, which stems from a deeply embedded patriarchal footprint within many western societies (Davies \& True, 2015).

Gender-based violence has also been linked to hegemonic masculinity, which is "defined in relation to the subordination of women, and in relation to other (marginalised/subordinated) masculinities (Messner, 1990: 205). As sport is a key institution in which hegemonic masculinity is produced, maintained, and legitimised, many studies have examined the socialisation of men into the institutional norms of masculinity in various sports (see Adams, Anderson, \& McCormack, 2010; Anderson, 2008). The findings of these studies suggest that male sports teams tend to nurture a version of masculinity that condones and normalises ostentatious displays of sexism 
and hostility towards women (Anderson, 2008). Problematically, sexist and misogynistic ideologies often underpin men's threat and use of VAW, and cultures of sexism and misogyny comprised of attitudes conducive to rape and VAW have been documented in countless international sporting cultures, including rugby (see Muir \& Seitz, 2004; Schacht, 1996).

In New Zealand, rugby plays a significant role in the formation of a governing male identity (Phillips, 1996). Pringle (2004) explains that due to its social significance, rugby works ideologically to define and reinforce dominant notions of masculinity in New Zealand. During the 1990s, however, literature examining the socio-cultural impacts of New Zealand rugby raised concerns about rugby's impacts on masculine subjectivities and gender relationships (Pringle, 2004). For example, Phillips (1996) warned that rugby's social significance works to construct a narrow image of the 'Kiwi bloke,' who is strong, heavy drinking, unemotional, aggressive, and strictly heterosexual. When strength and aggression are valued features of masculinity, men who act violently are simply performing socially normative male behaviours (Flood, 2003). Moreover, gender-based violence is found to be more prevalent in contexts where masculinity involves dominance, strength, and alcohol consumption (Heise, 1998). Given that hegemonic masculinity in New Zealand is a culturally robust prescription for men to be hands-on, aggressive, play rugby, and drink beer (Morin, Longhurst, \& Johnston, 2001), concerns that this version of masculinity may be harmful to women are not unfounded.

Nevertheless, it would be naïve to posit that involvement in rugby exclusively creates men who are imbued with sexist attitudes or are accepting of violence (Pringle, 2004). Although rugby players may be aggressive on the rugby field, this does not mean that their aggression will manifest in other circumstances (Pringle, 2004). Furthermore, allegations of violence and inappropriate and illegal conduct by New Zealand sportsmen are not confined to rugby (PS Services, 2010). However, rugby clubs make up the highest proportion of New Zealand sports clubs with criminal offences connected to them (PS Services, 2010) and, of significance to this research, alcohol is cited as a major contributing factor in cases of New Zealand rugby player misconduct (Cockburn \& Atkinson, 2017b). 
Despite alcohol's historically strong association with sport, New Zealand rugby and alcohol are said to be inextricably and problematically linked (Pringle \& Hickey, 2010). The 'inextricable' rugby-alcohol link is particularly discernible through the prolific alcohol-sponsorship of New Zealand rugby teams (Gee, Jackson, \& Sam, 2016). This link can also be observed through the viewing and celebration of alcoholsponsored rugby teams in alcohol-focused venues which, according to McEwan, Campbell, and Swain (2010), has become a standard feature of contemporary New Zealand's NTE. Although the celebration of rugby in contexts that involve alcohol may not seem problematic on the surface, one must note that employees of the NTE are found to be particularly susceptible to violence (Tutenges, Bøgkjær, Witte, \& Hesse, 2013), and that a relationship between alcohol consumption and gender-based violence has been well documented (Sønderlund et al., 2013). Furthermore, men involved in team sports are found to have a greater propensity for both VAW and hazardous drinking (Sønderlund et al., 2013) and, as mentioned, problems associated with New Zealand rugby appear to play out in contexts that involve alcohol (Cockburn \& Atkinson, 2017b). When contemplating the relationships between sport, alcohol, and gender-based violence, it is clear that an empirical examination of women's experiences of NZRC in gendered-environments where alcohol is consumed is not only warranted, but also necessary.

\section{Research Aims}

This research aims to explore how women working in the NTE perceive, experience, and navigate NZRC. In doing so, it aims to understand how NZRC may impact upon their lives. The following questions were used to guide the research process:

1. What do interactions with NZRC in the NTE look like and involve?

2. What role, if any, does alcohol play in the interactions between women working in the NTE and NZRC?

3. What impacts, if any, does interacting with rugby culture in the NTE have on the lives of women?

4. How do women working in the NTE navigate the potential impacts of NZRC in the context of their work and wider lives?

5. To what extent does NZRC create an unsafe environment for women in the NTE? 
This research draws on a developing body of literature that theoretically positions organised sport as a key institution for the production of masculinities that promote gender-based violence as socially normative behaviour (Messner, 1990). However, this literature is limited in providing a platform for women to express their views and experiences of sporting cultures, as it has been predominantly constructed from the standpoint of men. Challenging this masculinist bias, this research is qualitative, feminist, and seeks to provide an alternative perspective by emphasising the perspectives of women.

\section{Thesis Overview}

Having clarified the rationale for undertaking this research, chapter two reviews the pertinent literature exploring the intricate nexus of sport, masculinity, alcohol, and violence, to provide a theoretical framework to guide the interpretation of data. Chapter three outlines the methodological approach and research methods used, before discussing the ethical issues and personal challenges faced during the research process. The results commence with chapter four, which details perceptions of rugby as a 'masculinist' culture of intoxication, before outlining the respondents' personal experiences of NZRC. Chapter five examines how the respondents rationalised their perceptions and experiences of NZRC, while the final findings chapter, chapter six, explores the impacts that NZRC had on the lives and welfare of the participants. Finally, chapter seven outlines the significance of the research findings in the context of contemporary New Zealand society. 


\section{Chapter Two: Literature Review}

This chapter reviews the fragmented literature examining the nexus of gender, sport, alcohol, and violence. It begins by outlining the key phenomena related to the current research, through a discussion of gender, patriarchy, and VAW. Next, it explores the enactment of gender in the NTE, before moving on to examine the patriarchal origins

of sport and expressions of masculinity within the sporting context. The extent to which sports affiliation is linked to an increased propensity for gender-based violence and alcohol consumption is then analysed, and the influence of masculinity in the sport-alcohol-violence nexus is discussed. Having outlined the nuances of the 'alcohol-aggression-gender-sport' complex, the 'holy trinity' of Kiwi blokes, beer, and rugby is then explored. Since scant research attention has been given to the sociocultural impacts of rugby in contemporary New Zealand, this chapter draws heavily on international research. Nevertheless, New Zealand literature and examples are used where possible and, in the final section of this review, the international literature is discussed within the context of concerns about the impacts of NZRC on women and gender relations. Here, it is also crucial to note that men have traditionally dominated the world of sports research, both as researchers and as topics of investigation (Pringle, 2004). Thus, although this research aims to privilege the voices of women, this literature review paradoxically reflects the androcentric bias of existing research, and is heavily centred on men and masculinity.

\section{Doing Gender — Doing Violence}

\section{Explaining Gender}

Gender is a socially constructed phenomenon, which has been described as a complex system of social practices for categorising individuals as either man or woman, and for organising social relations of power based on differences within and between these categories (Russo \& Pirlott, 2006). The gender 'system' is comprised of many interwoven elements, including gendered traits, emotions, roles, environments, and institutions, which shift over time and across contexts, and vary within and across cultures (Russo \& Pirlott, 2006). Collectively, these elements define the "appropriateness of behavioural, psychological, and social characteristics" of men and 
women (Russo \& Pirlott, 2006: 180). Societal constructions of gender do not exist in isolation of the NTE or the sporting arena and, therefore, they are important to consider in this research.

Early theoretical research conceptualised gender as either an "unequivocally defined category of being" or an achieved "master status" (West \& Zimmerman, 1987: 128). Challenging these conceptualisations, West and Zimmerman (1987: 126) introduced the concept of doing gender, which involves a system of "socially guided perceptual, interactional, and micro-political activities" that position everyday pursuits as either masculine or feminine. Put simply, individuals 'do gender' through enactments of masculinity or femininity that reflect societal prescriptions of acceptable 'male' and 'female' behaviours (Connell, 2002). Feminine qualities traditionally ascribed to women include emotionality, sexual modesty, and submissiveness, whilst conventionally masculine qualities include dominance, heterosexuality, and aggression (Connell, 2002). However, gender is not a fixed character type (Connell, 1996). Instead, it is fluid, diverse, and subjective, and influenced by various factors including age, ethnicity, and social class (Connell, 2002). Furthermore, while masculinity and femininity refer to biological male and female bodies respectively, gender is not determined by biology (Connell, 2002). Thereby, a cis-gendered 5 woman who displays qualities stereotypically deemed 'manly' can be described as masculine, and vice versa (Connell, 2002).

Comparable to the notion of 'doing' gender, is Butler's (1994: 33) notion of performativity, which she describes as the mechanism through which "ontological effects are founded." Butler (1994) explains that the replication of socially constructed gendered norms works to solidify perceptions of gender as a 'natural' entity (Hey, 2006). While Butler (1994) supports West and Zimmerman's (1987) claim that gender is something people do and not an entity they possess, she argues that because societal understandings of gender are so deeply entrenched, people often mistake gendered performances as 'natural' and thus believe that they are mandatory (Morris, 1995). Consequently, those who fail to conform to gendered behavioural 'norms' are often punished or condemned for violating the 'natural' mandates of their

\footnotetext{
5. A person whose biological sex (male or female) corresponds to their gender identity is 'cis-gendered' (Tate, 2012).
} 
gender (Griffin et al., 2013).

\section{Theorising Gender-based Violence}

According to Kimmel, Hearn, and Connell (2004), the production of gender begins within the family, where men were traditionally assigned 'masculine' tasks, such as protecting their family from threats, whilst women were confined to tasks deemed subordinate relative to the 'masculine' tasks of their male counterparts, such as cooking, cleaning, and childcare. These gendered configurations reflect and reproduce the socially constructed ideals of masculinity and femininity, which depict men as powerful, superior, and dominant, and women as passive, nurturing, and subordinate (Brod \& Kaufman, 1994). Such gendered configurations are believed to strengthen intergender hierarchies of power that lend support to the construction and maintenance of patriarchy (Kimmel, 1994).

Problematically, gender-based violence is believed to be the mainstay of patriarchy: a central mechanism through which men can maintain their ascendant familial and societal positions (Edley, 2017; MacKinnon, 1982). Indeed, cogent social science research has found that men with more patriarchal attitudes have a greater use and acceptance of gender-based violence (see Abrahams, Jewkes, Laubscher, \& Hoffman, 2006; Fleming et al., 2015; Yllö, 1984). Furthermore, specific forms of gender-based violence, such as rape, are found to be more prevalent in patriarchal societies in which traditional gender-roles are institutionalised. For example, Sanday's (1981) crosscultural study of gender-based violence revealed women's sexuality was more likely to be appropriated for the use of men in patriarchal societies that promote a rigid adherence to traditional gender-roles. As such, many feminist scholars argue that acts of VAW are merely tangible demonstrations of men's power "juxtaposed against the lesser power of women" (Jewkes, 2002; 1427), which serve to assert and maintain social relations of male power (Brownmiller, 1976).

Although gender-based violence is widely understood as a 'weapon of patriarchy,' the concept of 'patriarchy' is analytically problematic, as it tends to present men as a homogenous group, ignore differences that exist within and between gender categories, and depict violence as an inherent feature of maleness (Messner, 1990). This depiction results in reductionist explanations of male-perpetrated violence, which 
ignore the complexities of gender and attribute violence to biological processes, such as testosterone (Edley, 2017). However, as social-scientific research reveals little compelling evidence that men are biologically predisposed to violence (BeecherMonas, \& Garcia-Rill, 2006), Messner (1990) asserts that violence is not an innate feature of maleness, but rather a behaviour that is learned via dominant expressions of masculinity. To elucidate the problems associated with the proposed link between patriarchy and VAW, Messner (1990: 205) explains that:

"Men as a group do enjoy power and privilege at the expense of women. Yet, this power and privilege is by no means complete, total, or uncontested, nor is it shared equally among all men. Hegemonic masculinity - that form of masculinity which is ascendant - is defined in relation to the subordination of women and in relation to other (subordinated, marginalized) masculinities."

In other words, what constitutes understandings of what it means to be a man is based on multiple and competing versions of masculinity (Robinson, 2005). This system of competing masculinities signifies the existence of a 'gender order' - a term originally used by Connell (1998) to describe the dynamics of the power relations that exist within and between gender categories. Connell (1998) describes hegemonic masculinity as the culturally desired version of masculinity that occupies the ascendant position within a given pattern of gender relations. While hegemonic masculinity is centrally connected to male dominance, not all men practice it or take it up to the same degree (Donaldson, 1993). Thus, while men collectively benefit from the control of women through hegemonic masculinity, the embodiment of hegemonic masculinity also affords some men with power over men who embody subordinate or marginalised masculinities (Donaldson, 1993)

The relationships of hierarchy and exclusion through which hegemonic masculinity maintains its ascendant position have been linked to gender-based violence (Connell, 1996). For example, as femininity is positioned as the 'antithesis' of hegemonic masculinity, the embodiment of hegemonic masculinity often involves the avoidance of femininity (Connell, 1996). Problematically, VAW can serve as a means through which men can relationally distance themselves from femininity (Connell \& Messerschmidt, 2005). Here, it is crucial to note that heterosexual success is integral to definitions of masculinity, and that masculinity is a homosocial enactment in which 
'manhood' is routinely demonstrated for, and legitimised by, other men (Kimmel 1994). Consequently, consensual and non-consensual heterosexual sexual acts can serve as a demonstration of masculinity, as a method of male bonding, and as a mechanism to preserve hierarchies of power existing within and between the sexes (Flood, 2008).

Indeed, research has found that rituals of competitive boasting about sexual feats are vital for achieving and maintaining a hegemonic masculine status within male peer groups, including sports teams. For example, Curry (1991) found that bonds between sportsmen were strengthened through actions that displayed masculinity and contempt for femininity, such as bragging about sexual conquests. Regularly embedded within such hypersexualised discussions are terms associated with sports, hunting, and war. For example, in a study of American campus party culture, male fraternity members described single women as 'fair game' (Sanday, 2007). The process of looking for a sexual partner was described as being 'on the prowl,' and those who helped their friends 'score' were called 'wingmen' (Sanday, 2007). Women, according to these metaphors, are merely opponents, enemies, or prey.

Research also suggests that men involved in sex-segregated groups are more likely to engage in acts of group sexual assault against women than those who are not (Crosset, Benedict, \& McDonald, 1995; O’Sullivan, 1991). Indeed, unlike second-hand stories about sexual achievements, the collective sexual harassment of women by groups of men provides substantiated 'proof' of masculinity (Franklin, 2004). When incorporated into understandings of 'good' sex, hegemonic masculine values can also dictate men's sexual behaviour (Searles \& Berger, 1995). For example, as hegemonic masculinity prizes aggression, men may perceive rough sex as 'normal' (David \& Brannon, 1976). Moreover, since passivity is a defining feature of femininity and dominance is a defining feature of masculinity, men are traditionally expected to initiate sex, whilst women are expected to refuse or concede (Searles \& Berger, 1995). Such expectations can pressure men to assert sexual dominance, as failing to do so may serve as a threat to their masculinity (Searles \& Berger, 1995). Consequently, sexual dominance, 'rough' sex, and even rape can become ways for men to validate their hegemonic masculine status (Searles \& Berger, 1995). 
While the enactment of gender varies across cultural, geographical, and temporal situations, the NTE and the sporting arena are key social spaces in which masculinity is expressed (Fileborn, 2016; Messner, 1990). While the overarching aim of this research is to understand women's experiences and perceptions of NZRC, it draws upon the perspectives of women working in the NTE - a hypersexualised setting in which rape and unwanted sexual attention occur with regularity (Kavanagh, 2013). To understand how NZRC is situated within this specific context and why alcoholfocused venues are a location of interest for exploring women's accounts of NZRC, one must first consider how women navigate the NTE more generally. The following section therefore outlines the existing research on women's experiences within the broader context of the NTE, before moving on to explore enactments of gender in the sporting context.

\section{Doing Gender and Violence in the Night-time Economy}

The NTE is a 'criminogenic environment' in which crime and violence frequently occur (see Finney, 2004; Hadfield, 2006). While a substantive body of research has examined violence in the NTE, the vast majority of this research is conducted in the UK and focuses on violence between male patrons (Fileborn, 2016). As the experiences of women and employees in the NTE have thus been omitted from academic discussions, little is known about how employees and female patrons experience and navigate the NTE (Fileborn, 2016). Nevertheless, there is some evidence to suggest that individuals working in nightlife venues are susceptible to violence. For example, in a study of 424 bartenders in Denmark, Tutenges et al., (2013) found that 82-percent of participants had been verbally abused, 8-percent had been physically attacked, 13-percent had witnessed a physical assault on a colleague, and 22-percent had intervened in a violent event. Research also suggests that sexual abuse is a common experience for female patrons of the NTE. For example, Watson (2000) and Fileborn $(2012,2016)$ found that women experienced a range of abusive behaviours in Australian nightlife venues, including unwanted sexual comments, sexual and violent assaults, and rape. Pertinently, an American study by Parks, Miller, Collins and Zetes-Zanatta (1998: 709) found that 33-percent of the 52 female participants had "experienced attempted or completed rape in bars." 
When contemplating women's experiences of sexual violence in the NTE, it is crucial to note that the NTE is a hypersexualised environment characterised by hypermasculine ${ }^{6}$ performances and heteronormative interaction styles between women and men (Kavanaugh, 2013: 22). While there is diversity in how gender is expressed in the NTE, masculine performances in this environment appear to be centered on alcohol consumption, violence, and heterosexual sexual relations (Anderson et al., 2009; Thompson \& Cracco, 2009). For example, research has repeatedly found that in alcohol-focused venues, masculinity is displayed through drinking contests, alcoholrelated fighting, and various sexualised interactions with women - both consensual and non-consensual (see Capraro, 2000; Giancola, 2002; Harford, Wechsler \& Muthen, 2003).

Thompson and Cracco (2009) explain that because social constructions of masculinity in the NTE tend to equate male sexuality with competition and conquest, men are expected to engage in masculine performances that involve sexual assertiveness, if not aggressiveness. Consequently, aggressive and unsolicited sexual behaviours against women can serve as a means to attaining a respected masculine status in nightlife venues (Anderson et al., 2009; Kavanaugh, 2013). Empirical support for the proposed link between masculinity and sexual aggression in the NTE can be observed through Thompson and Cracco's (2009) investigation of college men's sexual aggressiveness in the US. In this study, 90-percent of the 264 respondents reported engaging in sexually aggressive behaviours against women in bars, and adherence to masculine ideologies was found to predict sexual aggressiveness. Based on the latter finding, Thompson and Cracco (2009) concluded that sexual aggression is a normative expression of men doing masculinity in bars. Correspondingly, Anderson et al., (2009) found that men who scored high on hyper-masculinity measures were more frequently involved in nightclub crimes, including sexual violence, than respondents with more subdued masculinities.

Here, it is important to acknowledge that male patrons of the NTE are not a homogenous group (Ayres \& Treadwell, 2011). Instead, the NTE is a space where people from different subcultures, including those of sports, converge in the pursuit of

\footnotetext{
${ }^{6}$ Hyper-masculinity involves the exaggeration of traditionally 'masculine' behaviours, such as physical strength, aggression, and sexuality (Anderson et al., 2009).
} 
pleasure (Ayres \& Treadwell, 2011). In New Zealand, for example, licensed leisure venues are common locations where rugby fans gather. During the 1990s, SKY-TV purchased the broadcasting rights to rugby union (Gee \& Jackson, 2010). New Zealand's alcohol-hospitality industry was simultaneously undergoing transformations, and televisions were installed in many bars to allow patrons to watch major sporting events (Gee \& Jackson, 2010). Consequently, the viewing and celebration of rugby games in bars, clubs, and pubs is now a standard feature of New Zealand's NTE (McEwan et al., 2010). There is also anecdotal evidence to suggest that New Zealand brothels and strip-clubs are key venues for post rugby game celebrations. For example, New Zealand's sex industry took steps to prepare for an expected surge in trade during the 2011 Rugby World Cup (RWC). Specifically, a new brothel was opened in Wellington, exotic dancers ${ }^{7}$ were flown from Australia to New Zealand, and the New Zealand Prostitutes Collective (NZPC) doubled their condom order to keep sex workers ${ }^{8}$ in supply (Duff, 2011). Although the economic impacts of rugby events on the sex industry are unclear, social media adverts for New Zealand strip-clubs and brothels have explicitly targeted rugby fans. ${ }^{9}$

Hegemonic versions of masculinity promoted by NZRC closely resemble those found within the NTE (Pringle, 2004). However, as gendered performances shift in different contexts and at different times (West \& Zimmerman, 1987), performances of masculinity found within NZRC and the NTE are context-specific. Since research has not yet explored how NZRC is enacted in the NTE, one cannot assume how those involved in NZRC express masculinity in this specific context. However, research finds that when interacting in nightlife settings, men often display exaggerated

\footnotetext{
${ }^{7}$ Exotic dancers, also commonly referred to as 'strippers,' are individuals whose occupation entails removing their clothing for customers (Skipper \& McCaghy, 1970).

8 The term chosen to describe sex workers is often telling of one's perspective on sex work. For example, the term 'prostituted women' depicts sex workers as lacking autonomy and, therefore, is often used by abolitionists, who perceive sex work as forced and exploitative (Armstrong, 2011). Contrarily, those who acknowledge the role of individual choice and autonomy in sex work usually adopt the less stigmatising term 'sex worker' (Armstrong, 2011; Kinnell, 2008). In this research, I thereby adopt the term 'sex worker' to reflect my perception of sex work as a legitimate occupation that individuals should be able to choose freely, without the risk of violence or judgment.

${ }^{9}$ See: https://mobile.twitter.com/paradiseclubnz/status/1006295604580966402 https://www.facebook.com/mermaidbar/photos/a.158192317528325.44019.146987941982096/205748 $\underline{8250932046 / \text { ?type }=3 \& \text { theater }}$
} 
versions of hegemonic masculine traits (Anderson et al., 2009). According to Anderson et al., (2009: 324), this 'upwards masculine shift' is associated with an increased propensity for violence, and occurs because "men define nightlife settings as a highly sexualised, masculinised, and hedonistic endeavor, which is something they must 'macho-up' to navigate." In this sense, how sporting masculinities are enacted in the NTE may be intensified by the masculinised dynamics of nightlife settings. As a complex set of historical forces has created a naturalised relationship between sport, alcohol, and approaches to masculinity that appear conducive to gender-based violence (Wenner \& Jackson, 2009), this potential 'upwards masculine shift' raises valid concerns regarding the safety of women when interacting with sporting cultures in alcohol-focused venues. To elucidate the weight and significance of these concerns, the following section examines the historical forces through which sport has been constructed as a 'masculine proving ground,' before moving on to explore the links between sport, gender, and VAW.

\section{Sport, Violence and the Gender Order}

\section{Sport as a Masculine Proving Ground}

Organised sport emerged as a male response to momentous social changes (i.e., proletarianisation, urbanisation, and modernisation) that were perceived to destabilise the foundations of men's patriarchal power (Messner, 1990). During this 'crisis of paternity' in which boys were predominantly raised, taught, and supervised by women, male-only sports enabled men to seek refuge from women and the alleged 'feminisation' of society (Messner, 1990). The lessons taught by men to boys within the sporting sphere served a masculinity-validating function (Messner, 1990). Fundamental, were lessons about how to disguise and inflict pain and aggressively compete (Wenner \& Jackson, 2009). In addition to promoting competition and aggression among men, sports promoted the exclusion and domination of women (Crosset, 1990).

During the nineteenth century, the sporting arena was strictly 'off limits' to women (Wenner \& Jackson, 2009). The perpetuation of sport as a male preserve was substantiated by 'scientific' concerns that women would be physically harmed and that their participation would use up reproductive energy (Wenner \& Jackson, 2009). 
Furthermore, as the conventional values of sports (i.e., competition, aggression, and strength) are virtually "synonymous" to those of 'manhood' (Schacht, 1996: 550), sport was constructed as the antithesis of femininity. Consequently, female participation in sport was deemed to be a violation of 'normal' femininity (Messner, 1990). While women's participation, knowledge, and interest in sports have dramatically increased since this time, the perception of sport as a 'male' preserve remains deeply embedded in contemporary Western societies (Wenner \& Jackson, 2009). According to Crosset (1990), this perception strengthens an ideology of men's 'inherent' superiority and power over women. Echoing this view, Wenner and Jackson (2009: 8) contend that perceptions of sport as a male rite of passage explicitly naturalises men's place in the physical, which implicitly renders women's place as subordinate "on measures of physicality, and thus, life." In other words, it is not simply the marginalisation of women from sport, but also its physical nature that works to construct and embed definite gender relations that maintain and legitimise patriarchy (Wenner \& Jackson, 2009).

Pertinently, Brownmiller (1967) argues that male dominance essentially depends on the threat and use of violence. As industrialisation and modernisation promoted a 'civilised' society in which the use of violence was controlled, the balance of power was perceived to have skewed towards women (Messner, 1990). In response, combat sports were established and ideologically justified as training grounds for war, and as channels for the reproduction of masculine hegemony (Dunning, 1986). If it were the 'feminisation' of society that men wanted to escape, the implementation of non-violent clubs designed exclusively for men would have sufficed (Messner, 1990). Yet, since male hegemony is said to rest on the threat and use of violence, Messner (1990) argues that it was not the fear of a 'feminised' society, but the fear of losing power that facilitated the proliferation of combat sports.

Sports naturalise and glorify violence by teaching men physical toughness, dominance, extreme competitiveness, and insensitivity to pain (Flood \& Dyson, 2008). Problematically, these values are often incorporated into men's understandings of 'normal' masculinity (Schacht, 1996). Supporting this view, international literature has found that all-male contact team sports (hereafter, simply 'team sports') are particularly prone to nourishing a version of masculinity that rests on the use and 
acceptance of violence, socio-negative (i.e., sexist, misogynistic, and hostile) attitudes towards women, and alcohol consumption (see Curry, 1991; Messner, 2002; Muir \& Seitz, 2004). To illustrate, an ethnographic study of male rugby players in the US found that masculinity was measured by physical strength, the ability to inflict and withstand pain, the avoidance of femininity through forms of "misogynistic denigration," and alcohol consumption (Schacht 1996: 562).

The importance of alcohol for the enactment and expression of masculinity in the sporting context is not surprising, since alcohol, like sport, plays a vital role in the "foundational socialisation of what it means to be a real man" (Wenner \& Jackson, 2009: 6). Indeed, there are many similarities between the masculinity-alcohol dynamic and the one that exists between men and sport (Wenner \& Jackson, 2009). Namely, both emerged as exclusively male pursuits (see Lemle \& Mishkind, 1989), and both are linked to "hegemonic masculine norms and values that exclude women" (Hutton, Griffon, Lyons, Niland, \& McCreanor, 2016: 12). As such, men tend to consume alcohol in the company of other men during 'masculine' sporting activities, as it reinforces the masculine images of alcohol and sport, and allows the men engaged in these activities to seem more masculine (Wenner \& Jackson, 2009).

Like team sports, Messner (2002) contends that 'centre sports' (i.e., those that are culturally dominant, such as ice hockey in Canada and American football in the US) are especially prone to nourishing hegemonic versions of masculinity that are conducive to violence, compared to sports of a marginal societal position. Supporting this view, Anderson (2008) found that the socialisation of American football players into the homosocial team-sporting environment worked to produce a version of masculinity that prized aggression, devalued femininity, and promoted misogynistic ideologies. Significantly, Anderson (2008: 263) argues that the socialisation of men into these institutional norms of masculinity may encourage the perpetration of "symbolic, domestic, and public" VAW.

Due to its cultural prominence, New Zealand rugby is a quintessential example of a 'centre sport,' which, as this literature review will later demonstrate, is argued to play a fundamental role in the maintenance of male hegemony through the production of masculinities that promote the rejection and degradation of women (Phillips, 1996). As 
approaches to masculinity within some sporting cultures are found to glorify violence and the "misogynistic denigration" of women (Schacht 1996: 562), the notion that sportsmen may have a greater propensity for gender-based violence than other men has gained credibility in academic circles (Smith \& Stewart, 1993). The following section explores this idea further, and reviews the pertinent literature examining the link between sports participation and VAW.

\section{The Sports Participation and Violence Against Women Debate}

No issue in sport has received more media attention than the perpetration of genderbased violence by male athletes (Crosset, 1999). During the 1990s, the media's tendency to magnify the violent crimes of sportsmen resulted in the widespread public perception that sportsmen have an increased propensity for violence compared to other men (Scholes-Balog, Hemphill, Kremer \& Toumbourou, 2016). In contemporary times, this perception has been further solidified by multiple allegations of gender-based violence perpetrated by sportsmen across the globe. Despite such allegations, very little contemporary research on this topic exists. In fact, a recent study by McCray (2015) reports that in an American context, only two studies have examined VAW by sportsmen in the last 15 years. In contemplating a lack of research on this topic, Welch (1997: 396) notes that as professional sports teams work vigorously to maintain a reputable image, they are "impervious" to academic scrutiny, difficult to investigate and, consequently, remain "untouched" in the world of academia.

During the 1990s, however, a small number of quantitative studies examined the link between sports participation and violence, and the weight of evidence from these studies supports the notion that male athletes have an increased propensity for genderbased violence than non-athletes (Flood \& Dyson, 2008). For example, a college survey administered to 925 women in the US revealed athletes were significantly over represented as offenders of sexual and physical violence (Frintner \& Rubinson, 1993). Despite comprising less than 2-percent of the campus population in this study, sportsmen were involved in 22.6-percent of the reported sexual crimes. Similarly, Crosset et al., (1996) examined cases of sexual violence reported to campus officials across ten US colleges and found that despite making up only 3-percent of the student population, male athletes were responsible for 35-percent of the reported incidents of 
sexual and physical abuse.

In a survey of 477 male students, Boeringer (1996) found athletes were more likely than non-athletes to claim they would use coercion and force to have sex if they knew they would not be caught. In a more recent study, Young, Desmarais, Baldwin, and Chandler (2017) assessed attitudes towards women, rape-myth acceptance, and the prevalence of sexual coercion among 379 male athletes and non-athletes in the US. They found athletes were more likely than non-athletes to have hostile attitudes towards women and admit to sexually coercive behaviours. Supporting the existence of a link between gender-based violence and traditional gender-role ideology, when traditional gender-role ideology was statistically controlled for in this study, differences between athletes and non-athletes in the prevalence of self-reported sexual coercion was eliminated. This finding is significant, as it demonstrates that it is not simply sports participation, but rather norms of gender inequality within certain sporting subcultures that foster the conditions for VAW (Flood \& Dyson, 2008).

Although the aforementioned studies support the notion that athletes have a higher propensity for violence than other men, a greater proportion of male athletes accused of sexual assault and agreeing to rape-supportive statements does not necessarily mean that they are committing a disproportionate number of sexual crimes (Smith \& Stewart, 2003). Indeed, Schwartz and Nogrady (1996) and Caron, Halteman, and Stacy (1997) found no significant differences between athletes and non-athletes' self-reported sexually aggressive behaviour. Jackson (1991) warned that because student-athletes often have an elevated status, they are more likely to be falsely accused of sexual crimes. However, the elevated status of sportsmen can result in a sense of entitlement to power, which appears to be implicated in acts of sexual violence (Welch, 1997). Correspondingly, Shavers, Baghurst, and Finkelstein (2015) explored the influence of perceived status and social power on the sexual behaviour of male American football players, and found 80-percent of participants believed football players can have sex with women at will. Furthermore, 87-percent of participants reported women treated them in privileged ways because of their sporting status, which included doing their schoolwork, cleaning their rooms, and having sex with them.

Attaining a privileged 'athlete' status may also influence the legal consequences for sportsmen who perpetrate VAW (Flood \& Dyson, 2008). For example, Benedict 
(2003) notes that while American athletes are more likely than non-athletes to be charged with a crime, the conviction rates of athletes are lower than those of other men. This lower rate of conviction is likely influenced by factors such as the popularity of the sport, or pressure on the victim, judge, or jury to protect the perpetrator's sporting career (Flood \& Dyson, 2008). While no empirical studies have examined the conviction rates of athletes versus non-athletes in New Zealand, debates regarding the preferential courtroom treatment of New Zealand rugby players have ensued, due to knowledge that at least 15 professional rugby players have escaped convictions for various offences, including serious violent assault. ${ }^{10}$

While a relationship between sports participation and off-field violence is found to exist, there are various limitations of the published literature to date (McCray, 2015). Firstly, the majority of research is based on US college populations, which are especially prone to fostering violence-supportive attitudes (Boswell \& Spade, 1996). As such, the results of these studies may not generalise to other sporting populations. Secondly, these studies have various methodological issues including small sample sizes and the use of self-report methods (Koss \& Gaines, 1993). Moreover, they do not determine the direction of causality, so it is unclear whether more violent men are joining sports teams, or whether participation in sport makes men more violent (Scholes-Balog et al., 2016). Since most of these studies are quantitative, their aim is to determine whether sportsmen are more or less violent than other men (McCray, 2015). This approach to understanding violence is reductionist, as it ignores the specific mechanisms through which sports participation contributes to an increased probability of violence (Crosset, 1999).

Despite these limitations, the sports-violence link has been a source of concern among sports scholars, who contend that the perpetration of violence by professional sportsmen, both on and off the field, may encourage violence amongst sport fans (see Madigan \& Delaney, 2009; Ostrowsky, 2018). For example, Sage and Eitzen (2016: 86) argue that when watching a sport in which violence is sanctioned, or when seeing athletes go unpunished for off-field violence, fans are likely to become aggressively inclined themselves and, under certain circumstances, may engage in violent behaviours. Supporting this view, player violence has been found to instigate fan

\footnotetext{
${ }^{10}$ See: https://www.nzherald.co.nz/sport/news/article.cfm?c_id=4\&objectid=11717666
} 
violence at football matches in various countries including the Czech Republic (Duke \& Slepic`ka, 2002), Israel (Semyonov \& Farbstein, 1989), and the Netherlands (Braun \& Vliegenthart, 2008).

As sports-related violence has resulted in significant injury, trauma, and death across the globe (Ostrowsky, 2018), that much of the existing research overlooks the variables accounting for the sports-violence link is surprising. Within academic and media circles, however, alcohol has been identified and blamed as a "direct cause" and "aggravating factor" in much of the violence that plays out in the sporting arena (Ayres \& Treadwell, 2011: 85). As this research explores how women experience NZRC in contexts that involve alcohol, considering the influence of alcohol in the sports-violence dyad is therefore necessary.

\section{Alcohol Consumption and Sports-Related Violence}

There is evidence of a link between alcohol and various forms of violence including sexual crimes (Abbey, Zawacki, \& Buck, 2004) domestic violence (Kyriacou et al., 1999) and public stranger assaults (Finney, 2004). Although alcohol and violence are found to co-occur, this does not mean that alcohol causes violence (Abbey et al., 2004). In fact, the causal direction could be the opposite. For example, individuals may consume alcohol before offending in order to 'excuse' their behaviour (Abbey et al., 2004). Complicating matters further, the alcohol-violence link is affected by various pharmacological, situational, social, and individual factors such as the amount of alcohol consumed, the setting of consumption, peer group norms, and characteristics of the consumer (Sønderlund et al., 2013). Nevertheless, as the alcohol-violence link is found to remain across geographic borders and cultural divides, alcohol is widely recognised as a contributing factor in many cases of violence, including those within the sporting context (Sønderlund et al., 2013).

While sports participation is positively associated with health, academics have highlighted an important paradox, arguing that sports participation promotes alcohol consumption (Veliz et al., 2017). Indeed, international research has found a correlation between sports participation and alcohol consumption at the high school, college, and professional levels (Eitle, Turner, \& Eitle, 2003; Leichliter, Meilman, Presley, \& Cashin, 1998). Evidence also suggests that compared to non-athletes, 
athletes consume significantly more alcohol in a single drinking session (Nelson \& Wechsler, 2001), and have greater odds of engaging in 'binge drinking' behaviour ${ }^{11}$ (Veliz et al., 2017). Excessive alcohol consumption is also common among sports fans. For example, research finds that sports fans perceive game days as a chance to drink excessively (Glassman, Miller, Miller, Wohlwend, \& Reindl, 2012) and, in comparison to non-fans, are more likely to drink excessively and experience 'alcoholrelated' problems (Nelson \& Wechsler, 2003).

While the connections between alcohol and violence, and between alcohol and sport, appear relatively strong, little research has explicitly examined the links between sports, alcohol, and violence (Ostrowsky, 2018). Nevertheless, a study by Swahn and Donovan (2005) found that weekly involvement in sports was a significant predictor of excessive alcohol-use and alcohol-related violence among US college students. Correspondingly, Sønderlund et al., (2013) reported higher rates of alcohol-use and violence in athlete populations versus non-athlete populations. As this study indicated a stronger relationship between alcohol and violence in athletic populations, sports participation was argued to accentuate the relationship between alcohol and violence (Sønderlund et al., 2013).

Research examining the influence of alcohol on the violent behaviours of sports fans has produced inconsistent findings. Some studies suggest alcohol-use facilitates violent behaviour among sports fans (Fitzpatrick, 2015; Varela, 2014), while others have found that alcohol-use does not result in violence by sports fans (Guschwan, 2007; Peitersen, 2009). Despite this mixed evidence, alcohol-focused solutions are routinely implemented to mitigate sports-related violence (Ayres \& Treadwell, 2011). In the UK, for example, legislation (i.e., the Sporting Events Control of Alcohol Act, 1985) that aims to restrict alcohol consumption at sporting events has been implemented in an attempt to mitigate football violence (Ayres \& Treadwell, 2011).

\footnotetext{
11 The term 'binge drinking' is commonly used to describe a single drinking session that leads to intoxication. However, there is disagreement and confusion surrounding the number of drinks and level of intoxication that constitutes binge drinking, the length of which a drinking session must be to qualify as binge drinking, and the differences between binge drinking, drinking to excess, and drunkenness (Herring, Berridge, \& Thom, 2008). Consequently, numerous and often contradictory definitions of this term are used in research to describe very different patterns of drinking, which results in difficulties regarding data comparison and the estimation of prevalence rates, and raises questions about the usefulness of the concept altogether (Herring et al., 2008).
} 
Yet, as Dunning, Murphy and Williams (1988) found, some football fans refrain from drinking before partaking in violence, as to avoid hindering their ability to fight. In this sense, alcohol restrictions may inadvertently exacerbate disorder (Ayres \& Treadwell, 2011). While research supports the notion that alcohol restrictions can lead to violence among sports fans (see Schaap, Postma, Jansen, \& Tolsma, 2015), the tendency to view a reduction of alcohol-use as the primary solution to sports-related violence is widespread (Ayres \& Treadwell, 2011).

Attributing sports-related violence to alcohol-use is problematic, as it overlooks the socio-cultural factors that underpin violence and alcohol consumption - such as masculinity (Sønderlund et al., 2013). Indeed, as the sports literature consistently finds that male sports fans and athletes are more likely to consume alcohol and behave violently and than their female counterparts (Ostrowsky, 2018; Palmer, 2011), the link between alcohol, violence, and sports is believed to reflect broader associations between men, masculinity, and the acceptance of traditional gender norms (McCray, 2015). For example, Dunning, Murphy and Waddington (2002:12) argue that football, violence, and alcohol consumption are indirectly connected though masculine norms which commemorate the ability "to fight" and "hold one's ale" as markers of manhood. Pertinently, Ayres and Treadwell (2011: 90) found that the masculinity of UK football fans was measured by their ability to "consume large quantities of drugs and alcohol" and "employ violence while under the influence." Sønderlund et al., (2013) similarly identified masculine norms within team sports as a key socio-cultural factor underpinning the use of alcohol and violence among athletes.

Although research suggests that alcohol consumption and violence are fundamental components of masculinity within various sporting cultures, it is unknown whether masculinity is the underlying cause of alcohol-use and violence in the sporting context, or whether alcohol consumption influences the effect of masculinity on the use and acceptance of violence (Ostrowsky, 2018). Nonetheless, due to the historically strong and symbolically powerful links between alcohol, sport, and masculinity these three elements have been described as a "holy trinity" (Gee \& Jackson, 2010: 1517). Given that each of the interrelated components of this holy trinity have been individually linked to the perpetration of gender-based violence, it is clear that the 'alcohol-sportmasculinity' trinity is a significant cause for concern. 
In New Zealand, a holy trinity of rugby, Kiwi blokes, and beer is widely acknowledged (Gee \& Jackson, 2010; Phillips, 1996). While a lack of research in a New Zealand context creates uncertainty and debate regarding the extent to which the dynamics of this trinity may be problematic (Gee \& Jackson, 2010), there is evidence to suggest that alcohol-use by New Zealand rugby players is associated with unfavourable outcomes. For example, the RRR investigated 36 cases of professional rugby player misconduct, which ranged from sexual and physical violence to homophobic epithets overheard by the public (Cockburn \& Atkinson, 2017b). Significantly, alcohol was found to play a key role in over half of these misconduct cases (Cockburn \& Atkinson, 2017b). The authors note that while NZR is ostensibly aiming to be family-oriented, there are still many problematic behaviours and attitudes that exist towards women, as well as a "strong drinking culture that exacerbates, and at times, makes dangerous these attitudes and behaviours" (Cockburn \& Atkinson, 2017b: 14). To provide a deeper context for these problems, the following section explores the limited available research that has examined the socio-cultural influences of New Zealand rugby.

\section{Kiwi Blokes, Beer, and Rugby}

\section{Understanding the Holy Trinity}

First introduced by British settlers to teach boys to become men, rugby has been given patronage as the symbol of a hegemonic national consciousness that has consolidated the archetype of the strong, heavy drinking, and compulsorily heterosexual 'Kiwi bloke' (Phillips, 1996; Joseph \& Falcous, 2017). Phillips (1987) explains that the early civilisation of New Zealand society led Pākehāa $\bar{a}^{12}$ men to cling to images of exaggerated physical prowess and aggression, and identify vicariously with traditional rugby 'heroes' who were the quintessential 'Kiwi bloke.' Echoing this view, Cosgrove and Bruce (2005) argue that the adulation of rugby icons that epitomise a mythic 'national' character has been fundamental to the perpetuation of the Kiwi bloke stereotype, whilst Tovia (2014) argues that rugby remains a key site for the performance and celebration of hegemonic masculinity in the contemporary public sphere (Tovia, 2014).

\footnotetext{
12 Pākehā is a Māori term that refers to New Zealanders of European descent
} 
In the last thirty years, the 'Kiwi bloke' prescription of masculinity, which rugby is said to endorse, has been the target of academic scrutiny due to concerns that the masculine virtues of physicality, aggression, and heterosexuality may promote VAW as socially normative male behaviour (Phillips, 1996). Strengthening these concerns, Pringle and Hickey (2010: 128) found that rugby players identified the mistreatment and sexualisation of women as a "prime moral problem" within the sport, which they believed was linked to culturally dominant narratives of masculinity in New Zealand. Further emphasising the consequences that such a narrow prescription of masculinity might impose on women, Phillips (1996) explains that in a country where the national identity is defined in male terms and confirmed via participation in a male-dominated sport, the position of women in that country may be rendered marginal or subordinate.

Indeed, as rugby traditionally defined the essence of being a New Zealand male, women were, by definition, excluded from the game (Curtin, 2016). Historically, the role of women in rugby was confined to domestic tasks that served to benefit the players, such as providing meals and washing team uniforms (Thompson, 1988). Since the creation of strong, healthy sons to play rugby was a valuable commodity in New Zealand, arguments concerning the reproductive rights of women were formulated around protecting the future of rugby (Thompson, 1988). For example, the 1937 New Zealand government rationalised their views against abortion with regards to protecting unborn male babies who could potentially become All Blacks players (Thompson, 1988). Brookes (1981: 130) detailed a Parliamentary debate in which the speaker stated:

"Tomorrow the Springboks play the All Blacks in Auckland. I wonder how many of the 55,000 people who will be watching the match will realise that during the period of play, one child, perhaps a potential All Black, will have been willfully destroyed in the womb of its mother."

In recent years, the role of women in rugby has expanded beyond domestic tasks, and women are playing rugby at an increasing rate (Cockburn \& Atkinson, 2017). However, women remain under-represented in all aspects of the game, and perceptions of rugby as an exclusively 'masculine' pursuit are still a remnant aspect of NZRC (Cockburn \& Atkinson, 2017b). Despite its continuance as a patriarchal domain that represents the values of male culture that glorify violence (i.e., roughness, 
physicality, and strength), limited contemporary research attention has been given to the socio-cultural impacts of New Zealand rugby (Tovia, 2014). Nevertheless, a small body of research has revealed that the masculine virtues of New Zealand rugby were associated with elements of sexism, homophobia, corporeal risk, and violence (see Nauright \& Chandler, 1996; Price \& Parker, 2003; Pringle, 2001; Star, 1994, 1999; Thomson, 1993; Trevelyan \& Jackson, 1999).

The cultural dominance of rugby and its links to masculinities that prize heterosexuality have also been found to encourage men to adopt outwardly heteronormative practices (Town, 1999), limit the expression of alternate versions of masculinities and sexualities (Pringle \& Markula, 2005), and hinder men from outwardly expressing discontent towards sexist behaviours, including the sexualisation of women (Pringle \& Hickey, 2010). Research also suggests that rugby is associated with hazardous drinking. For example, in their examination of alcoholuse patterns among 348 New Zealand rugby players, Quarre et al., (1996) found weekly drinking sessions involving large quantities of alcohol were the norm for this group. Since rugby and beer are said to be an entwined, quintessential component of New Zealand's national culture (McEwan et al., 2013), this finding is not surprising.

The sponsorship of rugby by alcohol companies is argued to strengthen the link between masculinity, beer, and rugby (Gee \& Jackson, 2010). Although various sports receive alcohol sponsorship in New Zealand, rugby is the only sport in which teams receive direct funding from major alcohol sponsors nationally and regionally (PS Services, 2010). Like alcohol-sponsorship, alcohol promotion has a long association with rugby (Wenner \& Jackson, 2009). The dominant feature of contemporary alcohol marketing is the development of a 'brand' to represent an identity (Casswell \& Maxwell, 2005). For example, Speight's beer emerged as a "medium for the masculinisation of consumption and the consumption of masculinity" (Gee \& Jackson, 2010: 1524). The Speight's 'Southern Man' campaign reinforces the 'holy trinity' of beer, Kiwi blokes, and rugby through messages such as, 'real southern men watch and talk rugby, even during the cricket season' (Gee \& Jackson, 2010).

As mentioned, the ties between alcohol and rugby have been further entrenched through the regular viewing and celebration of rugby in contemporary alcohol- 
focused venues (McEwan et al., 2010). Given that hazardous drinking is associated with the perpetration of gender-based violence, and that men involved in team sports are found to have a greater propensity for both hazardous drinking and VAW (Sønderlund et al., 2013), the celebration of rugby in alcohol-focused venues raises legitimate concerns regarding the safety of women in these environments. These concerns are by no means irrational, as many incidents of sexual and physical violence allegedly perpetrated by professional New Zealand rugby players have occurred in and around alcohol-focused venues. For example, in 2015, an Auckland Blues player was charged with physically assaulting a man in a bar fight. ${ }^{13}$ In 2016 , Losi Filipo, who played for the Wellington Lions, was charged with assaulting four people, including two women, on their way home from a bar. ${ }^{14}$ In 2018, a representative player for Mid-Canterbury was imprisoned for attempting to rape a woman in Gisborne, after a night of drinking with his teammates. ${ }^{15}$

When outlining individual cases of rugby-player violence, it is important to emphasise that rugby does not cause violence, and of course, that the majority of rugby players are not violent. However, rugby is a violent sport that celebrates a specific type of masculinity - one that honours alcohol consumption, physicality, and aggression (Pringle, 2004). Given that the greater propensity for hazardous drinking and genderbased violence within sport populations has been linked to dominant versions of masculinity comparable to this version of masculinity, and since the NTE appears to be an environment in which the components of this 'masculinity-beer-rugby' trinity materialise, considering the ways in which women experience NZRC in this specific context is crucial.

\section{Conclusion}

Through an analysis of literature exploring the sport-masculinity-alcohol-violence complex, this review has demonstrated that sports participation is linked to an increased propensity for both gender-based violence and alcohol-use, and that the

\footnotetext{
${ }^{13} \mathrm{See}$ https://www.tvnz.co.nz/one-news/sport/rugby/george-moala-s-late-night-bar-brawl-amounts-toserious-misconduct-nzru-6325946

${ }^{14}$ See: https://www.newshub.co.nz/home/new-zealand/2016/09/wellington-lions-player-losi-filipoescapes-conviction-after-group-attack.html

${ }^{15}$ See: http://www.stuff.co.nz/nz-newspapers/central-north-island/sport/sport-region6459/89201165/Mid-Canterbury-rugby-player-admits-attacking-woman-after-Gisborne-match
} 
relationships between alcohol, violence, and sport, reflect broader associations between men, masculinity, and the acceptance of traditional gender norms (McCray, 2015). As rugby appears to be a key institution in which these relationships can be observed, the elevated societal position that rugby enjoys in New Zealand demands analysis. This position, however, remains unexplored territory and consequently, little is known about the impacts of NZRC on women and gender relations in contemporary society. By providing a platform for women to voice their perceptions and experiences of NZRC, this research aims to expand on the existing literature base, reveal the social significance of rugby in contemporary New Zealand, and demonstrate how valuable rugby can be as a subject of scientific endeavour, theoretical discussion, and socio-cultural debate. 


\section{Chapter Three: Methodological Framework}

As this research aims to privilege the voices of women by sharing their experiences and perceptions of NZRC, a qualitative methods design within a feminist framework was deemed appropriate. This chapter begins by outlining the philosophical underpinnings and methodological frameworks that support and guide this research. Next, it provides an in-depth discussion of the methods used to conduct this research, before outlining the ethical considerations and practical limitations of this study. This chapter concludes by detailing the personal transformations and challenges experienced throughout the research process.

\section{Philosophical Underpinnings}

\section{Feminist Standpoint Epistemology}

While this research considers how, from the perspective of the respondents, NZRC plays out in gendered environments where alcohol is consumed, it also aims to provide a platform for women to voice their opinions and experiences of rugby culture. This aim is congruent with feminist inquiry, which seeks to validate women's perspectives and knowledge (Sprague, 2005). Thus, epistemologically, I approached this research from a feminist perspective. Due to a history of women being devalued and overlooked as the focus of research and as capable researchers, feminist perspectives seek to uncover women's subjugated experiences and knowledge (HesseBiber \& Leavy, 2011). A fundamental principle of feminist inquiry is that research should be conducted "by women, for women" (Stanley \& Wise, 1993: 30) and "where possible, with women" (Doucet \& Mauthner, 2006: 40).

My approach to this research recognises the importance of empowering women and emphasises care, compassion, and collaboration between researchers and participants (Burgess-Proctor, 2015). While many feminist methodologies exist, the theoretical framework explicitly informing this research is feminist standpoint epistemology. Feminist standpoint epistemology is a distinctive philosophy of knowledge that aims to motivate social change by considering the world through the lens of historically oppressed groups (Wood, 2009). At the heart of this approach, is the focus on women's experiences as a means of producing knowledge (Braidotti, 2003). Feminist 
standpoint theorists argue that the historical oppression of women impacts how they navigate and understand the world, and that those who do not share their standpoint are unlikely to share the same worldviews (Beale, 2018).

Feminist standpoint theorists also contend that research is often limited in its analysis and conclusions, due to being predominantly constructed from the standpoint of men (Ezzy, 2002). When informed by a predominantly male viewpoint, research can create a distorted, androcentric picture of reality (Eichler, 1997). Thus, uncovering women's subjugated knowledge is crucial (Beale, 2018). The subjugation of women's experiences and knowledge is particularly discernable in the body of literature exploring the socio-cultural impacts of organised sport. Despite demonstrating how some male sporting cultures can work to maintain societal patterns of male empowerment and female subordination (Segrave, Mcdowell, \& King, 2006), this body of research is predominantly conducted from the standpoint of men. Consequently, it provides masculinised explanations of how sporting cultures may impact the lives the women. By using feminist standpoint epistemology, this research challenges the androcentric bias of existing research, and disrupts the traditionally masculinised ways of knowing to allow for new understandings that could be used to facilitate social change (Burgess-Proctor, 2015).

Due to the importance of reflexivity in feminist research, this thesis adopts a reflexive approach (Dowling, 2006). Reflexivity involves examining how one's social characteristics and worldviews impact the research process (Hesse-Biber, 2014). Crotty (1998) explains that researchers cannot devoid themselves of their humanness, nor can they erase the factors influencing their views, such as race or gender. Since researchers cannot detach themselves from their life experiences to conduct research from an objective standpoint (Becker, 1967), Letherby (2003: 5) argues that all research is ideological. As a form of "scientific rigor," reflexivity allows researchers to acknowledge how their worldviews influence their research interpretations (Crotty, 1998).

Given the ubiquity of rugby in New Zealand, my experience conducting research with rugby players, and my position as a young woman living in New Zealand, asserting complete 'objectivity' would be a flawed approach. However, feminist research 
interprets bias not as an influence that distorts research findings, but as a resource that can be used by researchers to clarify how they frame and identify the knowledge they generate (Dowling, 2006). Thus, in the subsequent section, I carefully consider my personal standpoint to elucidate my positioning in the research and the lens through which I have interpreted the research data (Hesse-Biber, 2014).

\section{My Standpoint}

My positioning in this research is complex and influenced by multiple layers of experience. As someone with little interest in sports, I had never considered the possibility of a relationship between sport, masculinity, and gender-based violence. This changed, however, when professional rugby player Losi Filipo physically assaulted two of my sister's friends. Following this incident, my interest in rugby culture piqued, as did my interest in the academic literature that surrounds it. As engaging with this literature increased my curiosity on the topic, I investigated the relationship between NZRC and gender-based violence through qualitative interviews with amateur male rugby players for an Honours level research project. This project allowed me to understand the complexities and nuances of potential problems associated with certain approaches to masculinity in NZRC, which in some instances, appeared to normalise and condone gender-based violence. This project provided the impetus to develop my research interest further, and explore women's experiences and perceptions of NZRC. In doing so, I aimed to consider whether their experiences aligned with or refuted the findings of literature exploring the nexus of sport, masculinities, and gender-based violence.

As a feminist, I believe in challenging gender hierarchies that lend support to patriarchy. Related to this, is my acceptance of feminist propositions that sport is a core institution for reinforcing dominant versions of masculinity, which in some contexts, can promote violence against 'gendered others' as socially normative behaviour (Messner, 1990). As this research adopts a feminist methodology, both the socio-cultural and individual meanings of rugby are interpreted in relation to this particular standpoint (Messner, 1990). Demonstrative of my multiple layers of understanding, however, I acknowledge a more subdued and respectful side of rugby that promotes health, facilitates life long friendships, gives individuals a sense of belonging, and teaches valuable lessons, such as the importance of teamwork. 
Our perspectives and worldviews are fluid and often change as we are exposed to the workings of particular phenomena (Tarnas, 2010). Adopting a reflexive approach encourages researchers to be amenable to information that challenges their worldviews (England, 1994). Indeed, my knowledge and understandings have been challenged throughout various stages of this research. Outlining the origins of my curiosity and standpoint in this research topic demonstrates an "acute awareness" (Olesen, 2011: 135) of how my experiences may have shaped the research process and the lens through which my interpretations of data were formed. This self-reflexive stance has allowed me to deliberate varying perspectives, which arguably increases the validity of the research findings and conclusions (Code, 1991).

\section{Methodological Approach}

\section{Constructivist grounded theory}

Aligning with qualitative methodologies in which theories are derived from the research data, this study views the link between research and theory as inductive and, therefore, adopts grounded theory as its methodological approach (Hesse-Biber \& Leavy, 2011). Grounded theory involves producing a plausible theory that is grounded in the data, rather than deductively applied to it (McLeod, 2001). When little is known about the phenomenon under investigation, grounded theory is a useful way to facilitate knowledge (Woolley, Butler, \& Wampler, 2000). Since no previous studies have considered how NZRC impacts the lives of women, grounded theory was deemed appropriate for this research. While multiple versions of grounded theory exist, the version informing this research is constructivist grounded theory. Contrary to traditionally objectivist versions of grounded theory that assume a value-free observer uncovers a single reality through objective inquiry (see Glaser, 1992), constructivist grounded theory assumes that multiple realities exist and recognises researchers as part of the research process (Charmaz, 2008). This approach is more interpretive than traditional grounded theory approaches, as it involves developing a "deeply reflexive stance," which allows researchers to scrutinise how their perceptions may impact their research (Charmaz, 2017: 34).

An "epistemological affinity" exists between feminist inquiry and constructivist grounded theory, evidenced by multiple points of "theoretical congruence" (Plummer 
\& Young, 2010: 305). Specifically, feminist research and constructivist grounded theory both acknowledge the importance of reflexivity in research, value women's lived experiences as a source of knowledge, recognise that knowledge is generated through social processes, and can be used to promote social change (Plummer \& Young, 2010). As the congruence between constructivist grounded theory and feminist research principles assists in revealing issues specific to the lives of women (Plummer \& Young, 2010), this version of grounded theory was deemed appropriate for this research.

Importantly, this research adopts constructivist grounded theory as the methodological approach to analysis, rather than the method of analysis itself. To understand this decision, one must consider the origins of grounded theory. Developed by Glaser and Strauss (1967) as a methodological approach to help researchers understand complex social processes, grounded theory was also designed as a method (Fassinger, 2005). As researchers began working with the grounded theory method, differences in its use emerged, and debates ensued about which of the multiple versions were accurate (Charmaz, 2008). The difficulty of establishing an agreed upon definition of what constitutes a grounded theory method is exemplified in the debates that eventuated between Glaser and Strauss (Charmaz \& Bryant, 2010). While an in-depth analysis of these debates is beyond the scope of this thesis, they are important to consider as they influence the current research practices.

At the root of the Glaser-Straus debates is the data analysis process (Fassinger, 2005). Both Glaser (1992) and Strauss and Corbin (1998) agree that the constant comparison method is fundamental to analysis in the grounded theory approach. The constant comparison method involves every part of the data being repeatedly compared with all other parts of the data, in order to reveal similarities and differences (Hallberg, 2006). According to Glaser (1992), this comparative method requires researchers to abandon preconceived theoretical ideas to generate a theory that emerges exclusively from the constant comparison of data. Thus, Glaser (1992) argues that grounded theory researchers should ignore all literature on the research topic, to ensure the data is analysed with minimal preconceptions. Through the constant comparison method themes are said to 'emerge' without any efforts of the researcher (Hallberg, 2006). Contrarily, Strauss and Corbin (1990) believe that because 'reality' can only be 
interpreted and not known, theory emerges from the effortful comparison of data and is informed by the researchers' interpretations.

Due to this convoluted genealogy, contemporary grounded theory methods are "inherently messy" (Suddaby, 2006: 638). Instead of being a universal procedure, grounded theory has become "a constellation of methods" (Charmaz, 2008: 161) that are often unintentionally used in a way described as grounded theory 'lite' - a set of procedures for coding data very much akin to thematic analysis (Braun \& Clarke, 2006). Indeed, grounded theory as an overall methodology shares many analytical tools with thematic analysis, including the method of constant comparison (Chapman, Hadfield, \& Chapman, 2015). Yet, thematic analysis is not a methodology in its own right, and is often situated as a method within 'major' methodological approaches, such as grounded theory (Braun \& Clarke, 2006). Therefore, some researchers choose to adopt grounded theory as the methodological approach informing their use of thematic analysis. As thematic analysis is more straightforward than the 'messy' analytic procedures of grounded theory, using thematic analysis within the methodological framework of grounded theory allows for a more systematic approach (Chapman et al., 2015). Furthermore, such analyses need not subscribe to the theoretical commitments of a 'full-fat' grounded theory, which demands analysis to be directed towards theory development (Holloway \& Todres, 2003). For these reasons, this thesis adopts thematic analysis as its method of data analysis and constructivist grounded theory as the methodological approach driving this process.

\section{Research Methods}

A qualitative design involving in-depth semi-structured interviews was the method used to obtain data. Qualitative methods allow for the intricacies of participants' experiences to be revealed in ways that cannot be achieved through quantitative or survey methods (Bryman, 2008). By legitimising participants as a vital source of knowledge, qualitative research can be emancipatory and help participants feel empowered in the research process (Grbich, 2013). As one of the primary aims of feminist inquiry is to empower women (Brown, Western, \& Pascal, 2013), a qualitative design was deemed appropriate for this research. 
Semi-structured interviews are appropriate for exploratory studies, as they give researchers the flexibility to respond to novel ideas (Merriam \& Tisdell, 2015) Semistructured interviews also complement feminist research, as their flexibility allows for the diversity of women's realities to be articulated (Brown et al., 2013). While much of the sports literature appears 'feminist' in that it considers the influence of sporting subcultures on masculine subjectivities and, by extension, the lives of women, it is predominantly constructed from a male standpoint. Consequently, women's voices are often rendered invisible. As semi-structured interviews enable women to voice, in their own words, how they perceive and experience NZRC, they were considered the most appropriate method of collecting data for this research (Hesse-Biber, 2011). This legitimisation of women's knowledge is an antidote to centuries of ignoring women's perceptions and experiences of sports altogether, or having men speak on their behalf (Reinharz, 1992).

Research often involves power imbalances between the researcher and the 'researched' (Harding \& Norberg, 2005). As the researcher selects the questions, theories, methods, and methodologies that guide the research process, they are inevitably in a position of power, relative to that of the respondents (Harding \& Norberg, 2005). As such, it is important that researchers adopt methods that minimise power inequalities. Contrary to quantitative methods that routinely objectify participants, qualitative methods recognise interviewees as human beings capable of navigating and evaluating their own situations (Sprague, 2005). Qualitative interviews help navigate power imbalances by allowing researchers to develop reciprocal relationships with participants through the disclosure of personal information (Brown et al., 2013). Thus, by disclosing details about my experiences working in the hospitality industry, ${ }^{16} \mathrm{I}$ aimed to achieve reciprocity and create an environment in which participants felt empowered.

\section{Recruitment}

Recruiting participants involved a combination of methods including recruitment posters, social media advertising, and snowball methods. As research suggests that

\footnotetext{
${ }^{16}$ The hospitality industry is comprised of commercial businesses that provide a range of services to customers, including accommodation, food, and alcohol.
} 
many tertiary students are in paid employment, most commonly in bars and restaurants (Manthei \& Gilmore, 2005), recruitment posters (see Appendix B) were placed in women's toilets around Victoria University campuses and, with the permission of the owners, in the staff rooms and toilets of various alcohol-focused venues. Recrutiment posters are suitable for research on sensitive topics, as they allow participants to note the researcher's contact details in private (Liamputtong, 2007).

To maximise response rates, the recruitment poster was also posted on social media. Using social media to advertise research is beneficial, as the reach and accessibility of the Internet can vastly increase the number of potential participants (Hamilton \& Bowers, 2006). However, to optimise the chance of recruiting individuals that meet the eligibility criteria, the researcher needs to select the most appropriate websites to advertise the study (Illingworth, 2001). After carefully considering which sites would be appropriate for advertising this research, the recruitment poster was advertised on a private Facebook group for New Zealand bartenders, a private Facebook group for New Zealand women, and a popular Facebook group among New Zealand university students. While these recruitment methods were effective in accessing participants who worked in bars, pubs, and clubs, gaining access to sex workers was more challenging.

Due to the stigma that surrounds the sex industry, sex workers are considered a 'hardto-reach' population (Armstrong, 2011). Individuals within hard-to-reach populations often refrain from interacting with researchers, due to a level of distrust towards 'outsiders' (Liamputtong, 2007). Nevertheless, as the sex industry is an important part of New Zealand's NTE, I wanted to ensure that the voices of sex workers were included in this research and, therefore, employed alternative recruitment strategies. Atkinson and Flint (2001: 2) promote the use of 'snowball strategies' for accessing hard-to-reach populations, as they "provide a means of accessing vulnerable and more impenetrable social groupings." Snowballing is a recruitment method whereby one participant gives the researcher's details to another subject, who in turn passes on these details to a third, and so on (Atkinson \& Flint, 2001). This chain of referral connects researchers with participants who may have otherwise been unreachable (Lamont \& White, 2005). As many researchers have successfully recruited 'hard-to- 
reach' participants through snowballing (Liamputtong, 2007), this strategy was adopted as my primary method for recruiting sex workers.

My first point of contact was an exotic dancer, who contacted me after seeing the recruitment poster on Facebook. After interviewing this participant, she agreed to send my recruitment poster to other sex workers. Snowballing proved to be an effective means of recruiting sex workers, four of whom were found through this technique. Compared to participants recruited through other methods, participants recruited through snowball methods seemed more comfortable divulging personal information. This observation supports Lamont and White's (2005) contention that participants recruited through snowball methods are often more sincere, trustworthy, and open to discussing personal information, likely because researchers have been authenticated by someone they trust. In this sense, using snowball methods may have allowed for more in-depth and accurate information to be gathered.

While snowball methods have many benefits, they are often criticised for only providing researchers with access to respondents from a single network (Atkinson $\&$ Flint, 2001). Moreover, as participants depend on the subjective choices of the respondents first accessed, they are not 'randomly' selected (Griffiths et al., 1993). Consequently, snowballed samples do not allow researchers to make claims of generalisability (Lamont \& White, 2005). Nevertheless, generalisability was not the aim of this research, nor did it intend to uncover comprehensive 'truths' about NZRC or how women perceive and experience it. Instead, it aimed to explore the perspectives and experiences of a particular group of women who have interacted with NZRC in the NTE, and serve as a vehicle through which their voices can be heard.

In their research, Benoit, Janssen, Millar, and Phillips (2005) and Armstrong (2011) made initial contact with sex workers through formal 'gatekeepers.' Benoit et al., (2005) argues that academics without sex work experience will find it difficult to access participants without the cooperation of formal gatekeepers involved in the sex industry. Similarly, Armstrong (2011) notes that because sex workers are likely to be wary of researchers with no links to friends or allies, working with formal gatekeepers can be beneficial. As establishing a relationship with the New Zealand Prostitutes 
Collective (NZPC) ${ }^{17}$ was thereby deemed appropriate, I arranged a meeting with the staff and volunteers at NZPC to discuss my research.

While I hoped NZPC would help me make connections with participants, I was aware that gatekeeping agencies have the power to keep the researcher out (Liamputtong, 2007). Thus, gaining the trust of frontline staff at NZPC was essential. It was particularly important to reassure the staff that I viewed sex work as a legitimate occupation, supported the decriminalization of sex work, understood the importance of reducing the stigma surrounding sex work, and believed in the minimisation of health and safety risks for all sex workers (Hubbard, 1999). After a successful first meeting, the NZPC staff offered to display my recruitment poster in their branches, and invited me to spend time at their Wellington site to facilitate connections with potential participants. I gratefully accepted this invitation and spent some afternoons at NZPC. However, this was not an effective way of quickly recruiting participants, as the number of sex workers visiting NZPC varied unpredictably and unfortunately, the days I visited were quiet. I am nevertheless thankful for the help and support offered by the team at NZPC.

\section{Interviews}

Corresponding to the feminist framework within which this research is situated, interviews were conducted in a feminist manner. While traditional interviewing techniques promote emotional detachment and objectivity, feminist interviewing promotes building emotional connections and rapport with participants (Punch, 2005). Establishing rapport is especially important when interviews cover sensitive topics, as it helps to create an environment in which participants feel comfortable to share their stories (Liamputtong, 2007). Establishing rapport is also crucial for exploratory studies, as it "opens the doors to more informed research" (Fontana \& Frey, 2005: 708).

To establish rapport, I exchanged texts, emails, or phone calls with each participant before meeting with them. During the interviews, I also attempted to connect with participants through my own experiences of working in hospitality, listen without

\footnotetext{
17 The NZPC is a sex worker led organisation that advocates for the rights, health, and welfare of sex workers.
} 
prejudice, be empathetic to sensitive information, and ensure that the participants' feelings were validated (Armstrong, 2011). Despite having experience working in hospitality, I have not worked in alcohol-focused venues, nor have I worked in the sex industry. Therefore, I did not assume that sharing some similarities with participants allowed me to be an 'insider' of their worlds (Brooks \& Hesse-Biber, 2007). Nevertheless, my 'outsider' status worked to my advantage, as I could facilitate indepth discussions about particular aspects of the NTE where knowledge would have been expected if I were an 'insider' (Brooks \& Hesse-Biber, 2007).

All interviews took place at a quiet café or private meeting room at Victoria University, and drew on a single interview guide (Appendix C) containing non-restrictive questions relating to the overarching research objectives. The interview guide ensured that the main areas relating to the key research questions were addressed and did not direct or limit the conversation (McCabe \& Holmes, 2009). The flexibility of semistructured interviews grants participants the power to determine the focus of the conversation (Bryman, 2008; McCabe \& Holmes, 2009). Thus, compared to structured interviews in which the data is likely to reflect only a partial version of the respondents' perceptions in response to a comprehensive set of interview questions, semi-structured interviews tend to yield data that is more representative of the respondents' all-around views (Bryman, 2008).

As this thesis emerges at a time where the media's scrutiny of cases of professional rugby player misconduct has fuelled concerns about the societal impacts of NZRC, I was aware of the possibility that respondents may only detail information that illuminates existing problems and concerns associated with NZRC. However, as I believe numerous realities exist, and that positive and negative experiences can coincide, I was interested in all kinds of perspectives, irrespective of whether they challenged or confirmed concerns about rugby. Therefore, the interview questions were carefully framed to allow participants to voice their overall views of NZRC, rather than a one-sided version of their perspective.

Before each interview commenced, participants were given an information sheet (Appendix D) and consent form (Appendix E), which outlined the purpose and possible uses of this research, and allowed participants to request a copy of their 
interview transcript and the final thesis upon its completion. After informed consent had been obtained, participants were asked to complete a brief demographic questionnaire (Appendix F). All interviews lasted approximately one hour and were digitally recorded with the participants' consent. After each interview, participants were given a $\$ 20$ supermarket voucher as a koha ${ }^{18}$ to acknowledge the value of their contributions, as well as a list of contacts for available support services to minimise any risk of harm associated with their participation (Appendix G),

\section{Participants}

To participate in this research, participants had to identify as female,${ }^{19}$ be over the age of 18, and have experience working in New Zealand's NTE. ${ }^{20}$ It was anticipated that this research would involve the perspectives of exotic dancers, bar staff, "promogirls, ${ }^{21}$ full-service sex workers, and security personnel. However, due to time constraints, I was unable to interview any promotional workers or security personnel.

A total of 15 women participated in this research. While many of these women had experience working in several occupations within the NTE, only the occupation from which they discussed their interactions with NZRC is reported here. As such, three of the women worked as bar managers, while seven worked as bartenders/waitresses. Of those seven women, two worked at a sports stadium. A further five women worked in the sex industry - three as exotic dancers and two as full-service sex workers. The length of time participants worked in these occupations varied from less than a year to more than ten years.

Seven of the women identified as New Zealand European, four as New Zealand European/Māori, two as British, one as French/Māori, and one as New Zealand

\footnotetext{
${ }^{18}$ Koha is the Māori term for gift, offering, or contribution.

${ }^{19}$ As I believe feminist research should be inclusive, I did not want to exclude women who are not cisgendered. This decision was reflected in my recruitment poster, which called for individuals who "identified" as a woman, so as to avoid perpetuating the notion that participants must be cis-gendered.

20 To ensure this research reflects experiences and interactions with rugby culture in contemporary times, it was required that participants were currently working in the NTE, or had done so in the past five years.

21 'Promo-girls' or 'promotional models' are women hired to interact with potential buyers to increase consumer demand for a service or product (Huntemann, 2015).
} 
European/Vietnamese/Trinidadian. The youngest participant was aged between 18 to 21 years, while the oldest participant was over the age of 45 .

\section{Data Analysis}

The qualitative method employed for the analysis of data was thematic analysis driven by grounded theory. Thematic analysis is a method for identifying, analysing, and reporting particular patterns in qualitative data (Braun \& Clarke, 2006). Revered for its theoretical flexibility, thematic analysis can be used within essentialist or constructionist frameworks (Braun \& Clarke, 2006). While this flexibility allows for detailed accounts of data, the theoretical independence of thematic analysis also means it is a relatively simple method that can be learned without the theoretical knowledge needed for other methods of data analysis (Braun \& Clarke, 2006). As thematic analysis also allows for interpretations of themes that are socially produced and influenced by sociocultural contexts (Braun \& Clarke, 2006), it was thereby suited for this research.

Like all methods, thematic analysis has disadvantages (Van Manen, 1990). The flexibility of this method, although advantageous in some regards, means that the data can be interpreted in multiple ways, which can make developing strategies for "higher-phase analysis" and choosing which areas of the data to focus on a "paralysing" task (Braun \& Clarke, 2006: 97). Furthermore, thematic analysis has "limited interpretative power beyond mere description" when used in the absence of an existing theoretical framework that supports the analytic claims made (Braun \& Clarke, 2006: 97). This potential issue was mitigated in the current study by ensuring that the feminist principles underpinning the research drove the analysis of data.

According to Braun and Clark (2006: 87), a good thematic analysis involves the following six steps: "familiarising yourself with your data; generating initial codes; searching for themes; reviewing themes; defining and naming themes; and producing the report." Following this process, digital recordings of interviews were listened to after each interview, before being digitally transcribed verbatim. Interview transcripts were then systematically explored to identify repeated patterns across the data set, before collating the data into initial codes using coloured highlighters. Using coloured highlighters meant coded data extracts were easily collated into three potential themes. 
Within these three thematic files, each data extract was further analysed to produce a refined understanding of the scope and content of initial themes (Braun \& Clarke, 2006). This analysis allowed for official themes to be named and defined. Producing the report involved the selection of significant quotes that were considered to facilitate an understanding of participants' perceptions and experiences of NZRC. The chosen extracts were analysed in relation to the research questions and literature informing this study. The supervisors then read each findings chapter, to ensure the validity and accuracy of the research interpretations.

\section{Ethical Considerations}

As this research is on a sensitive topic and includes the views of sex workers, who are highly stigmatised in popular discourse, several ethical issues required careful consideration to minimise risks for the researcher and participants (Liamputtong, 2007). Ethical approval was sought from the Victoria University Human Ethics Committee and granted on 14 May 2018 (see Appendix H). A detailed explanation of how ethical issues would be mitigated was required to obtain ethics approval, with privacy and confidentiality being key considerations for this research. As depictions of women in the sex industry are often comprised of negative stereotypes (Weitzer, 2018), sex workers often choose to keep their occupation a secret from friends, family, and employers (Armstrong, 2011). Being exposed as a sex worker could have profound consequences for participants, such as the breakdown of personal or professional relationships (Armstrong, 2011). Therefore, protecting the sex workers who chose to participate in this research from any possibility of exposure was crucial.

To minimise risks of exposure, interviews took place at a semi-private location mutually agreed upon with participants. In the unlikely event someone known to the participants or myself interrupted the interview, I planned to be discreet about my identity as a researcher, the purpose of the meeting, and the participants' occupation, by disguising the interview as a 'catch up with a friend.' The identity of the participants remained confidential to the researcher, and materials relating to their participation remained locked in a secure place. Audio and digital files were password protected and only accessible by the researcher. To further ensure participant confidentiality, participants were assigned a pseudonym, and identifying information including the names, locations, and descriptions of their workplaces, was removed. 
The names of professional rugby players and teams were also removed from interview transcriptions. The reason for this was two-fold. Firstly, as I felt that including this information would detract from the participants' narrative, removing it ensures that this research rigorously adheres to its aim of prioritising the participants' voices. Secondly, while protecting the identity of third parties mentioned in qualitative interviews is an element of confidentiality that researchers often overlook (Haverkamp, 2005), third parties are not participants and, therefore, cannot consent to the disclosure of private information (Hadjistavropoulos \& Smthye, 2001). Researchers must acknowledge that including such information in accessible accounts puts themselves and the participant at risk of unfavourable reactions from the third party (Haverkamp, 2005). Therefore, removing the names of specific rugby players and teams was necessary, not only for protecting the identities of third parties, but also for minimising the risk of harm to the participants and myself.

As this research is exploratory, there was a lack of certainty regarding what the interviews would uncover. However, because potential problems associated with NZRC have been reported to play out in contexts that involve women, alcohol, or both, I was aware that participants may recall distressing experiences. If participants were to disclose sensitive information and become upset, they could take a break or end the interview at any time without prejudice. Bergen (1993) advocates adherence to a 'feminist ethic of care' in sensitive research, centered on an orientation of support and respect for participants. This feminist ethic of care informed my interviewing technique, as I was attentive to the participants' limits on what they wished to discuss, yet empathetic to any sensitive information they disclosed.

As researching sensitive topics can have various emotional impacts (Coles, Astbury, Dartnall, \& Limjerwala, 2014), it was essential to consider the potential impacts of this study on my emotions, and to determine ways to mitigate these impacts. When participants detail distressing experiences, repeatedly listening to and transcribing interviews, coding data, and writing up reports can be profoundly upsetting and may result in vicarious trauma (Coles et al., 2014). Vicarious trauma refers to trauma reactions of individuals that result from their secondary exposure to another individual's first-hand traumatic experience (Trippany, Kress, \& Wilcoxon, 2004). To mitigate the risk of vicarious trauma and ensure my emotional safety during this 
research, I received formal support through therapy, and informal support through my supervisors, family, and friends.

For research to be conducted ethically, the researcher must be constantly aware of power inequities between themselves and the participants (Stanley, 2012). Awareness of power imbalances, alongside conscious efforts to minimise disparities, are core tenets of feminist research (Nazneen, Darkwah, \& Sultan, 2014). Feminist efforts to reduce power differentials between researchers and participants often take the form of strategies for empowering participants throughout the research process, and creating reciprocal participant-researcher relationships (Miller \& Boulton, 2007). To ensure participants felt valued, listened to, and empowered, I took a less active role during interviews, did not 'push' participants for information, and granted them total control over the direction of the interview and which information to disclose.

\section{Limitations}

Gender intersects with various social categories including ethnicity, religion, age, socioeconomic status, and sexuality (Bent-Goodly, 2009). Pertinently, this research incorporates the experiences of women from various backgrounds and of various ages and ethnicities. Importantly, this research includes the perspectives of Māori and Pākehā women. While I recognise the importance of intersectional approaches to gender research, an examination of women's experiences of NZRC with regards to ethnicity is beyond the scope of this thesis. Given my identity as a Pākehā researcher, I did not feel qualified to undertake such an analysis, and acknowledge that this is a considerable limitation that future research should aim to address. Another limitation of this research is that it explores the experiences of a relatively small sample of women, which limits the generalisability of the findings. However, this research aims to act as a vehicle through which insight into the diverse realities of these particular women can be developed, and through which their voices can be heard. As it does not intend to generalise, nor does it claim that the participants' views of NZRC represent the views of all New Zealand women, the validity of the insights engendered from this study cannot be measured by generalisability (Patton, 2002). 


\section{Navigating the Research Process}

Undertaking this research was an intensely emotional journey with many personal challenges. While I was able to quickly connect with my participants through my own experiences as a female patron of the NTE, I naively believed that because I had studied and tutored sexual violence courses at university, I would not be emotionally affected if they disclosed sensitive information. To my surprise, I was profoundly upset by the stories of sexual and physical violence shared by some of the participants. In fact, this research triggered a set of psychological impacts including anxiety, hypervigilancy, and night terrors. However, the strength displayed by the women who shared their stories gave me the motivation I needed to persevere.

While I joked with my supervisors that I could "write a thesis on the reactions to my thesis,' a major challenge I faced during this research was the reaction of friends, family, and academics. Although this research is exploratory and does not aim to attack rugby, it does not shy away from addressing issues rugby may face off the field. Due to rugby's strong articulations with discourses of masculinism and nationalism, however, female critics of rugby risk being positioned as unpatriotic and misandrous (Pringle \& Markula, 2005). Indeed, when explaining the nature of my research to others, I was usually met with the question "What do you have against rugby?" People seemed to hold a set of preconceived assumptions about my intentions as a researcher and about what my interviews would reveal, and I had to repeatedly reassure others that this research did not stem from a personal 'vendetta' against rugby or men. Ultimately, I found myself in the perplexing position of wanting to provide a platform for women to voice their opinions about NZRC, but fearing negative reactions to, and misperceptions of the research.

This fear was further solidified by comments made by some participants. For example, Jessica disclosed that she thought this research was "brave," whilst Jane commented that she "wouldn't have the balls to do it." As the fear of how others would interpret my research translated into a fear of 'exposing' it, I avoided presenting my research at academic conferences and delayed advertising it on social media. My fears were not unfounded, as when I eventually posted my recruitment poster on Facebook, I was called a "fucking feminist" and accused of "attempting to give rugby a bad name." Despite these negative reactions, the majority of the public comments on social media 
were supportive. As I learned to accept that "new discoveries are always the result of high-risk expeditions into unknown territory" (Suddaby, 2006: 633), and that feminist research often produces provocative analyses that challenge societal assumptions, understandings, and arrangements (Charmaz, 2017), my fears eventually subsided. 


\section{Chapter Four: Experiencing Rugby Culture in the Night-Time Economy}

This chapter explores four key themes relating to the respondents' experiences of NZRC. To facilitate an initial understanding of how the participants conceptualised rugby culture, this chapter begins by exploring the perception of rugby as a male preserve characterised by the 'masculine' pursuits of excessive alcohol consumption and violence. Next, this chapter outlines the respondents' accounts of being sexually objectified by rugby fans and players. Correspondingly, interviews revealed an overwhelming number of incidents of violence perceived to be linked to NZRC, which the respondents had either experienced directly or witnessed in the environment around them. This chapter therefore continues with an exploration of the respondents' personal experiences of 'rugby-related' violence. ${ }^{22}$ Finally, this chapter examines understandings of rugby-related violence as a 'normal' and expected part of interacting with NZRC in the NTE. The analysis of these four themes provides the context needed to understand the subsequent chapters, which explore how respondents rationalise their interactions with NZRC, and how interacting with this culture impacted upon their lives.

\section{Rugby as a Masculinist Culture of Intoxication}

While the numbers of women playing rugby in New Zealand are steadily increasing, the RRR notes that an "underlying assumption or expectation of the role of rugby as a purely male preserve is still a remnant aspect of rugby culture in New Zealand" (Cockburn \& Atkinson, 2017b: 31). This report also identifies alcohol as a 'remnant' feature of contemporary NZRC, which is said to reflect a long established relationship between rugby and alcohol sponsors (Cockburn \& Atkinson, 2017b). Supporting this view, virtually all of the women in this research perceived NZRC as a maledominated preserve, characterised by excessive alcohol consumption:

Rugby culture looks like lads, lads, lads... not really girls. I worked in a

\footnotetext{
22 Participants identified violence as 'rugby-related' if it involved individuals known to be rugby players, perceived to be rugby fans, or if it occurred on a 'rugby night' or 'game night' (i.e., the night on which a high-profile rugby game was being played or rugby event was being held).
} 
bar that sold steins ${ }^{23}$ of beer, so people would come to us before all the rugby games because you can drink massive amounts of beer and you are close to the stadium. Rugby culture is basically big groups of boys going out to get drunk. (Olivia, Bar Manager)

From my experiences, rugby culture involves getting drunk quite a bit and rowdy guys working each other up to show who's top dog. (Rose, FullService Sex Worker)

According to McEwan et al., (2010: 28), excessive alcohol consumption is a normalised practice in licensed leisure venues, which is linked to a pervasive 'culture of intoxication' in New Zealand. As this research focuses on interactions with NZRC in alcohol-focused venues, the perceived link between alcohol consumption and rugby culture may be symptomatic of a broader 'culture of intoxication' in New Zealand (McEwan et al., 2010: 28). Supporting this view, Aimee commented that rugby culture "connects a lot with the general drinking culture in New Zealand" whilst Holly expressed that, "New Zealand has a huge binge drinking culture, which I think goes hand in hand with rugby." By contrast, four participants perceived NZRC as being disconnected from New Zealand's 'binge drinking' culture. For example, Grace explained that NZRC and New Zealand's broader culture of intoxication "are separate entities for sure."

While rugby's long established relationship with alcohol makes disentangling rugby culture from New Zealand's culture of intoxication a formidable task (Gee \& Jackson, 2010), 12 out of the 15 participants described changes in the levels of patron intoxication on 'rugby nights' versus 'non-rugby nights,' perhaps delineating a point of difference between NZRC and the wider drinking culture in New Zealand. For example, Holly noted that, "intoxication levels are always higher on game nights," whilst Jane commented:

It's not uncommon for people to come to the strip-club drunk, and I think it's that binge-drinking thing coming through, but on game nights, it's noticeably different. People drink more, and everyone's absolutely shitfaced. Rugby culture is like binge drinking culture on steroids. (Jane, Exotic dancer)

\footnotetext{
${ }^{23}$ Beer steins are a type of mug that traditionally holds 1.0 litre of beer.
} 
Supporting contentions that the historically robust link between alcohol and rugby has contributed to the emergence of a binge drinking culture in contemporary New Zealand society (Gee \& Jackson, 2010, 2012), nine participants expressed that due to rugby's elevated societal position, NZRC works to normalise excessive alcohol consumption, which by extension, encourages and exacerbates a broader culture of intoxication. For example, Katherine explained that:

At rugby games, you see familiar faces coming up to buy alcohol for a fifth time, and I think it can support an unhealthy amount of drinking. I do think rugby culture promotes and normalises excessive drinking. (Katherine, Bartender)

Of the fourteen respondents who described NZRC as a male-dominated culture of intoxication, five commented that due to the social significance of rugby in New Zealand, the exclusion of women from NZRC plays a fundamental role in the subordination of women and in the maintenance of male hegemony:

Women are not part of rugby culture, and that's the dominant culture, and if you're not part of the dominant culture, then you're less. (Joanne, Exotic Dancer)

Women aren't welcome in rugby culture, and New Zealand is all about rugby, so as a woman, that actually makes you feel sidelined from our own country. (Jane, Exotic Dancer)

Pertinently, Grace commented that although she was a "big fan" of rugby, its maledominated nature made her feel excluded from the culture:

It's all about the boys. I am definitely a big rugby fan and I love going to watch the games, but as a female, you feel like you are never really part of the culture... it feels like you're kind of just tagging along. (Grace, Bartender)

Aligning with contentions that the cultural dominance of rugby glorifies a hegemonic 'Kiwi Bloke' version of masculinity that rests on physicality, aggression, and alcohol consumption (Phillips, 1996; Pringle, 2004), the respondents overwhelmingly identified excessive alcohol consumption, physical strength, and aggression as hallmarks of masculinity in NZRC. For example, Joanna argued that alcohol is an integral feature of NZRC because rugby is a "masculine space" and "drinking is such 
a masculine thing." Jessica explained that in rugby culture, masculinity is founded on the ability "to knock back all the beers and keep on going," whilst Jane noted that, "with rugby, being a man is about sinking piss, being physically strong, and using that strength aggressively." Pertinently, Neve described rugby as the "epitomisation" of masculinity in New Zealand:

I think rugby, the sport itself is kind of the epitomisation of masculinity. It's about men coming together and conquering using physical dominance. It's very much based on aggression. It's about how strong you are. There are other aspects like speed and agility that come into it, but essentially, it comes down to strength. I think that in itself, and men coming together as a group to use their strength to win, is something that epitomises hypermasculinity (Neve, Bartender)

While the respondents overwhelmingly described aggression as an integral feature of 'rugby masculinity' on the playing field, 10 out of the 15 women believed there was a tendency for violence to escape the confines of the rugby field and make its way into the wider community (Welch, 1997). For example, to emphasise the magnitude of the violence and physicality involved in playing rugby, Rose commented that, "rugby is very much like going to war. They play the game to fight." Moreover, she contends that violence on the rugby field works to create an "us and them mentality" amid rugby fans, which can result in off-field violence:

Rugby fans pick a side and so there's an "us and them" mentality. There's so much conflict in the game itself, and so even after the fans have finished watching the game, they still have that "us and them" mentality and that can result in violence. (Rose, Full-Service Sex Worker)

Supporting the notion that the authorised use of aggression, strength, and physical domination in sports can contribute to the perpetration of off-field violence (Schacht, 1996; Welch, 1997), 11 out of 15 respondents described witnessing violent behaviour involving rugby fans and players in the NTE. Jessica explained that at the strip-club where she worked, some groups of men who came to watch the rugby "would get violent and want to have fights with each other." Aimee similarly explained that when working the night of "a losing game," fights between rugby fans would occur:

If it's a losing game, fans are shitty about the loss and they kick off, start fights. I, for example, have been in the middle of multiple brawls trying to 
pull guys away from each other and there's girls getting knocked about.

(Aimee, Bar Manager)

Perhaps reflecting the extent of the violence in this particular venue and its apparent connection to NZRC, Aimee explained that in her workplace, "we don't let people wear their rugby colours or jerseys because it limits people kicking off." Holly also explained that in the bar where she works, "there have been so many fights over rugby teams, that we don't let people in rugby jerseys in anymore." In addition to witnessing violence between male patrons, five participants described witnessing female co-workers and patrons being incidentally harmed during fights between rugby fans:

There was one instance... where these guys were just being very aggressive and they were on the verge of throwing punches. One of my coworkers, who's a smaller woman, got in-between them. She was trying to diffuse the situation and she ended up with a punch to the face. Neither of the parties stopped or checked to see if she was okay or said sorry. She just got in their way and they didn't pay any attention to it and I think that is that rugby culture. (Neve, Bartender)

I saw a very small girl go flying because she got in the way between two blokes who decided they were going to have a punch up. That can happen potentially anywhere. That can happen in the stadium, it can happen afterwards, it can happen at the bar. (Brianna, Bartender)

When describing an incident in which she observed a co-worker "get knocked to the ground' during a fight between rugby fans, Jane commented that rugby-related violence stems from "that whole lad culture that surrounds rugby." The term "lad culture' has been defined as a group mentality that is articulated through 'male' activities, such as sport and alcohol-use, and often involves violent and sexist behaviours (Phipps \& Young, 2013: 28). Notably, eight out of 15 participants used the terms 'lad,' 'ladd-y,' 'laddish' and 'lad culture' when describing NZRC. For example, Grace commented that there is a "real lad culture around rugby" whilst Joanna expressed that rugby "...is just a boy's culture isn't it. It's the lads." According to Phipps and Young (2013), lad culture is closely associated with templates of masculinity that encourage the sexual objectification of women and normalise sexual violence. Supporting this view, the respondents overwhelmingly identified the sexual objectification of women as an integral part of being a 'lad' in 
NZRC. The following section builds from this and explores the respondents' experiences of sexual objectification.

\section{Experiencing Sexual Objectification}

Research has found that the sexual objectification of women is particularly prominent within male team sports (see Curry, 1991; Messner \& Sabo, 1994; Murnen \& Kohlman, 2007). Aligning with this literature, a common thread in the participants' narratives was their references to the sexual objectification of themselves and other women by rugby fans and players. For example, Holly worked at a bar regularly frequented by professional rugby players and described witnessing multiple players "cheat on their girlfriends and wives while they're sitting at home." Holly understood these infidelities as being "another part of rugby culture" in which "women are treated like sexual objects." Echoing this view, Danielle commented that in NZRC, "women aren't respected as women but as sexual conquests," whilst Monique commented that men in rugby culture often "belittle women" and treat them "like an object." Elaborating on the sexual degradation of women by men in rugby culture, Monique described witnessing a group of professional rugby players instructing a sixteen-yearold waitress to "touch her elbows together, so they could see her cleavage." With reference to an incident in which she described being "coerced" to perform oral sex on a professional rugby player, Jessica noted:

That's how they treat women. And that's how I perceive rugby players think that women should to be used. They're just like "Oh, I feel like a blowjob right now, I'll go pick up that 17-year-old." It's like women are nothing but a blowjob... That's our role in their culture. (Jessica, Erotic Dancer)

While Thompson (1988) contends the role of women in rugby was traditionally confined to domestic tasks, Sarah argues that in contemporary times, little has changed, noting that, "with rugby, women are there to serve the men, wait on them hand and foot, bring them their drinks, and have sex with them." Elaborating on the degradation of women by men in NZRC, Sarah explained that when working on game nights, her sessions ${ }^{24}$ usually involved groups of intoxicated men who made

24 Sex workers often refer to time spent with clients as "a job" or "a session" (Perkins, 199) 
derogatory and dehumanising comments about her appearance:

You go into a room and there's five big drunk guys saying, "we wanted someone taller with bigger boobs." Then they're like "oh yeah, you're not that great but you'll do." It's yuck. I'd rather have my regular clients who choose me and want to see me for my company, than just be on display. The way they look you up and down is revolting. It makes you feel like a piece of meat. (Sarah, Full-Service Sex Worker)

Johnson (2005) argues that comments about physical appearance serve to separate the body from the individual as a person, allowing for the body to be treated as an object that is instrumental for the use by others. One must note, however, that because sex work involves the commodification of the physical body, the sexual objectification and devaluation of women who sell sexual services is pervasive (Spivey, 2005). Nevertheless, Sarah delineates a point of difference between her 'regular clients' and 'rugby clients' (i.e., discernible rugby fans), by stating that her regular clients wanted to see her for "company," whilst her rugby clients made her feel "like a piece of meat." The identification of a rigid dichotomy between 'regular' and 'rugby' clients is significant, as it suggests that there may be features specific to NZRC that facilitate or condone the sexual objectification of women. Echoing the findings of international research (Boswell \& Spade, 1996; Flood, 2008), for example, five respondents conceptualised behaviours that position women as sexual objects as a fundamental proponent of homosocial bonding in NZRC:

I think younger groups of boys use meeting up to watch the rugby together as a time where they can talk about women, like "oh I got with like three chicks since the last time we watched a rugby game together." I think rugby gives them their bragging rights. It's all about how many girls they've got with... it's a time for them to gloat. (Laura, Bartender)

When describing her perception of NZRC, Monique similarly positioned the competitive boasting about sexual feats as a characteristic feature of NZRC:

What immediately comes to mind is a stereotype, which I don't think's necessarily a stereotype, but guys boasting about who they've had sex with, who's banged the most girls, who can knock a guy out, it's those typical things that you think of, but it's so true because I see it all the time. (Monique, Bartender) 
As well as being perceived as a mechanism through which male bonding can be enacted, respondents overwhelmingly viewed heterosexual achievements as vital to achieving masculinity in NZRC. For example, Sarah explained that to attain a masculine status in NZRC, men must "treat women like dirt. Like objects. Sexualise them. Have as much sex as you possibly can." Echoing this view, Joanna expressed that in NZRC, masculinity involves "treating women like shit because you're above them and just wanting to have sex with everyone because that's what a man does," whilst Holly commented that "to be a man" in NZRC "means to be big, to be tough, to be unapologetic, and to definitely and obviously sexualise and objectify women."

Indeed, discourses and behaviours that position women as sexual objects are central to hegemonic templates of masculinity (Connell, 1987; Donaldson, 1993), which, as mentioned, are particularly marked within the masculinities of sportsmen. Problematically, Pasko (2002) contends that the sexual objectification of women reinforces aspects of 'toxic masculinity' ${ }_{25}$ linked to sexual violence, including possession, violent domination, and the devaluation of women. Aligning with this contention, Rose conceptualised the sexual objectification of women in NZRC as a feature of "toxic masculinity," which she described as being "good for the sex industry in the fact that sex is inherent to it, but also bad in the fact that you're not treated so much as a human." Pertinently, Vaes, Paladina, and Puvia (2011) posit that because the sexual objectification of women implies that they are instrumental for men's sexual desires, it denies them of human characteristics, which can become dehumanising for the objectified. Indeed, when elaborating on her understanding of masculinity in rugby culture as 'toxic' and dehumanising, Rose explained that rugby fans view sex workers as being devoid of individuality, personality, and humanness (Vaes et al., 2011).

The guys who like rugby and go into brothels are not necessarily that great of guys. They want women they can treat not as a human but as an object. They don't treat us badly, but they don't see us as a person, they see us as a thing to have sex with... like a sex doll. (Rose, Full-Service Sex worker)

\footnotetext{
${ }^{25}$ The term toxic masculinity is often used to separate the aspects of hegemonic masculinity that are socially destructive, such as the devaluation of women, from those that are culturally accepted and valued (Posadas, 2017)
} 
While Joanna acknowledged the routine sexual objectification and commodification of her body in her job as an exotic dancer (Spivey, 2005), she explained that on rugby nights, this sexual objectification increased to the point where it was "almost dehumanising":

I think what it boils down to is feeling more like a piece of meat on rugby nights. We are way more objectified. It's almost dehumanising. (Joanna, Exotic Dancer)

Holly similarly explained that the "over sexualisation of women by professional rugby players, including of myself" made her feel like she was "not a person." Problematically, when sexual objectification is a normative experience, individuals can begin to internalise their experiences and view themselves as a sexual object who's worth is based on their physical appearance (Murnen \& Kohlman, 2007). Consistent with this literature, Holly recalled feeling a certain pressure to look " $h o t$ " in order to be respected by rugby players:

It makes you feel like you have to behave or look certain way to be respected by them [rugby players], you know, like, dressing up and looking hot. (Holly, Bar Manager)

For this self-objectification to occur, sexual objectification needs to be frequent, pervasive, and widespread enough to approximate a social norm (Smolak \& Murnen, 2011). Thus, Holly's contention that a "hot" appearance is necessary to gain the respect of rugby players is particularly significant, as it suggests that within this particular bar, the sexualisation of women by rugby players is, perhaps, socially normative behaviour. This is concerning, as the sexual objectification of women is found to be associated with the perpetration of sexual violence against them (Gervais, DiLillo, \& McChargue, 2014). Strengthening this concern, interviews revealed an overwhelming number of incidents of 'rugby-related' sexual, physical, and verbal violence. The following section builds from this, and explores the women's personal experiences of rugby-related violence and degradation. 


\section{Experiencing 'Rugby-Related' Violence}

\section{Verbal and Physical Violence}

A common thread in the participants' narratives was a perceived lack of respect for women by men in NZRC. For example, Monique expressed that rugby fans and players "treat women as if they're below them," whilst Jessica stated that men in NZRC "allow themselves to become pigs and treat women like absolute shit." Sarah explained that in her experience as a sex worker, clients who had been to watch a rugby game were usually "derogatory" and would "make jokes" about her appearance, whilst Joanna felt that men in NZRC perceived her as subordinate: "I sensed they felt I was less than them and that they were above me. They perceived me as less than." Aimee commented that her workplace interactions with rugby players differed from those of her male co-workers, whom she felt were treated with more respect:

They're [men in NZRC] more derogatory and speak down to women. In my experience, that's been through the players and fans speaking down to me and being ruder to the female bartenders. We do have male bartenders and they do, very obviously, get treated better by rugby players and fans. (Aimee, Bar Manager)

Holly similarly commented that the rugby players who regularly frequented her workplace had "more respect for the boys," and explained that "the players come in, shake the male bartenders' hands, say 'sup bro,' and act like they're mates." By contrast, Holly explained that when being served by female bartenders, these same rugby players would "refuse to behave and listen, demand drinks, and snap their fingers." Holly considered this behaviour to stem from a deeply embedded attitude of male superiority, which breeds contempt for women:

I think because I'm a woman, there's this attitude of "I'm not going to listen to you because I'm above you, and what the fuck can you do about it?" (Holly, Bar Manager)

Echoing this view, Jane commented that on rugby nights "customers acted like they generally just hated women" and attributed this contempt for women to dominant versions of masculinity in NZRC: 
Customers acted like they generally hated women on rugby nights. I'd hear them calling women sluts and whores and just making really sexist comments. Maybe it's because of that whole Kiwi masculinity thing, where being a man is essentially about being a dick to women. (Jane, Exotic Dancer)

When hegemonic masculinity looks disparagingly at women and femininity, violence can become a legitimate means through which men can express their disdain for women and reconfirm their hegemonic masculine positions within a heterosexualised gender order (Connell \& Messerschmidt, 2005). Correspondingly, 13 out of the 15 participants disclosed experiencing some form of rugby-related violence, which ranged from verbal abuse through to rape. Although participants were not asked to detail personal experiences of violence, four participants described instances in which they had been verbally or physically abused by rugby fans, players, or both. For example, Holly described numerous workplace incidents where professional rugby players had verbally abused her:

I've been called a bitch. I've been called a slut, and that happens a lot with the players. I've actually been labelled the bitchy manager. I've heard the players say it. If I say, "no you're too intoxicated I'm not going to serve you," I get yelled at from the end of the bar for the next half an hour. They'll say, "fuck you, you're a slut, you're a bitch, fuck you." It's exhausting. (Holly, Bar Manager)

Holly also described having "close to physical altercations" with professional rugby players, whilst Aimee described being "elbowed in the face a couple of times" during fights between rugby fans. Jessica commented that in the strip-club where she worked, rugby supporters would intentionally "pull a girl on stage, like, they'd pull on her heels and trip her over." Moreover, she described an instance in which she observed a co-worker being spanked on a game night:

One game night, a group of guys were spanking a girl in the strip-club in the private room and it was getting a bit too rough so I actually had to tell them to stop. (Jessica, Erotic Dancer)

Jane recalled being "pushed against the wall" in the private room of a strip-club by an "angry rugby head," after she told him to stop squeezing her breasts. Sarah described 
an incident where herself and another sex worker were verbally abused and had items thrown at them by rugby supporters at an outcall:

The girl I was with, because we were drinking with them, she threw up. Then the guys started yelling and throwing things at her. I basically had to drag her out of the hotel room. All these guys were screaming and yelling at us. It was horrible. They were saying, "you fucking cunts, you drunk bitch, we want our money back" all that stuff, and you don't know what way it is going to turn. (Sarah, Sex Worker)

While only two of the women who worked in bars, clubs, and pubs described instances of rugby-related physical abuse, an overwhelming majority of the sex workers in this research described being physically abused by rugby fans, players, or both. In contemplating this observation, it is important to note that due to the stigma attached to their work, sex workers are particularly susceptible to experiencing violence (Deering et al., 2014). Due to defying the patriarchal expectation of sexual modesty, female sex workers are considered to be in violation of 'appropriate' female behaviour (Sanders, 2001; Kinnell, 2008). Consequently, they are traditionally considered 'deviant' women and have been portrayed as hate figures deserving of punishment for their transgressions from 'respectable' femininity (Kinnell, 2008). This deviant positioning perpetuates the 'othering' of sex workers from individuals in other service industries and, consequently, stigma is attached to their work (Armstrong, 2011).

While sex workers are undoubtedly more vulnerable to experiencing violence due to problematic social mores relating to their work, research suggests that the majority of men who purchase sexual services are not violent (Deering et al., 2014). Correspondingly, the sex workers in this research indicated that there was 'something different' about their clients on rugby nights, which they felt increased their risk of violence. For example, Joanna explained that compared to her regular clients who "know how it works" and were "more respectful," clients on rugby nights were aggressive and unpredictable. Moreover, she felt that men used rugby as an excuse to be violent, not only towards sex workers, but also towards women more generally:

They'd never treat a woman like this usually, they'd never get this violent, or this rough, but because there's a rugby game on they would. They use 
rugby as an excuse to behave like animals and treat women like shit. (Joanna, Erotic Dancer)

Rose similarly commented that in her experience as a full-service sex worker, clients "would be rougher" on rugby nights, whilst Jane explained that she had only ever experienced physical violence on rugby nights:

I never have issues unless there's a rugby game on. The regulars are always respectful but on game nights, customers are more aggressive and will spank you, trip you up, and shit like that. It's not just because we're in the sex industry and they think it's okay to treat us like that. It's because we're women and they think its okay to treat any women like that. (Jane, Exotic Dancer)

Thus, Jane believes that due to a general disrespect of women by men in NZRC, rugby-related violence is a problem that likely extends beyond the confines of the sex industry. Indeed, while only two women in the hospitality sector of the NTE described experiencing verbal and physical violence at the hands of rugby fans and players, as will be demonstrated in the following section, an overwhelming majority of these women detailed experiences of rugby-related sexual violence.

\section{Sexual Violence}

A total of 14 out of 15 women in this research detailed experiences of ruby-related sexual violence or harassment. Consistent with the notion that in hypermasculine sporting cultures, women are often sexually exploited through the use of sexualised discourses that encourage and normalise sexual harassment (Boswell \& Spade, 1996; Curry, 1991), Danielle explained that when bartending at rugby events, customers would make 'harassing' sexualised remarks directed towards her:

They make these sexualised comments and they think they're being nice to you but it's not the type of comments you really want to hear... it's a demeaning kind of nice when you're a woman. (Danielle, Bartender)

Danielle also described a specific incident in which she had to swap places with a coworker who was being sexually harassed by a customer at a rugby game:

There was a girl who came up to me and was like "oh, I need to change places with you because he just keeps commenting on the size of my 
boobs and I just can't deal with it anymore," so I had to change places with her. (Danielle, Bartender)

While Katherine similarly commented that when she had bartended at rugby events, there were "inappropriate comments made" by customers, she explained that, "most of it was just joking." Consistent with research that finds women often do not identify unsolicited sexual attention as problematic or harmful when it is disguised as a joke (Mallett, Ford, \& Woodzicka, 2016), Katherine conceptualised this behaviour as meaningless: "They're just joking and having some fun and that, it doesn't mean anything." It is important to note, however, that unsolicited sexualised comments and unwanted sexual advances can work to exacerbate rape culture, as they often contribute to the normalisation and trivialisation of sexual violence (Ford, Triplett, Woodzicka, Kochersberger, \& Holden, 2013). In this sense, Katherine's contention that, "every female person who has worked at a rugby game would have experienced those inappropriate comments and been hit on," produces significant cause for concern. Strengthening this concern, virtually all participants described receiving unsolicited sexual comments or being sexually propositioned by rugby fans or players. For example, Monique recalled a specific incident in which a customer made an explicit reference to oral sex:

I worked a function on a night of a rugby game, and some guy kept saying really gross stuff to me. I was pouring a beer and I said, "Sorry, there's quite a bit of head on this beer" and he said, "who doesn't love a bit of head?" (Monique, Bartender).

Similarly, Joanna recalled being asked to perform oral sex on a professional rugby player at work:

I always just remember meeting (names professional rugby player). He was trying to get a bunch of the girls to go home with him and was saying things to us like "you know who I am, come on, you can suck my dick." It was so gross. (Joanna, Erotic Dancer)

Laura described a specific incident in which a customer "who was there for a rugby game" requested that she sit on his lap: "I asked if I could get them anything else and the old man was like yeah, could you sit on my lap." Reflecting on this experience, Laura situated sexual violence on a continuum in which she implicitly linked the more 
common, everyday forms of sexual violence, such as unsolicited sexual comments, with abuses officially labelled as 'crimes,' such as rape (Kelly, 1988):

I know with my experience, even though it's not as bad as others, it doesn't mean that you know, if I was outside by myself on the smoking deck serving one table of people and everybody else was inside, that they wouldn't try to grab me here or there or something like that. (Laura, Bartender)

Although Laura perceived her experience of workplace sexual harassment as "not as bad as others," situating sexual violence on a continuum is not intended to position alternate forms of violence as distinct points placed within a resolute order of harm (Kavanaugh, 2013). Instead, it enables all forms of sexual VAW to be recognised as expressions of male dominance, which blend into, constitute, and support each other (Bayard De Volo \& Hall, 2015). Thus, while unsolicited sexual comments may not meet the established criteria for classification as a sexual crime, such incidents are important, as they signify a broader cultural atmosphere surrounding rugby, in which attempts of sexual coercion, instances of unwanted sexual contact, and rape may be normalised (Kavanaugh, 2013).

Correspondingly, six participants described being sexually assaulted by men believed to be involved in NZRC. For example, Joanna recalled walking through crowds of rugby fans and "having to duck under people to avoid them groping me." Monique commented that when cleaning up empty glasses from a table of men at a rugby event, "one of them turned around and hit me on the bum." Holly similarly detailed an incident of workplace sexual harassment involving professional rugby players:

Some players were in drinking on a quiet night and I was being asked to give them a kiss, give them a hug. I was trying to cut them off and they were laughing at me. I only had one security guard on and he was too scared to remove them because there were ten of them and he was by himself and he didn't want to start a physical altercation that he couldn't deal with. I think that was one of the scariest experiences I've had and one of the times I actually felt unsafe and out of control in my own workplace. (Holly, Bar Manager)

Pertinent to contentions that men in hypermasculine cultures engage in the collective sexual harassment of women to provide substantiated 'proof' of masculine virility 
(Flood, 2008; Franklin, 2004), the common thread through which Joanna, Monique, and Holly's experiences of rugby-related sexual violence are linked, is that each involved groups of men. This observation is important, as it suggests that the codes of mateship, masculinity, and bonding among men in NZRC may work to perpetuate and condone sexual violence (Flood \& Dyson, 2008). While a disproportionate amount of the rugby-related sexual violence that participants reported involved groups of men, Jessica contrarily described meeting a professional New Zealand rugby player who was alone at a bar, before engaging in a "forcefur" sexual interaction with him:

I was at a bar and I met a professional rugby player... He was 27 and I was 17... I liked him and went back to his place and had some quite forceful sex. I wouldn't call it rape but it was definitely, well I said, "Okay I'm tired now, lets stop" and he kept going. I was actually really swollen down there the next day... One point he picked me up, and as a 17 year old, I was thinking we'd be going for coffee or something. But he drove me somewhere, parked up, and made me give him a blowjob... It was coerced. I didn't want to do it, but I didn't say no. (Jessica, Erotic Dancer)

Research suggests that over 50-percent of women who experience non-consensual sexual contact do not label their experience as 'sexual assault' or 'rape' (Littleton, Deborah, Rhatigan, \& Axsom, 2007). The complexity of recognising and naming sexual crimes is largely influenced by cultural definitions that promote narrow images of 'real' rape as an exceptionally violent sexual attack committed in a public space, at night, by an unknown assailant (Estrich, 1987; Weiss, 2009). When experiences of rape deviate from this real rape stereotype, victims are likely to minimise the severity of their experience (Kelly \& Radford, 1990). For example, research finds that when rape occurs between acquaintances or romantic partners and does not involve physical resistance by the victim or extreme physical force by the perpetrator, it is less likely to be labelled as rape by the victim (Littleton et al., 2007). When contemplating this knowledge, it is not surprising that Jessica conceptualised her experience as forceful sex as opposed to rape, as it occurred between acquaintances, did not involve physical resistance or exceptional violence and, therefore, does not conform to the stereotypical image of 'real' rape. 


\section{'Something about rugby culture is just different'}

When exploring the participants' experiences of 'rugby-related' violence, it is crucial to reiterate that the NTE is an intensely sexualised social space in which rape, harassment, and unwanted sexual contact occur with regularity (Fileborn, 2016; Kavanagh, 2013). Indeed, many of the participants acknowledged that violence was not confined to rugby culture. For example, Holly expressed that, "regardless of rugby games or not, you still have drunk people, you still have abusive people, you still have creeps." Similarly, Aimee noted that being groped at work "was something that happened regardless of rugby." Furthermore, five participants recalled experiences of workplace sexual violence that were not connected to rugby. In this sense, VAW in the NTE can hardly be considered the monopoly of NZRC.

However, many participants commented that the amount and severity of the workplace violence that they experienced was intensified on rugby nights. For example, although Monique acknowledged that violence was "not confined to rugby by any means," she stated that in NZRC, "it's so much worse. It brings it out and almost makes it acceptable." Joanna similarly explained that interactions with customers were "hugely different on rugby nights," as customers "would be really gropey." In fact, because this sexual assault "often got so out of hand," Joanna recalled asking her regular customers to come in to work on rugby nights, to avoid being sexually assaulted:

It often got so out of hand so I would just tell my regulars to come in on those days and say "hey it's a rugby game, do you want to come and take me away and we can hang out for the night" so I didn't have to deal with being groped. (Joanna, Erotic Dancer)

Consistent with research that finds 'centre sports' are more likely to preserve and endorse problematic notions of hegemonic masculinity that normalise, condone, and excuse gender-based violence than sports of a marginal societal position (Anderson, 2015; Messner, 2002), Sarah explained that while clients on rugby nights were often physically rough and derogatory, "guys who'd said they'd been to watch the football were absolutely fine. Football players don't seem to be like that." In contemplating why clients on rugby nights were "so much rougher" than her regular clients, Sarah stated, "something about rugby culture is just different." Similarly, Danielle explained 
that in contrast with customers at rugby games, customers at soccer games did not make inappropriate sexual comments:

Working soccer games is a lot different. Like, the customers are still arrogant, but they don't make those gross sexual comments. They make rude comments about how fast you serve instead of about what you look like. (Danielle, Bartender)

Perceived differences between interactions with NZRC and other sporting codes, in conjunction with contentions that violence is heightened on 'rugby nights' are particularly significant, as it suggests that there are factors specific to NZRC that may work to condone or normalise gender-based violence. Supporting this view, many respondents conceptualised violence as a 'normal' part of their workplace interactions with NZRC. The following section develops these arguments further, and explores the respondents' expectation and tolerance of 'rugby-related' violence.

\section{Expectation and Tolerance of Rugby-related Violence}

Pertinent to propositions that rugby fosters a hegemonic template of masculinity, which in certain contexts, promotes violence against 'gendered others' as socially normative behaviour (Pringle, 2004), nine out of the 15 women in this research conceptualised gender-based violence as an expected, inevitable, and characteristic part of interacting with NZRC in the NTE. For example, Laura commented that sexual harassment was "something that was expected... especially when there are a lot of lads, there's a game on, and they're all drinking," whilst Sarah described physical violence as an inexorable reality for sex workers on the nights of rugby events:

If you work for an agency and you work on rugby events, you're going to get guys that are rough, too drunk to perform, and do things like leave you with bruises. That's my experience anyway. (Sarah, Sex Worker)

Jessica similarly perceived violence against women in the NTE as an inevitable occurrence on rugby nights:

If you're out on the night of a rugby game, you're going to get shoved. You're going to get pushed over. If you're walking down the street and 
there's four of them, you're going to have to hide because they're going to be like "hey lady" and try lift your skirt or something... It's terrifying. (Jessica, Exotic Dancer)

As a bar manager, Holly described feeling a certain sense of responsibility to look after her staff and explained that although she would "dread" professional rugby players coming to the bar, she would "put on a brave face" in anticipation of abuse:

I have to be there for my team. I'm always there to make sure they're okay and looked after, so I just have to pretend that it's all good and put on a brave face. You have to take a breath before it happens and say right, I'm prepared for harassment, I'm prepared to be abused, and I'm prepared to have to call the security every five minutes to remove someone. (Holly, Bar Manager)

While Neve did not consider violence to be an inevitable reality of interacting with NZRC in the NTE, she latently acknowledged an increased probability of unfavourable interactions with customers when working on the nights of a rugby game:

I am more aware of the tentativeness of what was happening and that there was a higher chance something would go wrong very easily. I was more sensitive to it. That probably infiltrated my actions and the way that I treated people. I tended to treat people with a lot more delicacy on rugby nights than I usually would. (Neve, Bartender)

Kavanaugh (2013) notes that when violence becomes expected or anticipated in certain social situations or contexts, the implicit cultural message is that violence is a 'normal' part of the gendered interactions in these contexts. Thus, perceptions of violence as an inevitable part of working in the NTE on rugby nights may, in part, relate to the normalisation of violence in this particular context. Correspondingly, when discussing the alleged sexual assault of a sex worker by members from the Waikato Chiefs, Joanna explained that this incident was "expected because it's exactly what you see in the club. Not necessarily with the rugby players but just with everyone who is part of that rugby culture." Moreover, she conceptualised sexual assault as both a normalised and inevitable experience of working as an exotic dancer on rugby nights: 
I remember that case [Waikato Chiefs incident] happening and thinking "of course that's going to happen," which sounds so bad. I think a bunch of us were like yep, cool that happens, they're all like that... It's upsetting but you just become desensitised to that sort of shit. It's become normalised. That's honestly just what to expect from rugby fans and players. (Joanna, Erotic Dancer)

Research finds that perspectives of violence as an expected, inevitable, or normalised 'occupational hazard' can result in the passive acceptance of violence (Kensbock, Bailey, Jennings, \& Patiar, 2015; Ram, 2018). In turn, sexually aggressive behaviours are often conceptualised and tolerated as an inherent part of the job (Ram, 2018). Consistent with this literature, Sarah conceptualised violence as "part and parcer" of working as a sex worker on rugby nights, whilst Katherine described the inappropriate comments and sexual propositions from customers at rugby events as "something that comes along with the job." When outlining her reaction to sexual propositions from customers, Katherine stated, "I'll just, you know, politely laugh." Neve similarly explained that when customers made unwanted sexual advances, she would "laugh it off" or "ignore" them:

I'm always torn because part of me wants to be the kind of person who just completely destroys them... But on the other side, this is a regular interaction on a rugby night. They're not doing it with any kind of malice, they're reasonably well intentioned, and they're also customers at a bar that I'm working at. It's not appropriate. Because I'm torn between those two things I usually do neither and just ignore it. (Neve, Bartender)

Poulston (2008) argues that when sexual attention from a customer is passively tolerated or rewarded with a smile, the behaviour is reinforced and may be repeated with other workers. In the context of service, however, addressing customer harassment can be difficult for employees, due to the widespread philosophy of service as pleasing customers, reflected in the slogan "the customer is always right" (Yagil, 2008: 142). This slogan perpetuates the notion that the abusive behaviours of customers should be tolerated (Ram, 2018). Neve's contention that it was "not appropriate" to confront the unwanted sexual behaviour of customers supports this literature. Moreover, her perception of this behaviour as a "regular interaction" devoid of ill intent suggests that, to some extent, she perceived sexual harassment as socially normative behaviour. 
Poulston (2008: 28) also suggests that because sexual harassment is widely accepted by hospitality workers, it is thus, "to some extent, welcomed and enjoyed." Opposing this view, while many of the women accepted rugby-related violence as a 'normal' part of working in New Zealand's NTE, 10 out of the 13 respondents who had experienced this violence conceptualised their experiences as problematic. For example, despite perceiving sexual harassment as something that "comes with the territory" of bartending at a rugby-focused sports bar, Laura stated "it's not all good" and that "we shouldn't have to expect it at all." Similarly, Aimee explained that she "shouldn't expect to be harassed" and stressed that she was neither welcoming nor tolerant of harassment:

I have a lot of male cousins that have taught me how to stand up for myself. So I think to myself 'would they let that happen to me?' And if I think 'no they'd probably get shitty about that,' I'll turn around and say to the dude “don't touch me that way." (Aimee, Bar Manager)

While Jane commented that sexual harassment was an "expected" part of working on rugby nights, she explained that “just because you expect it, doesn't mean you aren't affected by it." Irrespective of the extent to which the respondents considered their experiences of rugby-related violence to be problematic, perceptions of rugby-related violence as an expected, inevitable, and characteristic feature of rugby culture in the NTE are significant, as they raise important questions regarding whether changes need to be implemented to ensure the safety of women when interacting with NZRC in alcohol-focused environments.

\section{Summary}

The respondents conceptualised NZRC as a predominantly male culture, characterised by excessive alcohol consumption and violence. Women were reportedly ostracised from NZRC, and elements of sexism and misogyny within this culture were readily identified. Virtually all of the participants reported experiencing some form of 'rugbyrelated' sexual objectification or violence. Due to the extent and regularity of these experiences, gender-based violence was perceived as a 'normal' and expected part of interacting with NZRC in the NTE. These findings strengthen concerns regarding the safety of women when interacting with NRZC, and suggest that changes may need to be implemented to ensure the safety of women when interacting with NZRC in 
nightlife venues. Furthermore, as alcohol consumption, the rejection and degradation of women, and violence, are regularly cited in academic literature as performances of hegemonic masculinity, these findings raise questions about whether changes need to be implemented to encourage alternative approaches to masculinity within NZRC. 


\section{Chapter Five: Rationalising Interactions with Rugby Culture}

This chapter explores how the respondents rationalised their interactions with NZRC. Given that virtually all of the women experienced some form of rugby-related violence, this chapter places emphasis on their understandings and explanations of these particular experiences. Within the context of concerns about the social impacts of the "binge drinking culture in rugby" (Cockburn \& Atkinson, 2017b: 28), this chapter begins by examining the perceived influence of alcohol on the respondents' interactions with NZRC. Next, this chapter outlines how a 'privileged' rugby player status, a 'respected' rugby culture membership, and a perceived 'pack mentality' in rugby culture were considered to perpetuate misogynistic, sexist, and violencesupportive attitudes. Finally, this chapter examines the perceived influence of approaches to masculinity in NZRC on the perpetration of rugby-related violence.

\section{'Alcohol Doesn't Help'}

Challenging essentialist perceptions of alcohol consumption as a causal agent of sports-related violence (Ayres \& Treadwell, 2011), virtually all of the women in this research described alcohol as either one of many factors facilitating rugby-related violence and misconduct in the NTE, or as a mere contextual feature in their experiences of rugby-related violence. For example, Joanna, who identified rugby fans and players as ardent consumers of alcohol, explained that although alcohol makes working rugby nights "difficult to handle," it was not the sole cause of this difficulty. Instead, she explained that alcohol, when combined with factors such as the number of customers in the strip-club, excitement levels, and 'testosterone,' works to facilitate inappropriate and sometimes violent behaviours amongst customers:

With rugby nights, everyone was extra rowdy and literally everyone was drunk. It's easy enough to deal with one or two people who are drunk and being grabby, mouthy, and gross, but when everyone is like that, it's a lot more difficult to handle and on rugby nights, it does seem like everyone's like that. It's not just that they're drunk. It's that they're rarked up and excited, so the impact of alcohol on rugby nights is different... they're rowdier, thinking they can get away with more, that testosterone filled like, 
you know, very grabby, very mouthy, very all over the place and they'll call you a fucking bitch or whatever. (Joanna, Exotic Dancer)

When contemplating the impact of alcohol on her workplace interactions with professional rugby players, Holly noted, "It's usually when the players are under the influence that they misbehave and swear at me and my staff." However, Holly rejects the notion that alcohol single-handedly causes this behaviour, maintaining that excessive alcohol consumption merely exacerbates disorder:

The players buy rounds... it'll be like twenty beers or vodkas and they're gone in two minutes and they come back for more. But I don't think it's alcohol that makes them misbehave, because most of our customers are drinking, and they don't seem to behave like that. I think it's more to do with that sense of entitlement that comes out in rugby culture. The amount of alcohol consumed just makes the existing problems worse. (Holly, Bar Manager)

Nevertheless, Holly implicitly situated alcohol consumption as a major contributing factor in incidents of rugby-related violence. At her workplace, she explained that various steps are taken to prepare for the drunken and disorderly conduct of rugby fans and players, which she described as an inevitable consequence of increased levels of intoxication on game nights:

Because intoxication levels are always at their highest when games are on, we know there will be problems with the players and the fans, we know they will abuse our staff, we know there will be fights, we know they will misbehave around women, so we put extra staff on and make sure we have two bouncers at the door. We actually had to get more bouncers to deal with all the problems we have. We used to have four and now we have six. (Holly, Bar Manager)

Monique described the NTE as an arena in which alcohol, rugby, and sexually inappropriate behaviour are symbiotic features (Finney, 2004). Moreover, she explained that she attempts to "keep interactions in the bar with men to a minimum, because they treat women pretty gross... Then it's definitely heightened when a game is on." When outlining her contention that the mistreatment of women in hospitality is heightened on rugby nights, she explained that excessive alcohol consumption creates a context in which inappropriate sexual behaviour is normalised: 
The main thing with rugby is that they're drinking more and that is definitely one of the main influences on their behaviour. It definitely changes your interactions... They just say things they might not usually and I think alcohol is like the main factor from rugby games. I don't know why people drink so much when they watch rugby, but it's definitely a thing... It's just completely normal and there's no question about it. They're going to get drunk and most likely be inappropriate around women. (Monique, Bartender)

While participants overwhelmingly identified a link between alcohol and rugbyrelated misconduct in the NTE, 7 participants identified rugby match outcome as a mediating variable in this link. Aimee noted that when a high-profile rugby team loses a match, customers get "angrier and drunker faster," which makes interactions with customers more difficult, and customer-aggression more likely:

If they've won a game, they're in a good mood and might get drunk, but because they're in a good mood it's easy to socialise with them. If they've lost, they get angrier and drunker faster. Little things are more likely to set people off when they're in a bad mood so I guess winning and losing, it determines that mood and whether there will be fights and abusive customers. (Aimee, Bar Manager)

The notion that customers are more aggressive when a rugby team loses opposes the findings of international research exploring the influence of sport match outcomes on spectator aggression. For example, Sivarajasingam, Moore, and Shepherd (2005) analysed the relationship between Cardiff emergency department (ED) attendance and outcomes of rugby and soccer matches between 1995 and 2002. When the local rugby and soccer teams won, there were higher numbers of ED attendances for treatment of assault injuries than when they lost or drew. Similarly, Moore, Shepherd, Eden, and Sivarajasingam (2007) examined the impact of rugby match outcomes on selfreported spectator aggression and alcohol consumption amongst male rugby fans in Cardiff, and found that team success, but not failure, increased aggression amid rugby fans, and that aggression, but not celebration, drove post-match alcohol consumption. By contrast, Card and Dahl (2011) examined the link between family violence and football match outcomes in the US, and found that when the home team was predicted to win by four or more points, losses were associated with a 10-percent increase in the rate of violence by men against their female partners. Yet, when the game score was expected to be close, both losses and wins were found to have small and insignificant 
impacts on domestic violence rates.

While there is anecdotal evidence that domestic violence rates increase when New Zealand's national rugby team loses, ${ }^{26}$ no empirical research has examined the relationship between rugby match outcome and spectator aggression in a New Zealand context. Nevertheless, a number of participants described hearing of a statistic that when the All Blacks lose a game, domestic violence rates increase. Katherine used this 'statistic' to support her contention that rugby culture is "not really a safe place for women," especially when alcohol is involved:

I heard this statistic that on the nights of rugby matches, domestic violence increases and based on my experiences working at rugby games, I can see that happening. If the team loses, they're angry, they're drunk, and if they're that type of person, they'd go home and take it out on someone. I think it's because with rugby, emotions are running high and when alcohol is added to the mix, it's not really a safe place for women to be involved, but I think it also heavily depends on who's winning. (Katherine, Bartender)

Neve similarly explained that because many New Zealanders are emotionally invested in the outcome of rugby games, she believes that when the All Blacks lose, domestic violence rates increase:

I've heard there's statistics that domestic violence goes up the nights that the All Blacks lose, and I one hundred percent believe that. There's a lot of, a sense of betrayal I would say, because the people they believe in have let them down. (Neve, Bartender)

Further, Neve explained that irrespective of the match outcome, customers are either "depression drinking, or victory drinking." Moreover, she explained that customers often use alcohol consumption as an "excuse" to behave inappropriately:

As soon as you have alcohol involved, whether the customers are drunk or not, it seems like there's more of an excuse to act in ways they wouldn't normally. They can do what they want, say what they want, and they can blame it on the drink... It's a liberation factor. A pseudo-liberation factor... Then of course you have nights where a game has happened, and everyone

${ }^{26}$ See: https://www.nzherald.co.nz/nz/news/article.cfm?c_id=1\&objectid=3568124 https://www.nzherald.co.nz/nz/news/article.cfm?c_id=1\&objectid=10829563 
has that really heightened sense of energy and they drink a lot more. (Neve, Bartender)

Although alcohol was not considered to be the sole 'cause' of perceived problems associated with NZRC, virtually all of the participants expressed that alcohol had a significant impact on their interactions with rugby culture, which, for the most part, was negative. For example, Katherine explained that customers at rugby events "get a very specific kind of drunk," which often leads to difficult interactions:

With rugby, it's a very specific kind of drunk where they're really excited at the same time, which would lead to problems. Like, I remember one shift last month, this guy was running and screaming and then half an hour later we see him getting dragged out by security. There will be the occasional funny chat to someone who is wasted and they're having a good time, but the impact of alcohol on my interactions with customers is mostly negative. People get more annoying and will hit on you and are more difficult to deal with when they're wasted. (Katherine, Bartender)

Rose explained that "on rugby nights clients are more drunk, and there's more drunk people," which can lead to difficult interactions. Elaborating on the influence of alcohol on the behaviour of clients, she commented that on rugby nights, men were often "rude" and would "get kicked out for being drunk." Moreover, she noted that when the local or national team loses, clients tend to "drown their sorrows" and, consequently, would be "more aggressive." By contrast, Olivia and Danielle explained that alcohol positively influenced their interactions with customers on rugby nights:

If big groups of guys are drinking, it's easier to talk to them and sell them things. So on rugby nights it's good because people drink more, and so they're more willing to talk and interact with you more. (Olivia, Bar Manager)

Some people get a little friendlier and you get to actually have conversations with people because they're more open when they've been drinking. You get to know the customers better, which makes it more enjoyable. (Danielle, Bartender)

However, Danielle identified a 'tipping point' in which harmless drinking and friendly conversation would, at times, become harmful. She noted, "As the night goes 
on, they drink more and seem to get more arrogant and inappropriate." Correspondingly, Jessica explained that levels of customer intoxication were higher on game nights, which made her job "more difficult," as she conflated an increased level of intoxication with an increased risk of violence. Interestingly, Jessica commented that she "didn't really care" when customers used cocaine, as she felt cocaine worked to reverse the effects of alcohol and, therefore, reduce her risk of experiencing violence:

On rugby nights, it's like "how wasted can we get, let's get a bunch of girls, let's get a room, let's get some champagne." They pull out some cocaine. I actually didn't care if they had cocaine because usually coke sobers you right up so the clients would be more likely to make the correct decisions when it comes to females. Whereas when they're drunk, they're more likely to be grabby and pushy... With cocaine, they're more switched on and more chatty. For me, when a customer is wanting to have a good yarn, that means they're not wanting to touch me and feel me up. (Jessica, Exotic Dancer)

As virtually all respondents believed that alcohol exacerbated disorderly and violent behaviours and made working on rugby nights more difficult, it is not surprising that nine respondents conceptualised excessive alcohol consumption as an aspect of NZRC that required change:

To make rugby culture a better experience for me, I'd say no alcohol. But that's a huge part of the culture and I think people would riot if we were suddenly like "we aren't allowed to serve alcohol at the venue any more." (Katherine, Bartender)

Although alcohol-focused solutions may help to minimise potential issues within rugby culture, it is crucial to reiterate that participants overwhelmingly described alcohol as one of many factors contributing to their experiences of rugby-related violence and degradation. This finding is important, as it suggests that the development of effective prevention and management strategies likely requires a better understanding of the multiple pathways to rugby-related violence. By exploring how the respondents understood and explained their experiences of rugby-related violence, this research revealed some alternative pathways through which involvement in NZRC was believed to encourage violence against, and the mistreatment of, women. This chapter moves on to explore these pathways, and 
begins by outlining how a 'privileged' rugby player status and a 'respected' membership in NZRC were considered to perpetuate misogynistic and sexist attitudes that are conducive to gender-based violence.

\section{Rugby Culture Membership as an Entitlement to Power}

Aligning with the literature that positions rugby as a defining feature of New Zealand's cultural identity (Phillips, 1996; Pringle, 2004), virtually all of the women in this research described rugby as an omnipresent feature of life in New Zealand, and considered professional rugby players to be of an elevated societal position. For example, Joanna noted, "being a rugby player in New Zealand means you are the shit. You are the biggest of the big. You are a god. People worship you." Correspondingly, Danielle described rugby as an integral feature of New Zealand's cultural identity, and considered professional rugby players to be of an elevated social standing:

Rugby is engrained in New Zealand. It's our identity. When you see a professional player you're like "wow, that's amazing” and you feel like they're higher people, because they have a status that puts them above others. (Danielle, Bartender)

Neve acknowledged rugby's strong articulations with discourses of nationalism in New Zealand (Pringle \& Markula, 2005), explaining that the country's "patriotism is tied into rugby." Neve also commented that due to the nationalistic discourses that position rugby as New Zealand's national sport (Pringle \& Markula, 2005), people tend to view New Zealand as a "very singular dimensional country," which can be sidelining for New Zealanders with little interest in rugby:

New Zealand and rugby are intrinsically linked... Overseas, if you say you're from New Zealand, people automatically mention rugby... I think the fact that we're known around the world as the sports team, makes people view us as a very singular dimensional country. There's no depth. It's not multifaceted. Rugby is what you are and if you don't act or present something that is in line with it, like if you're not someone who plays rugby or who knows who the All Blacks are, that goes against everything people believe a New Zealander should be like. I think that whole mentality of "us and them," that's quite dangerous. (Neve, Bartender) 
Nonetheless, consistent with the notion that rugby can be a beneficial and unifying force in New Zealand (Pringle, 2004), Neve noted, "rugby is unifying, it promotes healthy lifestyles, it brings kids together, and it gives our country an opportunity to band together." Echoing this view, Holly expressed that “I'm happy rugby's our national sport and I'm always proud when we win games. It definitely brings people together," whilst Monique explained that she "grew up around rugby" and enjoyed how it "brings everyone together." However, Monique contends that there is a "different side" to rugby, whereby a sense of entitlement amid players can work to promote the use of VAW:

I've grown up going to games, and seeing how cool it can be... But at the same time, there's such a different side to it and being older now, I see it. Especially being a young woman, and especially after that whole thing that happened with the rugby team who sexually assaulted the stripper. I think that was what made me notice it. These guys think they're gods and can therefore treat people however they want. (Monique, Bartender)

Echoing this view, a further 11 participants commented that the high-profile status of rugby and the celebrity treatment of professional rugby players work to create a sense of entitlement amid some men in rugby culture (Flood \& Dyson, 2007). For eight participants, this sense of entitlement was perceived to be associated with their personal experiences of rugby-related violence and degradation in the NTE, as well as with other high-profile incidents of violence perpetrated by professional rugby players. Like Monique, Grace commented there is a "dark side of rugby culture" whereby the metaphorical "pedestal" that elevates professional rugby players can work to enforce a sense of entitlement to power that can be exercised over others:

I think there's a dark side of rugby culture, not necessarily with the fans, but with the players themselves. We put them onto a pedestal and it probably inflates their ego and they think they can get away with certain things or that they're entitled to behave in a certain way and do what they want to people and get what they want from people. That's not a generalisation of all rugby players, that's just some of them. (Grace, Bartender)

Holly also considered a sense of entitlement amid some of the professional rugby players who regularly frequented her workplace to be implicated in their alleged displays of "disrespectful," abusive, and "rowdy" behaviour: 
The players think they can do whatever they want and that they're above the law... I think it's because they're professional rugby players and we, as a country, give them that sense of entitlement. In the weekends, I'm constantly telling them "no you don't make the rules, no you're not above the law or above any body else, no you can't come behind the bar, no you can't harass other customers, no you can't be too rowdy." They're rude, disrespectful, and they harass people, and I constantly have to treat them like children and tell them how to behave. (Holly, Bar Manager)

When outlining an incident in which she described being sexually harassed by a professional rugby player at work, Joanna similarly commented that the rugby player involved in this incident, alongside other rugby players she had interacted with, likely view their "privileged' rugby player status as permission to "misbehave," especially around women:

He [professional rugby player] was so gross and thought he could get whatever he wanted by saying "do you know who I am?" He was saying "come on baby, do you want to come home with me?" I just remembered being shocked and thinking "holy shit are all rugby players like this?" Then we had a couple more come in on a different occasion and every time they would misbehave, and I would be left thinking "who do you think you are? Just because you play a sport and you run around with a ball does not make you this God, and it does not mean that you get us and whatever you want from us for free."(Joanna, Exotic Dancer)

Correspondingly, while Jessica perceived the incident in which she described having "forceful sex" with a professional rugby player as related to misogynistic attitudes that position women as sexual objects, she also rationalised this experience as "an entitlement thing." This view is consistent with previous research that has linked some cases of gender-based violence perpetrated by sportsmen to a sense of entitlement or invincibility that stems from fame and money (Whannel, 2001). Appositely, DeKeseredy and Schwartz (1993) explain that patriarchy translates into individual attitudes of male sexual entitlement, which provides the motivation and justification for sexual violence. Supporting this contention, research has found that attitudes of sexual entitlement are linked to the perpetration of sexual crimes (Bouffard \& Goodson, 2017), and to various rape-supportive attitudes and behaviours associated with the perpetration of sexual aggression, including the sexual objectification of women (Bouffard, 2010). Pertinent to this literature, Aimee contends that because rugby is a male-dominated sport, there is a disproportionate 
level of recognition and support for the All Blacks compared to the Black Ferns, ${ }^{27}$ which ultimately works to enforce a "better than women" mentality and create a sense of entitlement to "women and women's bodies" in professional rugby players:

There are female rugby players, but the male teams are recognised because it's a male-dominated sport and they're considered to be 'naturally' better, which gives them more power. That makes them, and I'm not saying this applies to all players, but it makes them feel like they're better than women, and gives them power that women don't have. I think it's that they're treated better than the female team. The, what are they called? I mean exactly, I can't even remember what they're called. That goes to show the pedestal that the male players are put on, which I think makes them feel entitled to women and women's bodies. (Aimee, Bar Manager)

The identification of a "better than women" mentality is particularly significant, as perceptions of men as 'naturally' superior to women in the sporting context can translate into men's 'natural' supremacy in a broader social order, and serve as symbolic proof of their innate right to physically, sexually, and psychologically dominate women (Schacht, 1996). Given that rugby is claimed to heavily influence the social climate of, and gender relations within, New Zealand (Pringle, 2004), this better than women mentality may influence attitudes towards women in New Zealand more generally and, therefore, could be particularly dangerous for women (Schacht, 1996). Supporting this view, 10 participants described a "flow-on effect" in which they explained that the behaviours and attitudes displayed by some professional rugby players influenced the behaviours and attitudes of other rugby players, of rugby supporters, or of men in New Zealand more generally. Joanna explained that because professional rugby players are "idolised" in New Zealand, they have an "opportunity to be incredible role models." She also expressed that if professional rugby players "were modeling really exceptional awesome behaviour, it would have such a flow-on effect." Based on her interactions with NZRC in the NTE, however, Joanna explained that rugby currently works to perpetuate "rape culture" and "sexism" in New Zealand:

Because rugby is such a dominant culture, I think it overflows. I think so many people idolise and accept this behaviour set by the players, and it definitely has an impact on society... We see these people everywhere and if we're accepting their behaviour, it makes it okay for everyone else. Your

27 The Black Ferns is the name of New Zealand's national women's rugby team. 
average Joe will think "this rugby player treated women like this, why can't I?" (Joanna, Exotic Dancer)

Correspondingly, Holly explained that in the bar where she worked, the disrespectful behaviours, sexist attitudes, and "disregard for authority" displayed by some professional rugby players, encouraged similar behaviours and attitudes amongst patrons:

The players think they're untouchable. I know a few of them who have been banned from drinking by their managers, and I still see them out drinking. There's a real disregard for authority, and they think it's okay to treat women like shit, and that whatever behaviour they display isn't a problem. But it definitely is because it influences their fans in this environment, which is also why we've banned rugby jerseys. Fans see players misbehaving, and do the same... they get rowdy, inappropriate, and don't listen to staff or security. (Holly, Bar Manager)

When contemplating this 'flow-on effect,' it is crucial to emphasise that perceived attitudes of male sexual entitlement were not confined to professional rugby players. Many women expressed that due to rugby's social significance, any form of involvement in NZRC encourages individual attitudes of male sexual entitlement. For example, when discussing her experience of being groped by a rugby supporter at work, Monique noted that rugby supporters "seem to think they can do what they want and behave how they want, even if it's inappropriately." Pertinently, Neve explained that implicit attitudes of male sexual entitlement exist amid rugby fans, and attributed these attitudes to feelings associated with winning, such as dominance, victory, and control:

They don't explicitly demand people have sex with them but it's that general demeanor of "I won something" and it's almost like the bar staff become part of their feelings of being in control and winning. It's like they're walking around the world like they feel like they did something good, and that the world now owes them something. I think what it boils down to, is a sense of entitlement. (Neve, Bartender)

To elucidate how feelings associated with winning can encourage a sense of entitlement that may be exercised over others, Neve describes an incident whereby a rugby supporter reached over the bar and grabbed her hand. For Neve, this act served as a public demonstration of masculine dominance, and as a celebratory performance 
in which the group of rugby supporters were basking in their shared power and identity as winners (Franklin, 2004):

In the context of working whilst the game was on for example, one night I think the team had won so everyone was real hyped up, real energetic. I had my hand on the bar and one of the guys reached over and grabbed my hand. It wasn't aggressive, but it was a very dominant display and it was something that I personally, was not very comfortable with. I think that incident was related to that whole idea of 'we won and now I'm entitled to act in any way I see fit.' (Neve, Bartender)

Contrasting with the respondents who believed the violence-supportive attitudes of professional rugby players were likely to influence the attitudes and behaviours of other men, Aimee viewed attitudes and behaviours conducive to violence within rugby culture as micro-social expressions of broader patriarchal forces in $\mathrm{New}$ Zealand (DeKeseredy \& Schwartz, 1993). For example, when describing her perception of the Waikato Chiefs incident, she explained that while this incident reflects a sense of male sexual entitlement, it also reflects the sexism that already pervades contemporary New Zealand society:

I think the Waikato Chiefs thing comes back to how the players feel entitled to women and obviously think they can get away with sexually abusing women. It's definitely a combination of rugby culture and the general sexism that exists in New Zealand. The sexism that encourages that type of sexual behaviour, it's already present in New Zealand... I think it just comes out more in rugby culture (Aimee, Bar Manager)

Indeed, misogynistic attitudes and behaviours conducive to rape mentality among men in male-dominated spheres are not normally idiosyncratic (Jordan, 2004; Bouffard, 2010). Instead, they are usually reflective of the socio-negative attitudes towards women that are already embedded within the wider socio-cultural setting (Cossins, 1998; Gregory \& Lees, 1999). In other words, attitudes and behaviours within NZRC that may promote the perpetration of VAW are likely exaggerated forms of the general attitudes that exist within contemporary New Zealand society. From this perspective, tackling concerns about rugby's impact on women may not necessarily require the implementation of changes within New Zealand rugby itself. Instead, addressing such issues likely requires broader societal transformations that involve challenging the sexist ideologies that work to create and maintain the 
conditions for gender-based violence. Although rugby and the moral codes of its players and supporters cannot be divorced from broader New Zealand society, eight respondents perceived the elevated societal position of rugby and the 'god' like status of its players as aspects of NZRC that required change:

There needs to be a little less of this hyper-masculinity linked in, and less idolising or adulation of rugby players. They are just humans. They are just people like all of us. They are not gods. Because not only do we, I say we as a country, feel like they're gods, but it makes them feel like that too. It makes them feel like they've got more power, and they do have more power than they really should have. (Neve, Bartender)

I definitely think that rugby players need to be taken off their pedestal. Obviously that's not going to happen to the degree I want it to, but even if it's just holding them accountable for their actions and making sure they don't feel entitled to certain things. (Aimee, Bar Manager)

Understandings of rugby-related violence and degradation as connected to a sense of entitlement amid men in rugby culture is significant, as it implies that these behaviours are not necessarily inherent features of rugby culture. Instead, it suggests that certain individuals within rugby culture, (i.e., those with a sense of entitlement, invincibility, or superiority), may be more likely to display these particular behaviours than others (Benedict, 1998). Nevertheless, as individual attitudes of male sexual entitlement have been linked to the perpetration of sexual violence (Bouffard \& Goodson, 2017; Richardson, Simons, \& Futris, 2017), this finding accentuates the need to challenge and clarify the ways in which a 'privileged' rugby player status and a 'respected' rugby culture membership may encourage attitudes that accept, normalise, or excuse disrespectful and violent behaviour towards women. Closely connected to the 'privileged' status perceived to be associated with involvement in rugby was the notion of a 'pack mentality' within NZRC, which was considered to further promote the use of gender-based violence. The following section builds from this and unpacks the meaning and consequences of a perceived 'pack mentality' within NZRC.

\section{A Perceived Pack Mentality and Code of Silence}

Off-field aggression amongst sportsmen has been linked to the notion of "macho groupthink"- a mode of thinking within cohesive hyper-masculine subcultures where 
the need for acceptance by other group members supersedes correct judgment (Ananiades, 2012; Melnick, 1992). Macho groupthink is claimed to be a precursor of VAW that, in the case of team sporting cultures, results from aggression on the playing field, sexist attitudes, and an inordinate need to prove masculinity and loyalty to teammates (Melnick, 1992). Indeed, team sports tend to "foster strong feelings of exclusivity, camaraderie, and solidarity" (Melnick, 1992: 33). In fact, because group solidarity within team sporting cultures is so strong, Kift (2005: 137) argues that team sport players are "far from individuals: they are inculcated as mere parts of a much greater, bonded whole, into the iconic team."

Problematically, as methods of bonding within sex-segregated groups are found to foster the use of sexual VAW (Curry, 1991; Muir \& Seitz, 2004), individuals within such groups may allow their "group loyalties to override their personal integrity" (Flood \& Dyson, 2007: 38) and engage in coercive or non-consensual sexual practices to increase group cohesion and demonstrate their loyalty to the 'pack' (Flood, 2008). Pertinent to this literature, 11 respondents explicitly described a "mob" or "pack" mentality amid men in NZRC, and positioned rugby-related violence and degradation as connected to the notion of 'macho groupthink':

I think a lot of the disrespect towards the female staff and patrons is due to the fact that these players come in big groups, and it's that mob mentality that encourages them to be inappropriate around women. (Holly, Bar Manager)

When considering why clients were more aggressive on rugby nights, Sarah noted, "It's just that pack mentality. That's essentially what it comes down to." Olivia explained that sexual violence against female patrons was more prevalent on rugby nights, not because men in NZRC are more sexually aggressive, but because sexually aggressive behaviour is often encouraged within groups of men:

You know how I said guy's mess round more in groups? It's things like trying to dance with girls or grab their bums, when they're obviously uncomfortable. That behaviour is definitely way more intense for girls on rugby nights, and I think that comes down to men being in groups because they encourage each other. I don't necessarily think it's a rugby thing. It's more of a group thing. (Olivia, Bar Manager) 
When reflecting upon her contention that levels of workplace sexual violence increased on the nights of a high-profile rugby game or event, Joanna similarly commented that a "group mentality" amid rugby fans encourages the use of VAW:

I think it's the group mentality of a whole bunch of really rowdy rarked up men who wouldn't usually treat women like shit but when they're in a group they will... and there's always one person in that group that thinks it's wrong but wouldn't speak up because there's that whole group mentality and if they spoke out they'd be ostracised or ridiculed. (Joanna, Exotic Dancer)

This view can be linked to Phillips' (1996) contention that heterosexuality is a valued feature of masculinity within rugby culture. When masculinity places extreme emphasis on heterosexuality, homosexuality can become the 'antithesis' of maleness (Plummer, 1999). Consequently, group perpetrated sexual VAW can become a path for men to achieve solidarity, solidify social bonds, prove masculine virility, and protect themselves against homophobic ridicule (Franklin, 2004). In this sense, the rugby-related sexual violence that Joanna experienced may, in part, have functioned as a means for the perpetrators to establish a respected masculine, heterosexual identity (Connell, 1995). Consistent with this view, Jane contends that rugby fans sexually assault women to demonstrate their masculinity and avoid homophobic ridicule from their peers:

These men probably wouldn't be groping me if they were alone, but because they're in a group, if one person does it, everybody does just to prove they're men that like pussy. I remember one night, a group of guys all in their rugby jerseys were trying to touch my vagina, and one of them stood up and said, "Bro, don't do that. Be respectful." Then all of his mates just started laughing at him and calling him a faggot and continued trying to shove their fingers in me. So, yeah, I think that behaviour comes from the need to prove they're straight. (Jane, Exotic Dancer)

In addition to gendered explanations of group violence, social psychologists have identified several group processes involved in violence, including diffusion of responsibility and deindividuation (Franklin, 2004). With regards to antisocial group behaviour, diffusion of responsibility refers to "a reduction in the intrinsic disutility individuals experience from acting antisocially, as more people are involved in the decision-making" (Behnk, Hao, \& Reuben, 2017:1), whilst deindividuation theory 
assumes that factors including immersion in a group and anonymity lead to a loss of individual identity which, in turn, results in a loss of behavioural control (Reicher, Spears, \& Postmes, 1995). Brianna implicitly described these two group processes as being implicated in the Waikato Chiefs incident:

It's that, I want to say anonymity of being in a team, and being in a group, and being in a crowd. You know, if one person does something, then everybody goes "cool we can do that" and it escalates from one man grabbing a bum to the next throwing a drink or something like that. I think, especially with rugby teams being taught 'you're a team, you're one, you work together, you do everything together,' if your teammate is saying 'go on, grab her ass" what are you really going to do in that situation? Once you're part of that, I think it's quite hard to stand up and say "no I respect this woman, I'm not going to do this to her because I respect her," 'cause you will look like an idiot in front of your mates. (Brianna, Bartender)

While Brianna explained that the "anonymity of being in a team" likely encouraged the players involved in this incident to behave in ways that perhaps contradicted their individual values (Franklin, 2004), she nevertheless implies that since men in rugby culture are taught “you're a team, you're one, you work together," women's bodies may also serve materially as sites for male solidarity and group cohesion (Franklin, 2004). Closely connected to perceptions of a 'mob mentality' and 'privileged' status acquired through involvement in rugby culture was the perceived existence of a 'code of silence' within NZRC, whereby the antisocial behaviours of rugby fans and players were believed to be systematically concealed, ignored, or rewarded by the group (Messner, 2002). Echoing Messner's (2002) contention that men in sporting cultures remain complicit with a code of silence to avoid threatening their 'in-group' status, Jane commented that in NZRC, being complicit with a code of silence surrounding the use of VAW rewards individuals, by allowing them to maintain their 'privileged' rugby culture membership:

If you're part of a dominant group and someone in that group slaps a girl's ass or calls her a slut, even if you don't agree with it, you're not going to call them out on it. I mean, you could, but you probably won't be welcome in that group anymore. It seems like that's what happens with rugby, and I see it with some of the men who come to the club on game nights. You can tell they don't really want to be there, but they want to be part of the group 
so they just go along with whatever their mates decide to do. (Jane, Exotic Dancer)

Olivia expressed that men in rugby culture "have each other's backs. Like, if one of them grabs your bum, they'll all protect each other and say it wasn't them." When contemplating the Waikato Chiefs incident, Jessica expressed that because "NeW Zealanders are so protective of their precious fucking rugby," they would rather "throw that poor girl under the bus" than take her accusations seriously. Grace explained that her brother played for a rugby team who would "get up to mischief" at "secret" alcohol-fuelled holidays, and that "a code of silence" within his team worked to conceal certain behaviours:

My brother plays for a team, and I don't know the specific stuff that goes on, but I know that they get up to mischief. They have secret weekends away. They won a tournament that was sponsored by (names a beer brand), and got sent 200 trays of beer so they planned a big weekend away where they would drink it all, and I would hate to think what happened. I've heard about their initiations where they have to scull a certain amount of alcohol and do certain things... It's like the seniors think of the most outrageous things and the younger ones have to go along with it. To this day, I don't know what happened because he's never talked about it. It's almost like a code of silence and they always have each other's backs. If one was caught doing something illegal, or being unfaithful, they'll always have each other's back. (Grace, Bartender)

Grace also commented that because professional sports teams often work vigorously to maintain a reputable image (Welch's, 1997), coaching staff and managers are likely to cover up certain behaviours of New Zealand rugby players to avoid negative publicity:

The people who should be laying out the rules like the coaching staff and managers who oversee, I think they're the ones who try to hush things that do happen because ultimately, they don't want to stand players down. I mean, you can't really say "you cheated on your girlfriend so you can't play" but also, it's bringing bad media to the team. (Grace, Bartender)

Echoing this view, Aimee claims that because rugby is revered in New Zealand, attaining a 'professional rugby player' status is likely to minimise legal and professional consequences for those who perpetrate crimes: 
Whether it's from the rugby management, the police, or whoever, I think there is that level of, you know, these people are national heroes and people don't want to turn around and charge them for whatever reason. (Aimee, Bar Manager)

Holly described a particular incident whereby the manager of a high-profile rugby team asked her to delete security footage of a professional rugby player who "wasn't behaving":

The manager of (names professional rugby team) came in and was asking about my security footage. I asked why and he said one of his players wasn't behaving, and he wanted the footage deleted. I said he didn't have any rights over my footage and if he wanted access to it, he'd have to get a warrant, which means he'd have to make a formal complaint to the police. I knew if his player was in the wrong he couldn't do that. He was scared we were going to watch the footage and sell it to a newspaper. I just laughed in his face and said, "You have no idea what New Zealand rugby players do in here. If we were selling stuff to the newspaper, there wouldn't be any rugby teams left." (Holly, Bar Manager)

Emphasising the significance of a perceived 'code of silence' in which disorderly behaviours are denied, ignored, concealed, or minimized, Holly explained that the denial, concealment, and minimisation of such behaviours works to disguise them under the guise of normality, which renders them invisible and in turn, silences victims (Robinson, 2000):

When people let shit slide or sweep things under the rug, they're making exceptions for these players, which encourages the behaviour and silences the victims. Hundreds of players get away with things constantly because nobody wants to say anything. People are too scared to speak out against rugby because they probably won't be believed. (Holly, Bar Manager)

Indeed, while virtually all of the participants experienced some form of rugby-related violence, many expressed that they would not disclose their experiences because they felt they would not be believed. Monique, for example, argues that women's accounts of sexual assault perpetrated by rugby fans and players are not "taken seriously" or discussed, as such incidents are viewed as a normal part of gendered relationships in which boys are simply being boys (Weiss, 2009): 
There needs to be conversations and people need to know it's not okay to treat women like shit when you're with your mates and enjoying the rugby... Like, how bad does something have to get before it is taken seriously? What will it take to get people to listen? Would they listen to me if I said, "I got raped?" None of it's acceptable, but it has to be something so bad for people with power to actually be like "that's not okay" and for men to recognise it's not okay. It's the whole "boys will be boys" attitude. That attitude comes out during rugby, "we're just being boys." (Monique, Bartender)

This 'boys will be boys' attitude refers to distorted ideas about male sexuality, including that men cannot control their sexual urges and that male sexual aggression is a part of men's biological make up and, therefore, is a socially sanctioned response to arousal (Weiss, 2009). This attitude was reflected by Jessica, who expressed that men are "driven by their penis, and you cannot hold it against them. It's part of who they are, biologically," and Jane, who explained that she would not disclose her experiences of rugby-related violence to authorities because "men can't really help themselves." Elaborating on her decision not to report her experiences of rugbyrelated violence, however, Jane noted, "no one would believe me any way, and I'd be the one treated like a criminal for talking shit about rugby." Indeed, beliefs that disclosures of sexual violence will not be taken seriously are found to inhibit reporting and thus contribute to a cycle of silence (Schwartz \& DeKeseredy, 1997), and it is argued that New Zealand rugby's strong associations with discourses of nationalism and masculinism works to silence concerns and make resistance against rugby difficult (Pringle \& Markula, 2005: 490). Correspondingly, Holly explained that she was afraid to publically disclose her experiences of rugby-related violence, due to the possibility of negative public reactions:

You don't want to be 'the one' to speak out, you know? If you say something to a newspaper or write something online about rugby, it would all turn back on you. I think if I ever said anything to the public, I'd just get shit for it, so I personally would be too afraid to call players out for their behaviour and speak about it publically. But something needs to change because what's happening is shocking. (Holly, Bar Manager)

Aimee commented that upon telling her boyfriend about participating in this research, she was met with the question “what do people have against rugby?' Aimee was not deterred by this, however, noting that men who discredit, undermine, or doubt 
women's concerns about NZRC do not have the same experiences of a young woman who has worked "a rugby crowd" and, therefore, are not likely to be welcoming, sympathetic, or understanding of their concerns:

My boyfriend's a big fan of rugby, and I told him I was gonna talk to you and without knowing what I'd be asked or what I'd say, he's like "oh, what do people have against rugby?" And I was like, I get you're a fan but think about it before you open your mouth because we'll end up arguing. This is my view. This is my experience. You need to respect that and not tell me my perception's wrong because that's not okay. As a man, you literally can't understand what it's like as a woman... The men who say 'oh that's bullshit,' would've never been a female bartender working a rugby crowd. I think this is definitely something that needs to be put out there and I think it's cool that you actually have the balls to do it. (Aimee, Bar Manager)

By proposing that differences in how individuals experience and perceive rugby culture are likely to be a function of gender, Aimee acknowledges gender as being profoundly embedded in interactions with rugby culture in the NTE. Furthermore, her contention that men will not likely resonate with women's concerns about rugby culture perhaps points to the existence of a broader social system of masculine privilege in New Zealand.

\section{Masculinity: The Central Site of Violence?}

Pertinent to the literature that links the greater propensity for hazardous drinking and gender-based violence within sporting populations to hegemonic versions of masculinity (Sønderlund et al., 2013; Wenner \& Jackson 2009), 10 respondents voiced concerns about how approaches to masculinity in rugby culture may influence gender relations in New Zealand. Moreover, five respondents perceived their unfavourable interactions with rugby culture as symptomatic of 'typical Kiwi' approaches to masculinity that promote the degradation of women, heavy alcohol consumption, and aggressive displays as symbolic confirmation of 'manliness' (Pringle, 2004). As outlined in chapter four, an overwhelming majority of the respondents considered NZRC to encapsulate the 'Kiwi bloke' stereotype. Specifically, alcohol consumption, strength, aggression, and the sexual objectification of women were considered features of masculinity specific to NZRC. Jane positioned this masculinity as the underlying cause of rugby-related violence: 
Alcohol goes hand in hand with rugby, but it's that Kiwi bloke masculinity in rugby that encourages alcohol-use in the first place. That's what encourages men to be violent and rude to women. Changing alcohol won't help because alcohol's not the problem. So many customers come in drunk and don't behave the way the rugby guys do. If we change the masculinity thing, I think everything else will follow. (Jane, Exotic Dancer)

While a lack of research produces uncertainty surrounding the extent to which the apparent holy trinity of rugby, beer, and masculinity can be deemed problematic (Gee \& Jackson, 2010), Jessica commented that in the context of rugby culture, “...it's when the drinking and the masculinity come together, that's when it becomes a problem. That's when it becomes toxic." Aimee also voiced concerns regarding the consequences that narrow prescriptions of masculinity in NZRC might impose on both men and women:

In my opinion, if you're a man you're respectful and you treat women the way they deserve to be treated. Being a man isn't about drinking and being tough, but I don't think that's how it's perceived in rugby culture. To play rugby is to be a true Kiwi bloke. As a male, if you don't fit that stereotype of a Kiwi bloke, you change your behaviour so that you do. I've seen guys do that by speaking to the female staff in a disrespectful way. They'll just kick it up a notch to prove they're big and tough, and sometimes they take it too far. For women, it means we are treated like shit, basically. (Aimee, Bar Manager)

Laura, who identified the misogynistic boasting about heterosexual achievements as a path to achieving masculinity in NZRC, voiced concerns that this particular approach to masculinity may encourage sexually aggressive behaviour:

I think a consequence [of approaches to masculinity in NZRC] for women, is that men might try harder to get with them because they want something to report back to their group of boys that they watch the rugby with. It might not go as far as rape, but even just when a girl's saying "I'm not interested, thanks," they keep pushing a bit more... I think the biggest consequence for men is being shunned from their group or team if they're not seen as being as much of a "man" as the rest of them. You know, if they get less chicks or know less about the game... No one wants to be shunned from their group so they may try a little bit harder to get the girls so they aren't seen as lesser than the rest of them, which has obvious repercussions for women. (Laura, Bartender) 
Neve, who suggested that rugby consolidates the archetype of the 'Kiwi bloke,' contends that this version of masculinity is inherently problematic, as it nurtures the conditions for VAW. Moreover, she explained that this particular version of masculinity can be "terribly damaging," as it perpetuates the notion that the masculine ideals of physicality, dominance, and heterosexuality are required male traits, which encourages men to behave in ways that are particularly dangerous for women:

It puts pressure on men to be like that. To be physical, to be dominant, to be heterosexual and sexually successful. So any person that is anything other than a heterosexual, physically aggressive, strong male, they ultimately fail to meet these expectations. Even for women, it puts this idea out there that this is how men should act. So if they've got a man in their life who is embodying those traits of being physically dominant, being physically aggressive, and sleeping with lots of people, they just think "oh that's normal." It normalises these dangerous ideals, which individually, are not that bad. But when you put them together into a person and you combine it with behaviours that are unhealthy, it normalises that. It normalises men who commit domestic abuse, rape, and intimate partner violence. Because this is what men do. This is what our embodiment of masculinity is in New Zealand, and a lot of people don't understand that this is not normal. (Neve, Bartender)

Neve's contention that performances of masculinity in NZRC are culturally embedded to the extent that they have become perceived as 'natural' features of maleness echoes Butler's (1994) description of gender as performativity, in which the replication of certain gendered performances is said to influence societal understandings of those performances as 'natural' and thus mandatory (Morris, 1995). In this sense, Neve's proposition that certain displays of masculinity such as aggression and physical dominance work ideologically to create perceptions that VAW is simply "what men do," suggests that through repetition, men's use of gender-based violence may have come to approximate a social norm. This finding is important, as it suggests that the development of violence prevention strategies that promote alternative approaches to masculinity may help to undermine the social and cultural supports of gender-based violence among men in NZRC. 


\section{Summary:}

By examining how the participants rationalised their interactions with rugby culture, this chapter highlighted four pathways through which involvement in NZRC was deemed to facilitate violence in the NTE. Firstly, despite being overwhelmingly described as a mere contextual feature in the respondent's personal experiences of rugby-related violence, alcohol was considered to exacerbate existing problems within NZRC, and make interactions with rugby culture more difficult. Secondly, the 'highprofile' status of rugby and the 'celebrity treatment' of professional rugby players were considered to enforce a sense of entitlement amid men in rugby culture, which was believed to encourage the use and acceptance of gender-based violence. Thirdly, unfavourable interactions with NZRC were perceived to be connected to a "pack mentality,' whereby men allow their group loyalty to supersede their individual values (Flood \& Dyson, 2008: 38). This pack mentality was considered to encourage a 'dual code of silence' in which the disorderly behaviours of rugby fans and players are ignored, minimised, or concealed, and in which victims of rugby-related violence are consequently silenced. Finally, instances of rugby-related violence were considered to be symptomatic of 'typical Kiwi' approaches to masculinity in NZRC that rest on the degradation of women, alcohol consumption, and aggression (Pringle, 2004). These understandings of rugby-related violence are important, as they accentuate the need for further research to provide a more nuanced understanding of the multiple pathways to disorderly conduct in this specific context. Such research would be useful for the development of strategies that ensure the safety of women when interacting with NZRC in nightlife venues. 


\section{Chapter Six: Impacts of Interactions with Rugby Culture}

This chapter explores how interacting with NZRC impacted upon the respondents' working and wider lives. This chapter begins by outlining how the women's experiences of NZRC encouraged perceptions of women and femininity as 'at risk' in rugby culture, both within and beyond the confines of the NTE. Subsequently, this chapter demonstrates how an underlying fear of rugby-related violence compromised respondents' feelings of workplace safety and encouraged the adoption of 'safekeeping' strategies. Next, this chapter explores how interactions with NZRC resulted in anxiety and emotional distress for some women, before moving on to explore how alcohol and other drugs were used as a mechanism to cope with difficult interactions with NZRC. Finally, this chapter explores how the participants' experiences and perceptions of NZRC resulted in the general disinterest in, and deliberate avoidance of rugby.

\section{Perceptions of Women and Femininity as 'Vulnerable'}

Due to rugby's perceived status as a 'masculinist' culture alongside personal experiences of rugby-related violence, 14 out of 15 participants described women as 'at risk,' 'unsafe,' or 'vulnerable' when interacting with NZRC. For example, Monique commented that for women, involvement in rugby culture is "like an enter at your own risk thing." Elaborating on her perception of rugby culture as "threatening," Monique explained that regardless of whether NZRC poses any real threat to women, it "makes women feel unsafe," as it is a "culture dominated by men." Similarly, Joanna explained that because NZRC encourages misogynistic and violencesupportive attitudes that are characteristic of rape culture, it is not a culture that can be deemed 'safe' for women:

I don't think rugby culture is safe for women at all. It's a high testosterone environment and when you have that, there's high levels of violence, less respect for women, there's more of a rape culture, which comes out hugely in this situation. (Joanna, Exotic Dancer) 
When outlining her perception of masculinity in rugby culture, Brianna noted, "When I think rugby masculinity, I think of a big lad that can down a beer quite quickly." She explained that this prescription of masculinity makes her "worried," and is something she is "quite tentative towards." She explained that the "toxic masculinity" associated with NZRC is "alienating" and "sidelining" for women, as it perpetuates the notion that "you are not a part of our culture, and we are dangerous to you." Brianna further positions femininity as vulnerable in rugby culture, stating that:

It's hard to put into words but I definitely think in that culture, femininity gets both sidelined and targeted. If it's actively trying to become part of that group then it gets sidelined. It seems as if, you know, if the feminine is minding its own business, it gets targeted. (Brianna, Bartender)

Appositely, Neve expressed that "a big part" of working as a bartender on rugby nights is being "aware of the women." Moreover, she expressed that because rugby culture is dominated by men, "there's always a risk" for women who frequent that culture:

Every time a woman frequents that culture there's a risk. There's always a risk. Some people choose to be there, and some people don't. It's like putting yourself in a dark alley at night. You can make the choice to be there, but you do so knowing that there are risks and at any moment, it can go wrong. It's like walking a very slippery slope, and a very narrow ledge and at any moment, you will fall off. Sometimes you're putting yourself in a position where, honestly, when you're surrounded by a group of men, you have very little control. If these men decided they wanted to attack you, there is very little you could do, simply because of the fact that these men outweigh you. So by being involved in this culture, you're basically putting yourself in a position of massive vulnerability. (Neve, Bartender)

Perceptions of women as vulnerable in rugby's 'masculinist' culture of intoxication supports the notion that the relationship between masculinity and gender-based violence has resulted in deeply embedded assumptions that when frequenting 'masculinised' spaces, women are placing themselves at risk of violence (Brooks, 2011; De Crispigny, 2011). Problematically, this view can perpetuate the notion that women are individually responsible for preventing and avoiding violence (Brooks, 2011), and positions femininity as synonymous with vulnerability and masculinity as synonymous with aggression (Campbell, 2005: 134). In this sense, perceptions of 
rugby's 'male-dominated' culture as unsafe for women may reify essentialist models of gender that depict men as oppressors and women as victims, which, according to Campbell (2005), could inadvertently foster the conditions for VAW.

Challenging gendered configurations that construct 'masculinity-as-aggressive' and 'femininity-as-vulnerable' (Campbell, 2005), however, many of the women in this research believed that aspects of NZRC were unsafe for both men and women. For example, Brianna expressed that the 'toxic masculinity' associated with rugby culture "is quite dangerous for the men who are in it as well," whilst Katherine explained that "there's a degree of toxic masculinity involved in rugby culture, and I think that's dangerous for men and women." Neve explained that since men are routinely victims of male-perpetrated violence, going to watch a rugby game can be a significant "danger" for men, whilst Jane commented that those most vulnerable to aggression, degradation, and ridicule in NZRC were in fact men:

A lot of the guys who come to the strip-club to watch rugby, you can tell they don't really want to be here but they come because when you're a Kiwi bloke who likes rugby, you're meant to like tits, you know? Obviously, that can be dangerous for women, but I think it's actually worse for men. Like, if you came out as gay or talked about your emotions, you'd just get the piss taken out of you and I've seen that happen. So yeah, I think involvement in rugby culture is a risk for men who aren't your typical Kiwi blokes and because men are more involved in rugby, that's quite worrying. (Jane, Exotic Dancer)

This finding supports contentions that the widespread acceptance of the 'Kiwi bloke' stereotype can have significant costs for men who do not conform to this prescription of masculinity (Phillips, 1987, 1996), and emphasises the extent to which approaches to masculinity in NZRC may be harmful to both inter-gender and intra-gender relations in New Zealand. Although potential problems associated with NZRC were not considered to exclusively impact women, the gendered risks believed to be involved in interacting with rugby culture worked to construct an underlying fear of rugby-related aggression amid participants. The following section extends on these issues, and explores the respondents' personal accounts of safety with regards to their interactions with NZRC. 


\section{Personal Accounts of Safety}

While the presence of women in alcohol-focused leisure venues is now recognised and accepted as a common phenomenon, Chatterton and Hollands (2003: 148) contend "mainstream forms of nightlife remain highly masculinised in terms of male domination of space and the policing of compulsory heterosexuality." Furthermore, these authors contend that women's experiences in the NTE are organised by men's assumptions about their sexual availability, and by a vulnerability to attack and harassment. Although young women have been positioned as 'at risk' of violence when frequenting leisure venues in the NTE (Brooks, 2011), virtually no empirical studies have considered perceptions of safety amongst women who work in the NTE. Contributing to this literature gap, this research found that 12 of the 15 respondents expressed feeling unsafe, hyper-vigilant, or fearful of male predation when working in the NTE. Significantly, these feelings were either limited to, or exacerbated by, interactions with NZRC.

Contrasting with Grace, who explained that she did not "feel any less safe" working on game nights, Monique explained that "it's definitely more intimidating" working on rugby nights. Monique also expressed that unsolicited sexual comments made by customers on rugby nights elicited fear, due to the possibility that they could lead to other harassing behaviours: "Mainly, they just say gross stuff to you. It's just that fear of how far it's going to go. In those situations, you definitely don't feel safe." Due to feeling "unsafe" at work on rugby nights, Monique explained that she would often ask to "be put on dispense," to minimise interactions with customers:

If there's a game on, I'll ask to be put on dispense, which is a little bar in the restaurant that just makes drinks and doesn't actually serve customers. Once again, I just don't put myself in compromising situations. If it's with the guy who works on the bar with me, I'll sometimes be all good, but it depends how confident I feel... But a lot of the times I felt unsafe to the point where I didn't want to work in the bar and asked to be on dispense instead. (Monique, Bartender)

Monique's experiences of rugby-related sexual harassment also resulted in a generalised fear of male predation that hindered her from socialising with friends, and impacted on how she navigated her day-to-day life: 
I stopped going to parties because I didn't want to meet guys I didn't know. It definitely impacted my social life because I didn't want to be around drunk guys ever. I didn't want to walk through town at night. I didn't want to walk by myself from work. Even just every day in my life, I was just scared of men. I mean like, I had suffered from anxiety, but these experiences are definitely what tipped me over. (Monique, Bartender)

Monique's fear of, and struggle to socialise with men due to her experiences of rugbyrelated sexual harassment supports the findings of previous research, which reveals that experiences of sexual violence can hinder an individual's ability to manage interpersonal relationships and result in intense feelings of fear post-victimisation (Calhoun, Mouilso, \& Edwards, 2012; Jordan, Campbell, \& Follingstad, 2010). Like Monique, Jessica expressed that rugby disrupted her feelings of workplace safety. For example, she noted, "there's definitely an extra layer of caution" on rugby nights, and that "you have to be extremely carefur" leaving the club to go home since "all the rugby drunkards are still out on the streets." Moreover, she stated that she would never do an outstrip ${ }^{28}$ for a rugby team because "rugby players are just too dangerous." Holly similarly described rugby culture as "dangerous" and noted that her boyfriend "worries a lot" about her safety when she has to work on game nights. Nevertheless, Holly explained that her workplace had a "really good security team," which made her feel "relatively safe." By contrast, Jessica expressed that she could not solely depend on the bouncers for protection, since "some were pretty lazy, like, if you think of a sleeping gorilla, that's what you had." Correspondingly, Joanna explained that her feelings of safety decreased on rugby nights, and that having bouncers did not prevent her or her co-workers from experiencing rugby-related violence:

You do feel quite a bit more unsafe on a game night because there's a greater level of intoxication and there are more people in the club compared to the one or two bouncers that you have. So, the girls look out for each other a lot more on these nights. I remember having to pull a guy off one of the girls and being like "what the hell are you doing, where the hell is the bouncer?" I think it's definitely much less safe and people are also just more unpredictable. There's also that treating women like pieces of meat going on. I never felt completely unsafe but I definitely felt less safe on game nights. (Joanna, Exotic Dancer)

\footnotetext{
28 This term refers to strip-tease performances that occur outside the strip-club environment.
} 
Although some respondents did not explicitly describe feeling 'unsafe' at work on rugby nights, they nevertheless described their workplace interactions with NZRC as 'unnerving' or 'uncomfortable.' Moreover, many of the participants explained that they were more vigilant towards the possibility of male predation on rugby nights, which further signifies an undercurrent of fear. For example, despite commenting that her workplace was generally "a pretty safe place," Laura described being "more wary" of customers on rugby nights:

In general, our bar is a pretty safe place, but on game nights, I wouldn't say I feel unsafe, but I definitely can feel more uncomfortable. For example, if I'm going to clear glasses off of a table and they're all standing around, I try to keep quiet and I don't converse as much because I'm not sure how they'd react or anything. I just sort of pile the glasses up and walk back to the bar as quickly as possible. I just become more wary of the customers. (Laura, Bartender)

Despite commenting that she did not "consciously" experience fear when working on rugby nights, Brianna expressed an internalised fear of aggression when interacting with rugby culture. For example, she explained that she was more vigilant on rugby nights, would try to minimise interactions with customers, and was concerned about appearing "volatile" towards them:

When I was working rugby nights, I had my guard up more. There was always a feeling of being watched when I was in the bar. It was very open, and they had a pool table and a TV screen at the other end, and you'd be carrying glasses and you'd turn to put them down and notice them all looking at you. When you turned and looked, their eyes would go back to the screen, so that was kind of unnerving I guess... I don't really remember trying to have a conversation that much with customers on rugby nights. It was very much just get them in, get their food, get them a drink, they watch the game, and make them go. You try not to prolong it I guess. That was always kind of, keep your head down, don't say anything that could be volatile to them. (Brianna, Bartender)

Pertinently, research has found that women adopt a range of 'safe-keeping' strategies in response to both explicit and internalised fears of experiencing violence in public spaces (Brookes, 2011; De Crispigny, 2001). Aligning with this research, four of the women in this study described using 'safekeeping' strategies to navigate the perceived risks of experiencing rugby-related violence. For example, Jane explained that she 
would try to remain close to the bouncers on rugby nights, to navigate the risk of experiencing violence:

On game nights, there were so many people in the club, and the bouncers couldn't keep an eye on us, so guys could get away with more stuff. We had a bouncer that floated around the club, and people weren't usually as grabby and disgusting when he was close by, so I'd make sure he was always in my sight so I could grab him if I needed to, and I usually did at some point in the night. After work, my friend would always come inside the club and pick me up, because if I walked to his car alone I'd usually get some idiot doing something gross or saying something inappropriate to me, which is terrifying. (Jane, Exotic Dancer)

When contemplating the extent to which she felt safe at work, Rose (Full-service sex worker) commented that she generally felt "pretty safe," and explained that being "a bigger girl compared to others" and having "an intercom that you press and you can call for help" allowed her to feel physically safe and in control during her interactions with clients. On rugby nights, however, she explained that there were more likely to be group bookings, which made her "feel a bit more unsafe." Rose's 'safekeeping' strategy during these nights was to "stay close to the intercom." Interestingly, Brianna explained that she would pretend to be interested in rugby to help her "blend in." Moreover, she expressed that when interacting with customers on rugby nights, she would "take on a bit of butchness," since she felt that femininity was 'at risk' in rugby culture:

Something that I used to do, and still tend to still do now, is kind of take on a bit of butchness in those masculine situations. I have quite a good knowledge of beer. As silly as that sounds, that actually makes quite a big difference when they, they being men coming into watch the rugby game, come up and say "oh what beers have you got on tap" and you list them and give them a couple of details about each one in quite a fluent way, it would either attract them or it would completely repel them... Also, taking an interest in the game... I'm not a rugby person, but you could look up and go "oh yay" with the crowd, and it almost makes you one if them in a sense. It kind of makes you blend in a little bit more. I think, probably again not consciously, I figured out that it made you less of an outlier in that kind of "we can pick on you" sense. (Brianna, Bartender) 
Emphasising the extent to which her behaviour was controlled by the continual negotiation of risk (Brooks, 2008), Brianna explained that when walking home after working the night of a rugby game, she carefully calculated which route was likely to be the safest:

When I'm walking down the street after I've finished work and there are a few rugby fans singing and dancing, I'm thinking, "okay - how well are the streets lit? How many other people are around me right now? Actually, I was going to take this way home, but now I'm going to go this way because it's safer"... There was always a bit of a dilemma getting home. I could either go what I call "the back way," which was near the police station, but it wasn't very well lit... Or you could go a different way, which was more brightly lit but had a tendency to be busier, which for me was always a bad thing. I realise that's a bit of a contradiction, but having people around when they've had alcohol and they're fumbling to their hotel or whatever, they'd often get rowdy and shout stuff towards you. (Brianna, Bartender)

While rape culture is most discernible through the acts of sexual violence that can be visually examined, the effects of rape culture are often invisible, taking the form of women's internalised fears of men's sexual aggression (Sheets, 2017). For example, rape culture can be seen through the accepted social convention that a woman should not walk by herself at night due to the possibility of being sexually attacked (Sheets, 2017). As the adoption of safekeeping strategies on rugby nights appears to be influenced by internalised fears of aggression, this finding alludes to a broader cultural atmosphere surrounding rugby that may be conducive to rape culture (Kavanaugh, 2013). Problematically, both fears and experiences of sexual aggression and objectification are found to have a range of psychological consequences for women (Watson, Marszalek, Dispenza, \& Davids, 2015). The following section extends on this and explores the psychological impacts associated with the respondents' interactions with NZRC.

\section{Psychological Impacts}

While experiences of violence are associated with a variety of adverse mental health outcomes for women (Jordan et al., 2010), anxiety has been identified as one of the most common mental health outcomes of gender-based violence, and is particularly prevalent for women who have experienced sexual violence (Jordan et al., 2010). In fact, research has found that between 73 to 82-percent of sexual violence victims 
develop anxiety post-victimisation (Campbell, Dworkin \& Cabral, 2009; Basile \& Smith, 2011). Aligning with this literature, five of the women in this research disclosed experiencing some level of anxiety or emotional distress due to their experiences of rugby-related sexual violence. For example, Monique expressed that her existing anxiety was elevated after a customer groped her when she was working the night of a rugby game. As a direct result of this incident, she explained that she feared working, especially on game nights. Demonstrative of the profound impacts that anxiety can have, Monique further explained that her anxiety eventually caused her to stop working:

After already having quite bad anxiety at that time in my life, I just couldn't handle it. I would cry before going to work sometimes because I would be so scared. It was definitely worse when game nights were on because there were so many men and so many drunk people and I actually had to stop working in hospitality for a while because I had such bad anxiety over coming into work and interacting with drunk guys. (Monique, Bartender)

Jane similarly explained that she "took a break" from working to manage the anxiety and panic attacks that she had developed as a result of the routine sexual assault she experienced on rugby nights:

Working in a strip-club, I knew there'd be guys who try to push it too far, but it actually wasn't too bad, except for game nights. On those nights, we were constantly saying "fuck off, you can't touch me there." I actually took a break from working for a while, because I started getting bad anxiety. I would actually have panic attacks before going to work because I was so scared and just emotionally exhausted from having to deal with the constant abuse. (Jane, Exotic Dancer)

Holly expressed that "when a game's on, there is so much stress on the staff and the security. You just know it's going to be a shit night. I fucking hate it." Furthermore, she explained that her routine experiences of emotional abuse by professional rugby players had resulted in anxiety:

I get anxiety when games are on or when I know the players are going to come. I get anxious knowing that I'm going to be emotionally abused most of the night. As I said, I've had close to physical altercations with professional players four times my size, and that gives me anxiety. It's the anxiety of knowing that it's going to happen again and there's nothing I can 
do about it. When I know the players are coming out, my anxiety starts. The second they walk in the door, that anxiety elevates... I don't want to put my staff in a situation where they have to deal with it, so I'm the one dealing with it. I never want to, and it's exhausting, but because most of the staff are younger, it's not fair to put them in that position. (Holly, Bar Manager)

This finding is consistent with previous research, which has found dealing with aggressive and disorderly customers can result in anger, stress, emotional exhaustion, anxiety, and reduced job satisfaction for hospitality employees (Willness, Steel, \& Lee, 2007; Yagil, 2008). Despite experiencing anxiety during her workplace interactions with rugby culture, Holly explained that because her bosses considered the professional rugby players to be "good for business," she felt that to some extent, she was expected to tolerate their abusive behaviours:

If I stop letting them in, we lose business and my bosses wouldn't be happy. They love that they come in because they're good for business. They love that the fans come in when the players are in and that they bring us extra money, but they don't really understand the impacts it has on us. (Holly, Bar Manager)

Correspondingly, while both Sarah and Joanna commented that they "hated" interacting with rugby culture in the context of their work, they expressed that working on game nights was financially beneficial. For example, Sarah explained that, "if you can put up with the bullshit on rugby nights, it's good money," whilst Joanna stated that "none of the dancers liked working rugby games but you made a shit ton of money so you just did it." Here, it is crucial to note that while sexual violence can be traumatic and have profound psychological consequences for some victims, others may not be emotionally or psychologically affected by their experience (Basile \& Smith, 2011). Indeed, while an overwhelming majority of the respondents experienced some form of rugby-related violence, 10 out of the 15 participants did not experience adverse mental health outcomes associated with their interactions with NZRC. Yet, the number of participants that experienced psychological distress due to their interactions with NZRC is not important. That any of the respondents described experiencing anxiety or emotional distress due to their interactions with NZRC is important, as it demonstrates that the impacts of NZRC on women's psychological and emotional wellbeing can be significant. To further demonstrate the impacts of 
NZRC on the wellbeing of women, the following section explores alcohol consumption as a method to cope with unfavourable interactions with NZRC.

\section{Substance Use}

Four of the women in this research described using alcohol as a mechanism to tolerate intoxicated customers on rugby nights, cope with difficult interactions with rugby culture, and avoid negative emotions associated with these interactions. Jessica stated that when working during the 2011 RWC, she "became a massive alcoholic. Anything I could get my hands on drug wise I would." When contemplating the factors influencing her substance use, Jessica explained that alcohol consumption "made it easier to socialise with drunk people" and allowed her to cope with experiences of rugby-related violence:

The men definitely drunk a lot more on rugby nights ... When a guy's drunk and he's horny, he's not going to sit there and think "hmm, I shouldn't do that right now, I shouldn't touch her vagina." So there's that factor. And trying to have a conversation with drunk guys is like pulling teeth. That's why I would drink. It made it easier for me to socialise with drunk people. (Jessica, Exotic Dancer)

Although alcohol consumption served as a mechanism through which Jessica could cope with intoxicated customers and workplace sexual harassment on game nights, she noted that her substance-use also served as a method of coping with traumatic experiences that were not connected to rugby. Nonetheless, Jessica was not the only participant to disclose using alcohol to cope with difficult interactions with NZRC. For example, Rose (Full-Service Sex Worker) explained that she was "usually drinking" when working on rugby nights, so that she could "put up with more bullshit more easily," whilst Jane noted:

The only way I could get through a game night and put up with men constantly trying to touch my vagina was if I was as drunk as them. So, I was always drunk. (Jane, Exotic Dancer)

While substance use is a common form of avoidance coping among sexual violence victims, this coping method is found to be associated with long-term alcohol abuse problems, have adverse impacts on the overall physical and mental health of users, 
and has been identified as a risk factor for further victimisation (Ruback, Clark, \& Warner, 2014; Ullman et al., 2013). In this sense, the use of alcohol as a method of coping with interactions with NZRC raises important questions regarding the safety and overall wellbeing of women who interact with rugby culture in the NTE.

Contrasting with respondents who used alcohol to 'cope' with interactions with rugby culture, Joanna commented that when working non-rugby nights, she would "drink all the time" and was "constantly drunk." Yet, on the night of a rugby game, she explained that she would intentionally drink less, to navigate the perceived risk of violence:

I wouldn't get as drunk. I think just because I wanted to hide on rugby nights and in order to get drunk, you had to be at the bar and be visible... Also, if I get drunk I don't have as much control over what's going on and on a night like that, you need to have your wits about you. If I'm drunk and stumbling around and people are grabbing me, I'm not going to be able to do much about it. (Joanna, Exotic Dancer)

As mentioned, internalised fears of aggression are often symptomatic of rape culture, in which the trivialisation and normalisation of sexual violence have become institutionalised (Buchwald, Fletcher, \& Roth, 1993). As Joanna's avoidance of alcohol on rugby nights appears to be influenced by an internalised fear of experiencing sexual aggression, this finding further signifies a broader cultural atmosphere surrounding rugby that may be conducive to rape culture. Significantly, internalised fears of rugby-related aggression encouraged the deliberate avoidance of rugby culture for an overwhelming number of the respondents. The following section extends on this finding and explores the lengths to which the respondents went to avoid NZRC, both in their working and wider lives.

\section{Avoidance of Rugby}

Challenging dominant discourses that position rugby as a 'unifying' component of New Zealand's cultural identity that works to connect people of diverse social standings (Pringle, 2004), nine of the women in this research expressed disinterest in being involved in rugby. Significantly, eight out of the nine respondents who expressed disinterest in rugby took deliberate measures to avoid NZRC, both within and beyond the NTE. For example, Olivia explained that she would "never" go to 
watch a professional rugby game because "the fact that it's all men is really quite offputting." Brianna similarly explained that she would not want to be involved in rugby culture, because she felt that it was not a safe environment for women:

I wouldn't attempt to integrate into the culture at all. For one, I'm not interested in it. Even as a social experiment, I wouldn't want to be in that culture. I wouldn't want to hear the things that I'm sure get thrown about as jokes. I think physically, it's not a good space for women to be in. I don't think it's very safe. (Brianna, Bartender)

Jane described engaging in numerous behaviours to avoid rugby culture, both within and beyond the context of her work:

If a game's on and I'm not working, I don't go to bars. When I worked rugby nights, at least I was making money. Choosing to go to a bar on a rugby night would be like going to work as a stripper and not getting paid, because these guys are going to objectify and grope you anyway. I'd often call in sick to work on rugby nights because I just couldn't face another weekend of being treated like a piece of meat. It got to the stage where even just seeing the rugby on $T V$ would make me so angry and feel like throwing up, so I'd hide the remote or TV cord so my flat mates couldn't watch it. There's no way I'd ever choose to play rugby or be involved in that world. (Jane, Exotic Dancer)

Echoing this view, Jessica expressed that she would "never go to a bar on a rugby night" as she believed that rugby culture "is such an unsafe environment" for women. Sarah similarly explained that due to her workplace experiences of rugby-related violence, she avoids watching rugby, going to the city on rugby nights, and engaging in relationships with individuals who enjoy rugby:

I avoid rugby at all costs. I wouldn't have a relationship with anyone who was into rugby. I would never watch or go to a game, or go into town when a game is on. If some guy asked me out to watch the rugby I'd say, "nah, I'm not going," because why would you want to? ... If you go out after a game and walk around, you see the packs of them throwing up, and then going into strip-clubs, and you just know what's going to happen. (Sarah, Full-Service Sex Worker)

Holly explained that due to the abuse she had endured at the hands of rugby fans and players, she no longer watches rugby, would never go to watch a professional rugby 
game, refuses to drink at bars where professional rugby players are likely to be, and, like Sarah, tries to avoid rugby culture "at all costs:"

I don't watch rugby now. I wouldn't go to a game. I avoid it at all costs. I hate seeing players outside of work. If I see them on the street, I get scared they'll recognise me and I'll be abused again, so I cross the street. If I see them when I'm out I just avoid them as much as I can. If I'm out drinking, I don't drink at my bar. I go to another bar where they're less likely to be. (Holly, Bar Manager)

Joanna similarly explained that due to her experiences of rugby culture, she no longer enjoys rugby and intentionally tries to avoid it:

I come from a family of massive rugby fans who put these players on pedestals. Now, after working these nights and interacting with these players and fans, I just think "ew"... It's changed my perception of rugby itself, and also, now I would never go to town on a rugby night. It really puts you off. I find it repulsing, just the attitudes they seem to have towards women especially, that we're nothing but pieces of meat, make me want to avoid rugby as much as I can, as I know how women get treated on those nights. (Joanna, Exotic Dancer)

Three women explained that they quit their jobs or changed the times in which they worked in order to avoid rugby culture entirely. For example, Jane commented: "I just couldn't put up with the harassment you get on rugby nights anymore so I eventually just stopped showing up for work," whilst Sarah explained that she "stopped working at night" altogether, because she was "not prepared to put up with the abuse you get on rugby nights." Neve explained that she decided to stop working in alcohol-focused venues, as she opposed some of the attitudes she was exposed to when interacting with NZRC within this context:

I stopped working in bars. I suppose that's a follow through consequence, because I didn't like that lifestyle, but also a lot of it has to do with rugby games and the kind of people you spend time around during those moments, and the kind of energies and attitudes that you're surrounded by. I think after a while I just got sick of being a part of that world and having to stand by and experience certain attitudes without being able to say, "that's not okay." (Neve, Bartender) 
Contrasting with the respondents who actively tried to avoid rugby culture, Rose explained that while she usually preferred to work privately, she chose to work at a brothel on rugby nights "because that's when I know a lot of guys will be going in so a lot of money will be made." Despite maximising interactions with rugby culture within the context of her work for financial gain, Rose attempted to minimise interactions with rugby culture in other contexts. For example, she explained that she had previously lived with three men who would invite their male friends over to watch the rugby. Rose noted that because these men would make "sexist" comments towards her, she now deliberately chooses to associate with people who "aren't that closely connected to rugby:"

The rugby nights that I had at my old flat where all the boys would be over sort of reinforced the idea that I don't want to be around those types of people anymore... Now I hang around with people who aren't really into rugby. I have a lot of guy friends who like rugby, but they aren't die-hard fans. (Rose, Full-Service Sex Worker)

That some respondents attempted to avoid NZRC is particularly significant, as it demonstrates how the sexism and violence that were considered to be associated with rugby culture in the context of the NTE can reinforce perceptions of rugby environments as 'unsafe' for women, and discourage the participation of women in rugby culture. Problematically, the absence of women as spectators, supporters, and players of rugby reinforces the masculine nature of the sport, which is likely to further embed perceptions of rugby culture as an exclusively male preserve that is 'unsafe' for women. Moreover, as the exclusion of women from sports is believed to contribute to men's sustained authority over women and promote the use of violence against them (Crosset, 1990), this finding highlights the importance of encouraging women's involvement in NZRC, and suggests that changes are needed to ensure that all rugby environments are deemed safe and inclusive environment for women.

\section{Summary}

This chapter outlined the consequences associated with the respondent's experiences of NZRC. Alongside personal experiences of rugby-related violence, rugby's perceived status as a masculinist culture encouraged perceptions of women and femininity as vulnerable in rugby culture. When working on rugby nights, 13 
respondents described feeling uncomfortable, unsafe, or hyper-vigilant, and four of these respondents described using safekeeping strategies to navigate the perceived risks of rugby-related violence. For nine respondents, experiences of rugby-related violence and degradation were associated with adverse mental health outcomes or substance use. The use of alcohol and other drugs appeared to serve as a mechanism to cope with difficult interactions with intoxicated and abusive customers on rugby nights. For eight of the women in this research, workplace interactions with NZRC resulted in the deliberate avoidance of rugby, both within and beyond the confines of the NTE. These findings are important, as they provide a novel understanding of, and reify concerns about, the impacts of NZRC on women and gender relations. Furthermore, these findings signify the urgent need to prioritise ways of addressing the supports for gender-based violence that appear to be associated with NZRC in the NTE. 


\section{Chapter Seven: Conclusion}

I think it'll be good when this research is out there and it's not just one person saying this. If there's a bunch of women saying the same thing and experiencing the same stuff, I think our concerns about rugby will be taken more seriously. (Sarah, Full-Service Sex Worker)

While previous research exploring the socio-cultural impacts of rugby raised important questions regarding rugby's impact on women and gender-relations in New Zealand, no specific research on women's experiences and perceptions of NZRC beyond the grassroots level has been conducted. This exploratory study is therefore novel, and emerges at a time where a string of high-profile cases of professional rugby player misconduct have heightened concerns about NZRC's impact on gender relations and masculine identities. Within this context, this study examined how women working in the NTE perceive, experience, and navigate NZRC. In doing so, it aimed to facilitate a novel understanding of how interacting with rugby culture in the NTE impacts the lives of women. While the findings of this research cannot speak for all women, this thesis highlighted a myriad of issues regarding the safety and welfare of women when interacting with NZRC in the NTE. Moreover, it identified numerous pathways through which involvement in rugby culture may facilitate violence in the NTE. To demonstrate the significance of this research in the context of contemporary New Zealand society, this final chapter discusses the key issues identified in the research findings, addresses the implications of these findings, and outlines key areas for future research.

\section{Rugby-related Violence: Considering the Extent of the Issue}

While the women in this research acknowledged rugby's potential as a beneficial force within society, they paradoxically perceived rugby as a male-dominated culture characterised by excessive alcohol consumption, misogynistic attitudes, the exclusion and sexualisation of women, and violence. Importantly, aggression, alcohol-use and the alleged sexual objectification of women by men in NZRC were conceptualised as 'laddish' behaviours connected to a hegemonic version of masculinity within rugby culture. This finding is significant, as it supports previous contentions that rugby 
glorifies a 'Kiwi bloke' version of masculinity, which rests on the degradation and rejection of women, physicality and strength, the acceptance of violence, and alcohol consumption (Phillips, 1996; Pringle, 2004). Moreover, this finding provides an initial insight into how, from the perspective of the respondents, NZRC is enacted in gendered environments where alcohol is consumed. Supporting the notion that the narrow depiction of maleness perpetuated by the 'Kiwi bloke' stereotype may be harmful to women (Phillips, 1996), interviews revealed concerning insights into how approaches to masculinity in NZRC manifest in attitudes and behaviours towards women. Of overriding concern was that virtually all participants recalled experiencing physical, sexual, or verbal abuse at the hands of individuals believed to be connected to NZRC.

These findings have a number of important implications. Firstly, that virtually all respondents experienced some form of rugby-related violence suggests that in gendered settings where alcohol is consumed, NZRC may work to create an unsafe environment for women - one that perpetuates gender-based violence and unequal power relations between women and men. Secondly, collective understandings of alcohol consumption, the exclusion and sexualisation of women, and violence as features of a hegemonic version of masculinity specific to NZRC suggests that alternative approaches to masculinity in this culture may need to be encouraged. Given that alcohol consumption and the rejection and degradation of women are regularly cited in academic literature as performances of masculinity that are linked to the perpetration of gender-based violence (Connell, 2002), encouraging alternative approaches to masculinity in NZRC may be crucial to ensure the safety of women when interacting with this culture in the NTE.

While the extent to which the respondents considered their experiences of rugbyrelated violence to be problematic varied, this violence was positioned as a 'normal' and expected part of interacting with NZRC. This finding raises important questions regarding the nature and extent of rugby-related violence, as for a phenomenon to be widely accepted as either normal or inevitable, it must be frequent, pervasive, and widespread enough to approximate a social norm (Smolak \& Munen, 2011). Nevertheless, the results of this research cannot be generalised to represent the perspectives of all women, nor can they be interpreted as concrete truths about rugby. 
Furthermore, it is possible that the women who participated in this research may have done so, due to having had unfavourable interactions with rugby culture. As such, the findings of this research should not be interpreted to represent the levels or pervasiveness of rugby-related violence in the NTE. Without an understanding of the nature and extent of this violence, however, determining how best to prevent, manage, and respond to incidents of rugby-related violence when they do arise is difficult. This thesis thereby serves as an urgent call for further research to determine the nature and extent of rugby-related violence.

\section{Possible Pathways to Violence and their Significance}

By exploring how the women in this research rationalised their experiences and perceptions of NZRC, this thesis highlighted four pathways through which involvement in NZRC was considered to encourage violence. These were: alcohol consumption, attitudes of sexual entitlement, a perceived pack mentality, and 'Kiwi bloke' approaches to masculinity. The identification of these pathways is significant, as it broadens and challenges existing knowledge about perceived problems relating to NZRC. This knowledge is likely to be useful for the design, development, and enhancement of strategies to ensure the safety of women when interacting with NZRC. Here, it is vital to reiterate that while the respondents identified misogynistic attitudes and behaviours conducive to violence in rugby culture, such attitudes and behaviours rarely occur in a vacuum and, therefore, are likely reflective of the sexist and misogynistic ideologies already embedded within the wider socio-cultural setting (Cossins, 1998; Gregory \& Lees, 1999). However, rugby undeniably holds an elevated societal position - one that affords it with the power to influence the social climate of, and gender-relations within, New Zealand (Pringle, 2004). As such, this section draws upon the knowledge produced by the respondents as outlined in chapter five, to demonstrate how the power and influence accompanying rugby's privileged societal position could be used to enhance the safety of women in rugby environments and facilitate broader societal change.

Currently, discussions about problems associated with rugby tend to focus on the 'problematic' use of alcohol. For example, while the RRR recommends numerous approaches to deal with issues associated with NZRC, it states that "alcohol 
consumption is often the harbinger of bad behaviour," and places emphasis on the importance of strategies to "separate rugby performance from alcohol" (Cockburn \& Atkinson, 2017b: 106). Although the women in this research believed alcohol-use exacerbated existing problems within NZRC, alcohol-use was described as a mere contextual feature in their unfavourable interactions with rugby culture, rather than the 'harbinger' of bad behaviour. This finding is important, as it challenges the notion that breaking the seemingly inexorable link between alcohol and rugby will effectively mitigate the potential problems associated with rugby culture in the NTE, including violence. Nevertheless, as the impact of alcohol on the respondents' interactions with NZRC was predominantly negative, participants tended to conflate a reduction in alcohol consumption with a reduction in the disorderly and violent behaviours of rugby fans and players.

Although alcohol-use is a risk factor for the perpetration of violence (Sønderlund et al., 2013), alcohol-focused solutions do not elucidate the social and cultural nuances underpinning such behaviour (Ayres \& Treadwell, 2011). Such solutions also fail to acknowledge the seemingly inseparable connection between alcohol and masculinity, which in the context of sport, has been repeatedly linked to gender-based violence (Sønderlund et al., 2013). This failure is particularly noteworthy, as the participants conceptualised excessive alcohol consumption, the sexual objectification of women, and their personal experiences of rugby-related violence as symptoms of a 'Kiwi bloke' version of masculinity in NZRC. This finding is important, as it suggests that mitigating these issues may require a critical evaluation of the various pathways to rugby-related violence, including the potential mechanisms through which certain approaches to masculinity within NZRC nurture the conditions for both gender-based violence and alcohol consumption. This evaluation would likely be useful for the design and implementation of violence prevention strategies that explicitly address the norms, behaviours, and relations associated with ideals of manhood in NZRC that are conducive to violence. While seemingly absent from the recommendations of the RRR, strategies that address potentially problematic aspects of masculinity are found to be more effective at reducing gender-based violence than those that remain blind to the powerful influences of gender norms and systems of inequality (see Jewkes et al., 2015). For this reason, the importance of understanding how certain approaches to masculinity in NZRC may work to perpetuate, excuse, or normalise gender-based 
violence should not be overlooked.

Involvement in NZRC was also believed to enforce a sense of male sexual entitlement that encourages the use and acceptance of gender-based violence. This view supports the findings of the RRR, which posits that a sense of entitlement amid elite players can result in "disrespectful and irresponsible attitudes and behaviours" (Cockburn \& Atkinson, 2017b: 93). In light of research that finds attitudes of entitlement amid sportsmen are linked to the perpetration of sexual violence (Whannel, 2001), the RRR calls for the development of strategies that challenge attitudes of entitlement amid elite players. However, as the women in this research considered all forms of involvement in NZRC to encourage attitudes of entitlement, interventions that simply target the attitudes of individual players may not be the most effective means of mitigating the attitudes of entitlement that are believed to permeate throughout the wider rugby culture. Instead, such strategies may need to target individuals associated with all roles (i.e., coaches, managers, players, and supporters) within the sport. Nevertheless, as empirical research has not yet examined the attitudes of entitlement that are allegedly linked to NZRC, further research is needed to ensure that any strategies developed to challenge such attitudes are both evidence-based and effective. Future research should thereby aim to consider the extent to which involvement in NZRC instills a sense of entitlement in men, as well as the mechanisms through which a 'privileged' rugby player status and a 'respected' rugby culture membership may perpetuate misogynistic and sexist attitudes that promote the use of gender-based violence.

Finally, experiences of rugby-related violence were perceived to be linked to a 'pack mentality' in which men allow their loyalty to supersede their individual values (Flood \& Dyson, 2008: 38), and in which the degradation of women functions to increase group cohesion and demonstrate loyalty to the 'pack.' This perceived 'pack mentality' was believed to encourage a 'dual code of silence' in which rugbyaffiliated individuals systematically conceal, ignore, and minimise the disorderly behaviours of rugby fans and players, and in which victims of rugby-related violence are thus systematically silenced. If men in NZRC are complicit to a 'code of silence' surrounding the disorderly behaviours of those involved in rugby, and if women's concerns about problems associated with rugby remain unspoken, it is unlikely that 
these problems will be acknowledged or discussed. A cloak of silence surrounding issues associated with rugby is concerning, as silence may be erroneously interpreted as the absence of a problem, which reduces the potential for interventions and change. This thesis therefore emphasises the need for the implementation of structures and processes that ensure individuals who experience rugby-related violence can speak out about their experiences without fear of persecution or disbelief. Moreover, it suggests that potential efforts to prevent rugby-related violence may need to focus on moving the "silent majority" (Messner, 2002: 30) of rugby-affiliated individuals away from being quietly complicit with the cultures of misogyny, sexism, and violence that many participants believed were connected to NZRC.

It is important to acknowledge that since the release of the RRR in 2017, an independent complaints and resolution system to deal with cases of rugby player misconduct has been implemented. While having an independent body to deal with complaints is a commendable first step, the current process does not deal with complaints regarding members of the public who are not registered players or administrators (i.e., rugby supporters). Therefore, while there is an avenue to voice concerns about rugby player misconduct, developing appropriate processes through which the public can express concerns about rugby's broader cultural atmosphere may assist NZR in their aim to create an "organisational and cultural" shift within the sport (Cockburn \& Atkinson, 2017a: 16). Furthermore, if it is widely believed that individuals associated with NZR systematically conceal the misconduct of rugby players to protect their rugby careers or avoid reputational damage, this independent complaints process may not be used. The 'dual code of silence' identified in this research is thus particularly important, as it suggests that additional steps to gain the public's confidence in the existing complaints process need to be taken. These steps could include actively promoting the independent nature of the process, and publically reporting its effectiveness and resolution rates.

\section{Managing Risks, Fears, and Impacts of Encounters with Rugby Culture}

The impacts of NZRC on the lives and welfare of the women in this research were serious and wide-ranging. Experiences of rugby-related violence and rugby's perceived status as a male-dominated arena encouraged perceptions of women and 
femininity as 'unsafe' or 'vulnerable' in NZRC, both within and beyond the confines of the NTE. This underlying fear of male predation compromised feelings of workplace safety, and encouraged the use of 'safe-keeping' strategies on rugby nights. Interactions with NZRC were also associated with a range of adverse psychological impacts including anxiety, panic attacks, substance-use, and emotional exhaustion. These impacts severely limited the women's ability to enjoy their working environments on 'rugby nights' and, in some cases, led participants to quit their jobs. As well as providing the first in-depth insight into how NZRC can impact the lives of women, these findings signify the urgent need to prioritise ways of addressing the sexism and violence that appears to be associated with NZRC within the context of the NTE.

As outlined in chapter six, internalised fears of aggression and the adoption of 'safekeeping' strategies are often symptomatic of rape culture (Buchwald, Fletcher, \& Roth, 1993). Thus, the undercurrent of fear that was present in the respondents' personal accounts of rugby culture is significant, as it points to the existence of a broader cultural atmosphere surrounding rugby, which may be conducive to rape culture. Nevertheless, prevalent concerns regarding the 'dangerousness' of certain groups can also be indicative of a 'moral panic,' which refers to the widespread fear of particular groups or phenomena, usually due to the distortion, fabrication, or misrepresentation of evidence in the media (Cohen, 2002). Undeniably, as recent cases of professional rugby player misconduct have been heavily scrutinised by the media, it is possible that the respondents' conscious and unconscious fears of rugbyrelated aggression may signify a media instigated 'moral panic' surrounding NZRC. However, as the participants expressed that their increased feelings of fear, hypervigilance, and discomfort on rugby nights were primarily influenced by personal experiences of rugby-related violence, the possibility of a media instigated 'moral panic' surrounding the safety of women in the context of NZRC does not undermine the significance of the current research findings and conclusions.

Furthermore, while a 'moral panic' typically suggests that certain reactions or concerns are disproportionate to the behaviours they scrutinise (Garland, 2008), determining the extent to which the women's fear of rugby-related aggression is proportionate to the threat that NZRC may impose is difficult, as women's accounts 
of NZRC have been excluded from academic research. Nonetheless, whether the perceived threat of violence that rugby culture poses to women is proportionate to the actual threat posed by rugby culture is not important. That interacting with NZRC made the women in this research feel unsafe or uncomfortable, and that these interactions contributed to anxiety, substance use, panic attacks, and job dissatisfaction is important, as it signifies the need for changes to ensure that women feel safe when interacting with rugby culture in the NTE.

Perceptions of women and femininity as vulnerable within the 'masculine' culture of rugby are particularly important when contemplating NZR's commitment to improving gender equity within the sport. The RRR notes that NZR is proactively working to encourage girls and women to "participate at all levels and in all roles" associated with rugby (Cockburn \& Atkinson, 2017b: 111). However, if women do not consider rugby environments to be safe or inclusive, efforts to encourage female participation in rugby may be unsuccessful. The findings of this research support this view, as many respondents took deliberate measures to avoid rugby, both within and beyond the NTE. Problematically, the continued absence of women from sporting cultures is argued to play a vital role in the construction and maintenance of male hegemony, as well as in the preservation of sexist attitudes that lend support to gender-based violence (Crosset, 1990). Thus, while NZR's commitment to improving gender equity within the sport is commendable, the current research findings suggest that additional efforts may be needed to ensure that NZRC is considered safe and inclusive for women, not only at the 'grassroots' level, but also at a broader societal level.

While the findings of this research demonstrate that the impacts of NZRC on the lives of women can be significant, this study has several limitations. Firstly, as the respondent's perspectives and experiences were based on individuals who were clearly identifiable as being 'rugby affiliated,' it is possible that a more subdued and respectful side of NZRC, one that involves fans and players who are discreet about their rugby affiliations, is not represented in their stories. Secondly, this research examined how women experienced and perceived NZRC within the context of a hypersexualised setting, characterised by hyper-masculine performances and sexist attitudes (Kavanaugh, 2013). Examining women's experiences and perceptions of 
NZRC in other contexts may yield different results, and is something that future research should aim to do. Finally, while this research includes experiences of NZRC across five New Zealand towns, it does not consider how these experiences may vary according to geographic location, and the majority of the women's experiences of NZRC were based in Wellington. As Tovia (2014) found that the influence of NZRC is stronger in some areas (i.e., the Bay of Plenty, Taranaki, and in the South Island) than others (i.e., Wellington), considering how experiences of NZRC vary according to geographic location would make a fruitful topic of investigation and is something that future research could also explore.

\section{Moving Forward}

This thesis provides the first in-depth insight into how women perceive and experience NZRC. The experiences of NZRC shared by the women in this research overwhelmingly involved incidents of sexual, physical, and verbal violence, which profoundly impacted upon their ability to enjoy or participate in rugby, their feelings of workplace safety and job satisfaction, and their physical, psychological, and emotional well-being. These findings suggest that within the context of the NTE, rugby culture is not an environment that can be deemed safe for women and, given the weight of the impacts of rugby culture on the women in this research, signify the urgent need to prioritise ways of ensuring the safety of women when interacting with NZRC in the NTE. While the women in this research identified multiple pathways through which involvement in NZRC may encourage the use and acceptance of violence, further research is needed to ensure that any strategies developed to mitigate potential issues associated with rugby are evidence-based and effective. As such, it is hoped that this thesis encourages further public and academic discussions regarding the impacts of NZRC on women and gender relations, and gains the momentum needed to facilitate the changes needed to ensure that women are respected and safe when interacting with or participating in NZRC. 


\section{Appendices}

\section{Appendix A: An Open Letter to New Zealand Rugby}

\section{Dear New Zealand Rugby management and board members,}

Right now, thousands of New Zealanders are questioning the culture of our country's favourite sport and those in charge of it.

We are writing to you publicly in the hope that you will listen to our calls for you to act with courage.

The internal investigation into an incident involving a woman called Scarlette and members of the Chiefs rugby team has highlighted to all New Zealanders that New Zealand Rugby's judiciary process is not appropriate for dealing with issues of integrity, mana, respect and basic personal rights.

We are offering our expertise, experience and support. Louise Nicholas has been working alongside New Zealand Police to successfully enhance their internal culture for some time now. We encourage you to do the same. Dr Jackie Blue offered to assist a month ago and this offer still stands.

Rugby is like a religion in New Zealand, with players worshipped by young Kiwis throughout the country. New Zealand Rugby could not operate without thousands of women volunteers and players in clubs and towns across the country: we must address the culture that exists from the top down and set the right example, particularly for our young New Zealanders.

Now is the time for you and those involved in the incident with Scarlette to be courageous, and to take personal leadership on an issue that we can all work on addressing together.

As much as New Zealanders love rugby - we need New Zealanders to respect women.

We look forward to hearing from you.

Signed by,

Dr Jackie Blue, EEO Commissioner

Louise Nicholas, Sexual Violence Survivors Advocate 
Rae Duff, National President, National Council of Women of New Zealand

Prue Kapua, National President, Māori Women's Welfare League

Barbara Williams, National Council of Women

Dr Kim McGregor QSO , Director of Tiaki Consultants

Caren Rangi, National President, P.A.C.I.F.I.C.A (Pacifica Allied (Women's) Council

Inspires Faith in Ideals Concerning All) Inc

Dame Susan Devoy, Race Relations Commissioner

Nive Sharat Chandran, Co President YWCA of Aotearoa New Zealand

Sina Wendt-Moore, Co President, YWCA of Aotearoa New Zealand

Monica Briggs, CEO, YWCA Auckland

Karen Johansen, Indigenous Rights Commissioner

Jan Logie, Member of Parliament

Ruth Dyson, Member of Parliament

Tracey Martin, Member of Parliament

Catriona McClennan, Barrister and Social Justice Advocate

Leonie Morris, Auckland Women's Centre

Eileen Brown, Council of Trade Unions

Sue Kedgley, UN Women

Dr Janette Irvine, General Practitioner

Vicky Mee, Business and Professional Women

Jane Drumm, Shine

Erin Polaczuk, PSA

Deborah McKenzie, Inner City Women

Christine King, President, Pacific Women

Denise Ritchie, Stop Demand 
Appendix B: Recruitment Poster

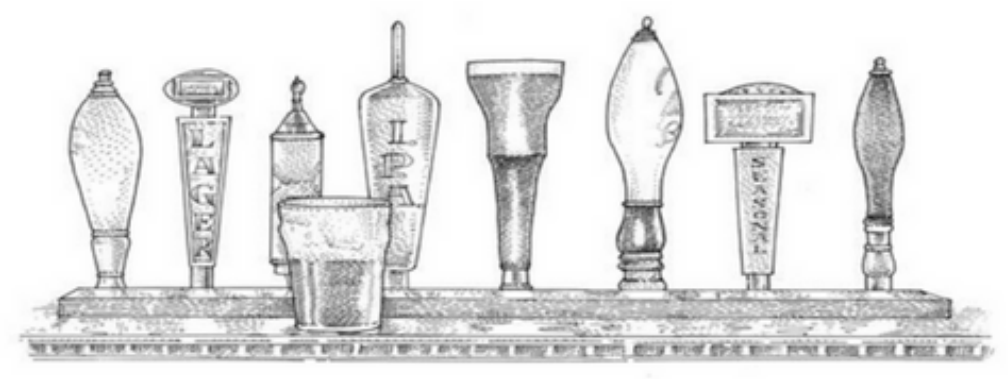

Her.

If you identify as a woman, are over the age of 18 , and have experience working as a bartender, waitress, promo girl, erotic dancer, or sex worker including on the nights of rugby games...

\section{I would love to hear from you!}

My Name is Genevieve and I am completing my Masters in Criminology at Victoria University of Wellington. I am interested in exploring how rugby events may impact the lives of women. If you would like to take part in a confidential interview with me for this research or have any questions or queries, please get in touch.

All participants will receive a $\$ 20$ supermarket voucher for their time This research has received ethical approval from the VUW Human Ethics Committee \#0000025939

RESEARCHER: Genevieve Courtney CONTACT DETAILS:

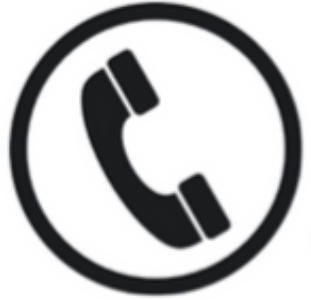

0278057101

(Text is fine)

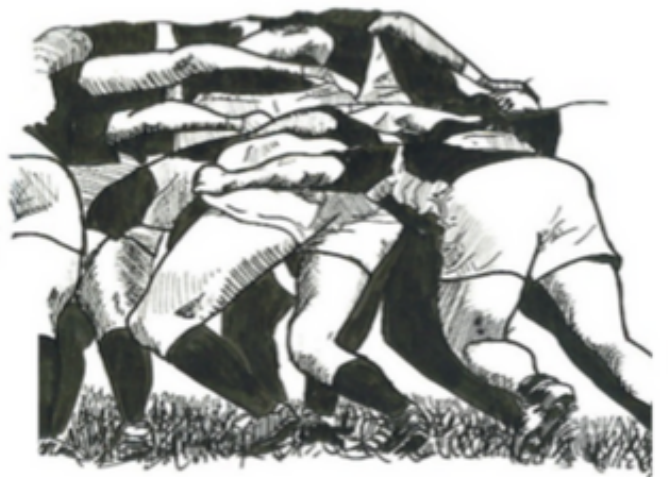

Supervisor: Lynzi Armstrong Email: lynzi.armstrong@vuw.ac.nz 


\section{Appendix C: Interview Guide}

\section{Draft Participant Interview Guide}

Introduction and Informed Consent:

- Introduce myself

- Explain the project and why I am doing this research

- Ask if they have any questions about the interview or research

- Ensure information sheet has been read, consent form has been signed, and the pre-interview demographic questionnaire has been filled out.

- Provide participant with copy of contacts details for support services.

- Inform participants that they can end the interview or turn off the recorder at any time.

Interview Questions:

Could you tell me about when and how you became involved in your work?

○ Generally speaking, what do you like about your work?

- Are there any negative aspects of your job? What are they?

Can you please describe what your interactions with customers/clients usually like at work?

To what extent do you notice differences in your interactions with customers/clients when working the night of a rugby game?

- If your interactions with customers differ when a rugby game is on, what do these differences look like and involve?

Based on your own experiences and interactions with rugby culture, what do you think New Zealand rugby culture looks like or involve?

$\circ$ What does this culture mean to you?

How do you experience rugby culture or interact with rugby players/fans while carrying out your work?

- What do these experiences/interactions usually entail?

- How do these experiences/interactions make you feel?

- How have these experiences/interactions impacted you and/or your work?

In general, how safe do you feel when carrying out your work?

$\circ$ Does this change when a rugby game is on? If so how? If not, why not?

What steps, if any, do you take to ensure your safety when carrying out your work?

$\circ$ Do these steps change when a rugby game is on? If so, how? If not, why not?

What impacts, if any, have your workplace interactions with rugby culture had on areas of your life?

- How do you deal with these impacts? 
To what extent, if any, does alcohol impact your interactions with customers/clients?

○ Does this impact change when a rugby game is on? If so how?

To what extent do you think New Zealand rugby culture can be considered a safe environment?

- What makes you think that it is a safe/unsafe environment?

In New Zealand rugby culture, what does masculinity look like and involve?

$\circ$ What impact, if any, do you think this depiction of masculinity has on people in New Zealand?

Based on your experiences, to what extent, if any, do you think aspects of rugby culture need to change?

- If you believe changes are needed, what aspects need to change, and what would this change look like and involve?

- If you do not believe changes are needed, why?

\section{Closing:}

- Summarise the content of the interview, ask participants if there is anything they would like to add or discuss. Thank participants for their time and provide with a copy of contact details for support agencies and give them a koha to acknowledge the value of their time and contribution. 


\title{
Appendix D: Information Sheet
}

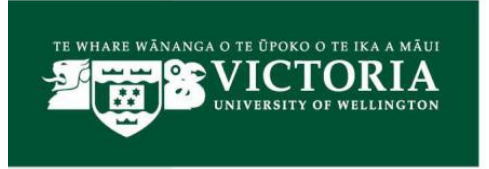

SCHOOL OF SOCIAL \& CULTURAL STUDIES

TE KURA MAHINGA TANGATA

VICTORIA UNIVERSITY OF WELLINGTON PO Box 600, Wellington 6147, New Zealand

Phone + 64-4-463 5317 Fax +64-4-463 5064 Email: sacs@vuw.ac.nz Web www.victoria.ac.nz/sacs

\section{Lager, Lads, and Rugby: An exploratory study of women's interactions with New Zealand rugby culture \\ PARTICIPANT INFORMATION SHEET}

\author{
Researcher: Genevieve Courtney, School of Social and Cultural Studies, Victoria \\ University of Wellington
}

You are invited to take part in this research. Please read this information carefully before deciding whether or not to take part. If you decide to participate, thank you. If you decide not to participate, thank you for considering this request.

Who am I? My name is Genevieve Courtney and I am a Masters student in Criminology at Victoria University of Wellington. This research project is work towards my thesis.

What is the aim of the project? This project aims to explore the perceptions and experiences of women who work in alcohol based venues on nights when a rugby game is on. Specifically, it considers the extent to which these women consider their experiences of rugby events, spectators, fans, or players to have positive or negative impacts on their lives. This research has received approval from the Victoria University of Wellington Human Ethics Committee [Approval number: 0000025939].

How can you help? I am inviting individuals that are over 18, identify as a woman, and have experience working at alcohol based venues where post rugby game celebrations are likely to take place, to participate in this research. If you agree to take part, I will interview you at a mutually agreed upon location, such as a quiet café or a private room at Victoria University. The interview will last approximately 1 hour. I will audio record the interview with your permission and write it up later. I will ask you questions about your experiences of working when rugby games are on. You can choose to not answer any question and you are able to stop the interview at any time, without giving a reason. You can withdraw from the study by contacting me at any point up until the $30^{\text {th }}$ of September 2018. If you withdraw, the information you provided will be destroyed or returned to you.

What will happen to the information you give? This research is confidential. This means that only the researcher and the research supervisors named below will be aware of your identity, and that your identity will not be revealed in any reports, presentations, or public documentation. Care will be taken to remove any identifying information, and any details that 
could potentially identify you will be discussed with you in advance, and removed at your request. Any information you provide will remain confidential to the researcher and research supervisors. The only exception to this is if you disclose that yourself or another person is at serious risk of harm. If confidentiality does need to be broken on this basis, I know that this would be discussed with me first. You should also be aware that in small projects your identity might be obvious to others in your community. Only my supervisors and I will read the notes or transcript of the interview. The interview transcripts, summaries, and any recordings will be kept securely and destroyed 5 years after the research has been completed.

\section{What will the project produce?}

The information from my research will be used in my Masters thesis, which will be submitted for marking to the School of Social and Cultural studies and deposited to the university library. The findings of this research may be used in academic publications and data from this research may be presented at academic conferences.

\section{If you accept this invitation, what are your rights as a research participant?}

You do not have to accept this invitation if you don't want to. If you do decide to participate, you have the right to:

- Choose not to answer any question;

- Ask for the recorder to be turned off at any time during the interview;

○ Withdraw from the study before at any point up to four weeks after the interview;

- Ask any questions about the study at any time;

- Receive a copy of your interview recording;

- Receive a copy of your interview transcript (to check and make any ammendments you feel necessary)

- Be able to read any reports of this research by emailing the researcher to request a copy.

If you have any questions or problems, who can you contact?

If you have any questions, either now or in the future, please feel free to contact me:

Researcher: Genevieve Courtney

Email: genevieve.courtney@vuw.ac.nz

Phone: 0278057101
Primary Supervisor: Lynzi Armstrong

Email: lynzi.armstrong@vuw.ac.nz

Phone: 044635372

Secondary Supervisor: Fiona Hutton

Email: Fiona.hutton@vuw.ac.nz

Phone: 044636749

Human Ethics Committee information:

If you have any concerns about the ethical conduct of the research you may contact the Victoria University HEC Convenor: Associate Professor Susan Corbett. Email

hec@vuw.ac.nz or telephone +64-4-4639451 


\section{Appendix E: Participant Consent Form}

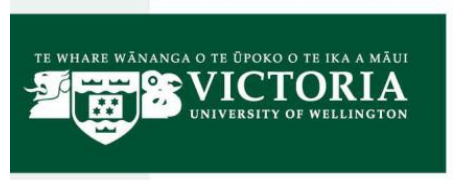

SCHOOL OF SOCIAL \& CULTURAL STUDIES

TE KURA MAHINGA TANGATA

VICTORIA UNIVERSITY OF WELLINGTON PO Box 600, Wellington 6147, New Zealand

Phone + 64-4-463 5317 Fax +64-4-463 5064 Email: sacs@vuw.ac.nz Web www.victoria.ac.nz/sacs

\section{Lager, Lads, and Rugby: An exploratory study of womens interactions with New Zealand Rugby Culture}

\section{PARTICIPANT CONSENT FORM}

(This consent form will be held for five years).

Researcher: Genevieve Courtney, School of Social and Cultural Studies, Victoria University of Wellington

- I have read the Information Sheet and the project has been explained to me. My questions have been answered to my satisfaction. I understand that I can ask further questions at any time.

- I agree to take part in an audio recorded interview

I understand that:

- I am able to withdraw myself (or any information that I have provided) from this project by contacting the researcher at any point up until the $30^{\text {th }}$ of September 2018 , and any information that I have provided will be returned to me or destroyed.

- The information I have provided will be destroyed 5 years after the research is finished.

- Any information I provide will remain confidential to the researcher and her supervisors. The only exception to this is if I disclose that I or another person is at risk of harm. If confidentiality does need to be broken on this basis, I know that this would be discussed with me first.

- The findings will be used for a Masters report and may be used in academic reports and/or presented at conferences

- I understand that my name will not be used in any publications associated with the research and care will be taken to remove any details that could potentially identify me or anyone else

I would like a copy of the transcript of my interview:

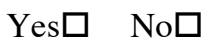

I would like to receive a copy of the final report and have added my email $\quad$ Yes $\square \quad$ No $\square$ address below.

Signature of participant:

Name of participant:

Date:

Email: 


\section{Lager, Lads, and Rugby: An exploratory study of women's interactions with New Zealand Rugby Culture}

\section{Pre-interview demographic questionnaire}

Day and Date:

Time:

Location of Interview (City):

Victoria University

Wellington library

Other (write in)

1. Within what age range are you now? (Please indicate in the box provided)

\begin{tabular}{|l|l|}
\hline $18-21$ years & \\
\hline $22-29$ years & \\
\hline $30-45$ years & \\
\hline Over 45 years & \\
\hline
\end{tabular}

2. Which ethnic group do you belong to?

\begin{tabular}{|l|l|}
\hline NZ European & \\
\hline Māori & \\
\hline Samoan & \\
\hline Cook Island Māori & \\
\hline Tongan & \\
\hline Niuean & \\
\hline Chinese & \\
\hline Indian & \\
\hline Other? & \\
\hline Please state: & \\
& \\
\hline
\end{tabular}

3. Which of the following do you have experience working as? (Please tick all that apply)

\begin{tabular}{|l|l|}
\hline Bartender & \\
\hline Waitress & \\
\hline Bar manager & \\
\hline Security personnel & \\
\hline
\end{tabular}




\begin{tabular}{|l|l|}
\hline Escort & \\
\hline Promo girl & \\
\hline Erotic Dancer & \\
\hline Full-service sex worker & \\
\hline Other? & \\
Please state: & \\
& \\
\hline
\end{tabular}

4. How many years of experience do you have in this occupation? (If you have experience in more than one of the occupations listed above, please indicate how many years experience you have had working in each of these occupations, by writing the occupation (e.g., bartender) next to the appropriate time frame (e.g., 1-2 years).

\begin{tabular}{|l|l|}
\hline Less than a year & \\
\hline $1-2$ years & \\
\hline $3-5$ years & \\
\hline $5-10$ years & \\
\hline $10+$ years & \\
\hline
\end{tabular}




\section{Contact information for support services:}

Sexual Abuse and Rape Agencies in the Wellington Area:

Tu Pakari Ora: Cuba Street Clinic

(SAAT - Sexual Assault Assessment \& Treatment Service)

Wellington Sexual Abuse HELP Foundation:

048016655

(Support and information, medical services,

info@,wellingtonhelp.org.nz

counselling for children and adults, women

and men, individuals and families)

Hutt Valley Sexual Abuse Support and Healing (SASH):

800226694

(Counselling for women)

Wellington Rape Crisis:

473-5357

WIRC@xtra.co.nz

Awhina Wahine Wellington Incorporated:

232-9817

(Counselling for Maori women, children and whanau)

\section{Women's Refuge:}

Wellington Women's Refuge:

939-0455

(24 hours)

Te Wharekohe Rokiroki Maori Women's Refuge:

380-0917

(24 hours)

Hutt City Women's Refuge:

$569-1040$

Porirua Women's Refuge:

234-6118

Kapiti Women's Refuge:

04-297-2595

Kokiri Marae Maori Women's Refuge:

566-5025

(24 hours)

\section{Family Support:}

Catholic Social Services

$385-8642$

The Counselling Group

499-6990

Gay Wellington Helpline

473-7878

\section{Health Services:}

Wellington Mental Health Consumers Union:

Psychiatric Emergency Response (CATT Team):

Eating Disorder Services:

Wellington Sexual Health Clinic: 
(Offers counselling and treatment service to help people over come alcohol, drug, and gambling issues and support people who are recovering from mental illness and/or overcoming addiction).

\section{Other Counselling Services:}

Pacific Island Women's Project:

(Counselling for women, men and children)

VUW Counselling Services: (Kelburn Campus)

Wellington Violence Intervention Programme:

(Offers education programmes for abusive men, and education/support groups for women in abusive relationships) Wellstop:

(Treatment programmes for men and male adolescents who are abusers; and support, education and counselling for families of abusers) 
MEMORANDUM

Phone $\quad 0-4-4636028$

Email judith.loveridge@vuw.ac.nz

\begin{tabular}{l|l}
\hline TO & Genevieve Courtney \\
\hline FROM & Dr Judith Loveridge, Convenor, Human Ethics Committee \\
\hline DATE & 14 May 2018 \\
\hline PAGES & 1 \\
\hline & $\begin{array}{l}\text { Ethics Approval: 25939 } \\
\text { Sager, Lads, and Rugby: an exploratory study of women's } \\
\text { interactions with New Zealand rugby culture }\end{array}$ \\
\hline
\end{tabular}

Thank you for your application for ethical approval, which has now been considered by the Human Ethics Committee.

Your application has been approved from the above date and this approval is valid for three years. If your data collection is not completed by this date you should apply to the Human Ethics Committee for an extension to this approval.

Best wishes with the research.

Kind regards

Judith Loveridge

Convenor, Victoria University of Wellington Human Ethics Committee 


\section{References}

Abbey, A., Zawacki, T., Buck, P. O., Clinton, A. M., \& McAuslan, P. (2004). Sexual assault and alcohol consumption: What do we know about their relationship and what types of research are still needed? Aggression and violent behavior, 9(3), 271-303.

Abrahams, N., Jewkes, R., Laubscher, R., \& Hoffman, M. (2006). Intimate partner violence: prevalence and risk factors for men in Cape Town, South Africa. Violence and victims, 21(2), 247.

Adams, A., Anderson, E., \& McCormack, M. (2010). Establishing and challenging masculinity: The influence of gendered discourses in organized sport. Journal of language and social psychology, 29(3), 278-300.

Ananiades, T. (2012). Penalty on the Field: Creating a NCAA Sexual Assault Policy. Vill. Sports \& Ent. LJ, 19, 463.

Anderson, E. (2008). I used to think women were weak: Orthodox masculinity, gender segregation, and sport. Sociological Forum, 23(2), 257-280

Anderson, E. (2015). Assessing the sociology of sport: On changing masculinities and homophobia. International review for the sociology of sport, 50(4-5), 363-367.

Anderson, T., Daly, K., \& Rapp, L. (2009). Clubbing masculinities and crime: A qualitative study of Philadelphia nightclub scenes. Feminist Criminology, 4(4), 302-332.

Armstrong, L. (2011). Managing risks of violence in decriminalised street-based sex work: A feminist (sex worker rights) perspective. (Doctoral Thesis, Victoria University of Wellington, New Zealand). Retrieved from: https://researcharchive.vuw.ac.nz/xmlui/bitstream/handle/10063/2978/thesis.p df? sequence $=1$

Atkinson, R., \& Flint, J. (2001). Accessing hidden and hard-to-reach populations: Snowball research strategies. Social research update, 33(1), 1-4.

Ayres, T. C., \& Treadwell, J. (2011). Bars, drugs and football thugs: Alcohol, cocaine use and violence in the night-time economy among English football firms. Criminology \& Criminal Justice, 12(1), 83-100. 
Basile, K. C., \& Smith, S. G. (2011). Sexual violence victimization of women: Prevalence, characteristics, and the role of public health and prevention. American Journal of Lifestyle Medicine, 5(5), 407-417.

Beale, (2018). Feminist Ethnographies in Sport and Leisure. In Mansfield, L., Caudwell, J., Wheaton, B., \& Watson, B. (Eds.). (2018). The palgrave handbook of feminism and sport, leisure and physical education. (pp. 227-240). Palgrave Macmillan UK.

Beecher-Monas, E., \& Garcia-Rill, E. (2006). Genetic Predictions of Future Dangerousness: Is There a Blueprint for Violence?. Law and Contemporary Problems, 69(1/2), 301-341.

Behnk, S., Hao, L., \& Reuben, E. (2017). Partners in Crime: Diffusion of Responsibility in Antisocial Behaviors. IZA Discussion Papers, No. 11031, Institute of Labor Economics (IZA), Bonn

Benedict, J. R. (2003, August 5) Athletes and Accusations. New York Times.

Benoit, C., Jansson, M., Millar, A., \& Phillips, R. (2005). Community-academic research on hard-to-reach populations: Benefits and challenges. Qualitative health research, 15(2), 263-282.

Bergen, R. K. (1993). Interviewing survivors of marital rape: Doing feminist research on sensitive topics. SAGE FOCUS EDITIONS, 152, 197-197.

Boeringer, S. B. (1996). Influences of fraternity membership, athletics, and male living arrangements on sexual aggression. Violence Against Women, 2(2), 134-147.

Boswell, A. A., \& Spade, J. Z. (1996). Fraternities and collegiate rape culture: Why are some fraternities more dangerous places for women? Gender \& Society, $10(2), 133-147$.

Bouffard, L. A. (2010). Exploring the utility of entitlement in understanding sexual aggression. Journal of Criminal Justice, 38, 870-879

Bouffard, L., \& Goodson, A. (2017). Sexual coercion, sexual aggression, or sexual assault: how measurement impacts our understanding of sexual violence. Journal of aggression, conflict and peace research, 9(4), 269-278.

Braidotti, R. (2003). Becoming woman: Or sexual difference revisited. Theory, Culture \& Society, 20(3), 43-64.

Braun, R., \& Vliegenthart, R. (2008). The contentious fans: The impact of repression, 
media coverage, grievances and aggressive play on supporters' violence. International Sociology, 23, 796-818.

Braun, V., \& Clarke, V. (2006). Using thematic analysis in psychology. Qualitative research in psychology, 3(2), 77-101.

Braun, V., \& Clarke, V. (2013). Teaching thematic analysis: Overcoming challenges and developing strategies for effective learning. The psychologist, 26(2), 120123.

Brod, H., \& Kaufman, M. (Eds.). (1994). Theorizing masculinities (Vol. 5). Sage.

Brookes, B. (1981). Housewives' depression: the debate over abortion and birth control in the 1930's. The New Zealand journal of history, 15(2), 115.

Brooks, A., \& Hesse-Biber, S. N. (2007). An invitation to feminist research. Feminist research practice: A primer, 1-24.

Brooks, O. (2008). Consuming Alcohol in Bars, Pubs and Clubs: A risky freedom for young women?. Annals of Leisure Research, 11(3-4), 331-350.

Brooks, O. (2011). 'Guys! Stop doing it!' young women's adoption and rejection of safety advice when socializing in bars, pubs and clubs. The British Journal of Criminology, 51(4), 635-651.

Brown, G., Western, D., \& Pascal, J. (2013). Using the F-word: Feminist epistemologies and postgraduate research. Affilia, 28(4), 440-450.

Brownmiller, S. (1976). Against our will: Women, men, and rape. London: Penguin Books

Bryant, A., \& Charmaz, K. (2010). Grounded theory in historical perspective: An epistemological account. Handbook of grounded theory, 31-57.

Bryman, A. (2008). Of methods and methodology. Qualitative Research in Organizations and Management: An International Journal, 3(2), 159-168.

Buchwald, E., Fletcher, P. R., \& Roth, M. (1993). Transforming a rape culture. Minneapolis: Milkweed Editions.

Burgess-Proctor, A. (2015). Methodological and ethical issues in feminist research with abused women: Reflections on participants' vulnerability and empowerment. In Women's Studies International Forum. 48(1),124-134.

Butler, J. (1994). Gender as performance. Radical Philosophy, 67: 32-39.

Calhoun, K. S., Mouilso, E. R., \& Edwards, K. M. (2012). Sexual assault among college students. In R. McAnulty (Ed.), Sex, love and psychology: sex in 
college, the things they don" $t$ write home about (pp. 299-324). Santa Barbara: ABC-CLIO

Campbell, A. (2005). Keeping the 'lady' safe: The regulation of femininity through crime prevention literature. Critical Criminology, 13(2), 119-140.

Campbell, R., Dworkin, E., \& Cabral, G. (2009). An ecological model of the impact of sexual assault on women's mental health. Trauma, Violence, \& Abuse, 10(3), 225-246.

Capraro, R. L. (2000). Why college men drink: Alcohol, adventure, and the paradox of masculinity. Journal of American college health, 48(6), 307-315.

Card, D., \& Dahl, G. B. (2011). Family violence and football: The effect of unexpected emotional cues on violent behavior. The Quarterly Journal of Economics, 126(1), 103-143.

Caron, S. L., Halteman, W. A., \& Stacy, C. (1997). Athletes and rape: is there a connection? Perceptual and motor skills, 85(3_suppl), 1379-1393.

Casswell, S., \& Maxwell, A. (2005). Regulation of alcohol marketing: a global view. Journal of Public Health Policy, 26(3), 343-358.

Chapman, A. L., Hadfield, M., \& Chapman, C. J. (2015). Qualitative research in healthcare: an introduction to grounded theory using thematic analysis. Journal of the Royal College of Physicians of Edinburgh, 45(3), 201-205.

Charmaz, K. (2002). Grounded theory analysis. In J. F. Gubrium \& J. A. Holstein (Eds.), Handbook of interview research (pp. 675-694). Thousand Oaks, CA: Sage

Charmaz, K. (2008). Constructionism and the grounded theory method. Handbook of constructionist research, 1, 397-412.

Charmaz, K. (2017). The power of constructivist grounded theory for critical inquiry. Qualitative inquiry, 23(1), 34-45.

Chatterton P and Hollands R (2003) Urban Nightscapes: Youth Culture, Pleasure Spaces and Corporate Power. London: Routledge

Cockburn, R \& Atkinson, L. (2017a). Respect and Responsibility Review - New Zealand rugby: Summary. Wellington, Lumin. Retrieved from http://files.allblacks.com/NZRU_Media_Releases/2017/NZR_RRR_Summary _Document_FINAL_070917.pdf

Cockburn, R \& Atkinson, L. (2017b). Respect and Responsibility Review - New 
Zealand Rugby: Full Report. Wellington, Lumin. Retrieved from http://files.allblacks.com/NZRU_Media_Releases/2017/NZR_RRR_Final_Re view_Report_070917.pdf

Code, L. (1991). What can she know? Feminist theory and the construction of knowledge. Ithaca: Cornell University Press.

Cohen, S. (2002). Folk devils and moral panics: The creation of the mods and rockers. Psychology Press.

Coles, J., Astbury, J., Dartnall, E., \& Limjerwala, S. (2014). A qualitative exploration of researcher trauma and researchers' responses to investigating sexual violence. Violence against women, 20(1), 95-117.

Connell, R. W. (1996). Masculinities. Berkeley: University of California press CA.

Connell, R. W. (1998). Masculinities and globalization. Men and masculinities, 1(1), $3-23$.

Connell, R. W. (2002). Studying men and masculinity. Resources for feminist research, 29(1/2), 43-56.

Connell, R. W., \& Messerschmidt, J. W. (2005). Hegemonic masculinity rethinking the concept. Gender \& Society, 19(6), 829-859

Cook, J. A., \& Fonow, M. M. (1986). Knowledge and women's interests: Issues of epistemology and methodology in feminist sociological research. Sociological Inquiry, 56(1), 2-29.

Cosgrove, A., \& Bruce, T. (2005). "The way New Zealanders would like to see themselves": Reading white masculinity via media coverage of the death of Sir Peter Blake. Sociology of sport journal, 22(3), 336-355.

Cossins, A. (1998) 'Tipping the Scales in Her Favour: The Need to Protect Counselling Records in Sexual Assault Trials', in Easteal, P. (ed.) Balancing the Scales: Rape, Law Reform and Australian Culture, pp. 94- 106. Leichhardt, Sydney: The Federation Press

Crosset, T. (1999). Male athletes' violence against women: A critical assessment of the athletic affiliation, violence against women debate. Quest, 51(3), 244-257.

Crosset, T. W., Benedict, J. R., \& McDonald, M. A. (1995). Male student-athletes reported for sexual assault: A survey of campus police departments and judicial affairs offices. Journal of Sport and Social Issues, 19(2), 126-140. 
Crosset, T. W., Ptacek, J., McDonald, M. A., \& Benedict, J. R. (1996). Male studentathletes and violence against women: A survey of campus judicial affairs offices. Violence Against Women, 2(2), 163-179.

Crossett, T. W, (1990). Masculinity, Sexuality, and the Development of Early Modern Sport. In Messner. M. A. \& Sabo. D. F( Eds.), Sport. Men and the Gender Order: Critical Feminist Perspectives. Human Kineties, Publishers, Champaign, IL

Curry, T. J. (1991). Fraternal bonding in the locker room: A profeminist analysis of talk about competition and women. Sociology of sport journal, 8(2), 119-135

David, D. S., \& Brannon, R. (1976). The forty-nine percent majority: The male sex role. Addison Wesley Publishing Company.

Davies, S. E., \& True, J. (2015). Reframing conflict-related sexual and gender-based violence: Bringing gender analysis back in. Security Dialogue, 46(6), 495-512.

De Crespigny, C. (2001). Young women, pubs and safety. Alcohol, young persons and violence, 31-46.

Deering, K. N., Amin, A., Shoveller, J., Nesbitt, A., Garcia-Moreno, C., Duff, P., ... \& Shannon, K. (2014). A systematic review of the correlates of violence against sex workers. American journal of public health, 104(5), 42-54.

DeKeseredy, W. S., \& Schwartz, M. D. (1993). Male peer support and woman abuse: An expansion of DeKeseredy's model. Sociological Spectrum, 13(4), 393-413.

Diehl, K., Thiel, A., Zipfel, S., Mayer, J., Litaker, D. G., \& Schneider, S. (2012). How healthy is the behavior of young athletes? A systematic literature review and meta-analyses. Journal of sports science \& medicine, 11(2), 201.

Donaldson, M. (1993). What is hegemonic masculinity? Theory and society, 22(5), 643-657.

Doucet, A., \& Mauthner, N. S. (2006). Feminist methodologies and epistemology. Handbook of 21st Century Sociology. Thousand Oaks, CA: Sage, 36-45.

Dowling, M. (2006). Approaches to reflexivity in qualitative research. Nurse Researcher (through 2013), 13(3), 7.

Duff, M. (2011, July 29). More hookers off field than on for world cup. The Dominion Post. Retrieved from http://www.pressreader.com/new-zealand/thedominion-post/20110729/281638186872659 
Duke, V., \& Slepic ${ }^{`} k a$, P. (2002). Bohemian rhapsody: Football supporters in the Czech Republic. In E. Dunning, P. Murphy, I. Waddington, \& A. Astrinakis (Eds.), Fighting fans: Football hooliganism as a world phenomenon (pp. 4961). Dublin, Ireland: University College Dublin Press

Dunning E, Murphy P and Williams J (1988) The Roots of Football Hooliganism. New York: Routledge.

Dunning, E. (1986). Sport as a male preserve: Notes on the social sources of masculine identity and its transformations. Theory, Culture \& Society, 3(1), 79-90.

Dunning, E. G., Murphy, P. J., \& Waddington, I. (2002a). Towards a sociological understanding of football hooliganism as a world phe- nomenon. In E. Dunning, P. Murphy, I. Waddington, \& A. Astri- nakis (Eds.), Fighting fans: Football hooliganism as a world phenomenon (pp. 1-22). Dublin, Ireland: University College Dublin Press

Edley, N. (2017). Men and masculinity: the basics. Routledge.

Eichler, M. (1997). Feminist methodology. Current sociology, 45(2), 9-36.

Eitle, D., Turner, R. J., \& Eitle, T. M. (2003). The deterrence hypothesis re-examined: Sports participation and substance use among young adults. Journal of Drug Issues, 33(1), 193-221.

England, K. V. (1994). Getting personal: Reflexivity, positionality, and feminist research. The Professional Geographer, 46(1), 80-89.

Estrich, S. (1987). Real rape. Harvard University Press.

Ezzy, D. (2002). Qualitative analysis. Routledge.

Fanslow, J. L., \& Robinson, E. M. (2011). Sticks, stones, or words? Counting the prevalence of different types of intimate partner violence reported by New Zealand women. Journal of Aggression, Maltreatment \& Trauma, 20(7), 741759.

Fanslow, J., Robinson, E., Crengle, S., \& Perese, L. (2010). Juxtaposing beliefs and reality: Prevalence rates of intimate partner violence and attitudes to violence and gender roles reported by New Zealand women. Violence Against Women, 16(7), 812-831.

Fassinger, R. E. (2005). Paradigms, praxis, problems, and promise: Grounded theory in counseling psychology research. Journal of counseling psychology, 52(2), 
156.

Fileborn, B. (2012). Sex and the city: Exploring young women's perceptions and experiences of unwanted sexual attention in licensed venues. Current Issues Criminal Justice, 24(1), 241-60

Fileborn, B. (2016). Doing gender, doing safety? Young adults' production of safety on a night out. Gender, Place \& Culture, 23(8), 1107-1120.

Finney, A. (2004). Violence in the night-time economy: Key findings from the research. London: Home Office.

Fitzpatrick, B. (2015). Broken bats and broken bones: Holding stadium owners accountable for alcohol-fueled fan-on-fan violence. Sports Law Journal, 22, 663-691.

Fleming, P. J., McCleary-Sills, J., Morton, M., Levtov, R., Heilman, B., \& Barker, G. (2015). Risk factors for men's lifetime perpetration of physical violence against intimate partners: results from the international men and gender equality survey in eight countries. PloS one, 10(3), e0118639.

Flood, M. (2003). Engaging men: Strategies and dilemmas in violence prevention education among men. Women Against Violence: An Australian Feminist Journal(13), 25.

Flood, M. (2008). Men, sex, and homosociality: How bonds between men shape their sexual relations with women. Men and masculinities, 10(3), 339-359

Flood, M., \& Dyson, S. (2008). Sport, athletes, and violence against women. Australian Research Centre in Sex, Health and Society, La Trobe University, republished in NTV Journal, 4(3), 37-46

Fontana, A., \& Frey, J. (2005). The interview: From neutral stance to political involvement. In The Sage handbook of qualitative research (3rd ed., pp. 695727). Thousand Oaks, CA: Sage.

Ford, T. E., Woodzicka, J. A., Triplett, S. R., Kochersberger, A. O., \& Holden, C. J. (2014). Not all groups are equal: Differential vulnerability of social groups to the prejudice-releasing effects of disparagement humor. Group Processes \& Intergroup Relations, 17(2), 178-199.

Franklin, K. (2004). Enacting masculinity: Antigay violence and group rape as participatory theatre. Sexuality Research and Social Policy, 1(2), 25-40.

Frintner, M. P., \& Rubinson, L. (1993). Acquaintance rape: The influence of alcohol, 
fraternity membership, and sports team membership. Journal of Sex Education and therapy, 19(4), 272-284.

Garcia-Moreno, C., Jansen, H. A., Ellsberg, M., Heise, L., \& Watts, C. H. (2006). Prevalence of intimate partner violence: findings from the WHO multi-country study on women's health and domestic violence. The lancet, 368(9543), 12601269.

Gee, S., \& Jackson, S. J. (2010). The Southern Man city as cultural place and Speight's Space: locating the masculinity-sport-beer 'holy trinity' in New Zealand. Sport in Society, 13(10), 1516-1531.

Gee, S., \& Jackson, S. J. (2012). Leisure corporations, beer brand culture, and the crisis of masculinity: the Speight's 'Southern Man' advertising campaign. Leisure Studies, 31(1), 83-102.

Gee, S., Jackson, S. J., \& Sam, M. (2016). Carnivalesque culture and alcohol promotion and consumption at an annual international sports event in New Zealand. International Review for the Sociology of Sport, 51(3), 265-283.

Gervais, S. J., DiLillo, D., \& McChargue, D. (2014). Understanding the link between men's alcohol use and sexual violence perpetration: The mediating role of sexual objectification. Psychology of Violence, 4(2), 156.

Giancola, P.R. (2002). Alcohol-related aggression during college years: Theories, risk factors and policy implications. Journal of Studies on Alcohol, 14, 129-139.

Glaser, B. G. (1992). Basics of grounded theory analysis. Mill Valley, CA: Sociology Press

Glaser, B. S., \& Strauss, A. (1967). The discovery of grounded theory. New york, 581-629.

Glassman, T., Miller, J., Miller, M. E., Wohlwend, J., \& Reindl, D. (2012). Game day alcohol expectancies among college students from a university in the southeast. American Journal of Health Education, 43(4), 202-208.

Grbich, C. (2013). Phenomenology. In Qualitative Data Analysis. An Introduction (pp. 92-104). SAGE, London.

Gregory, J \& Lees, S (1999). Policing Sexual Assault. London: Routledge.

Griffin, C., Szmigin, I., Bengry-Howell, A., Hackley, C., \& Mistral, W. (2013). Inhabiting the contradictions: Hypersexual femininity and the culture of intoxication among young women in the UK. Feminism \& Psychology, 23(2), 
184-206.

Guschwan, M. (2007). Riot in the curve: Soccer fans in twenty-first century Italy. Soccer and Society, 8, 250-266

Hadfield, P. (2006). Bar Wars: Contesting the Night in Contemporary British Cities, Oxford: Oxford University Press.

Hadjistavropoulos, T., \& Smythe, W. E. (2001). Elements of risk in qualitativeresearch. Ethics \& Behavior, 11(2), 163-174.

Hallberg, L. R. (2006). The "core category" of grounded theory: Making constant comparisons. International journal of qualitative studies on health and-well-being, 1(3), 141-148.

Hamilton, R. J., \& Bowers, B. J. (2006). Internet recruitment and e-mail interviews in qualitative studies. Qualitative Health Research, 16(6), 821-835.

Harding, S., \& Norberg, K. (2005). New feminist approaches to social science methodologies: An introduction. Signs: Journal of women in culture and society, 30(4), 2009-2015.

Harford, T.C, Wechsler, H., \& Muthen, B.O. (2003). Alcohol related aggression and drinking at off-campus parties and bars: A national study of current drinkers at college. Journal of Studies on Alcohol, 64, 704-711.

Haverkamp, B. E. (2005). Ethical perspectives on qualitative research in applied psychology. Journal of counseling psychology, 52(2), 146.

Heise, L. L. (1998). Violence against women an integrated, ecological framework. Violence against women, 4(3), 262-290

Heise, L., Ellsberg, M., \& Gottemoeller, M. (1999). Ending violence against women. Population reports, 27(4), 1-1.

Herring, R.,-Berridge, V., \& Thom, B. (2008). Binge drinking: an exploration of a confused concept. Journal of Epidemiology \& Community Health, 62(6), 476-479.

Hesse-Biber, S. N. (2011). Handbook of feminist research: Theory and praxis. Sage publications.

Hesse-Biber, S. N. (2014). Feminist approaches to in-depth interviewing. Feminist research practice: A primer, 182-232.

Hesse-Biber, S. N., \& Leavy, P. (2011.) The Practice of Qualitative Research. Sage Publications. 
Hey, V. (2006). The politics of performative resignification: Translating Judith Butler's theoretical discourse and its potential for a sociology of education. British Journal of Sociology of Education, 27(4), 439-457.

Hickey, C., \& Fitzclarence, L. (1999). Educating boys in sport and physical education: Using narrative methods to develop pedagogies of responsibility. Sport, Education and Society, 4(1), 51-62.

Holloway, I., \& Todres, L. (2003). The status of method: flexibility, consistency and coherence. Qualitative research, 3(3), 345-357.

Hubbard, P. (1999). Researching female sex work: reflections on geographical exclusion, critical methodologies and 'useful' knowledge. Area, 31(3), 229237.

Human Rights Commission (2016, September 8). An Open Letter to NZ Rugby [open letter]. Human Rights Commission. Retrieved from: https://thestandard.org.nz/nz-human-rights-commission-open-letter-to-nzrugby-union-on-respecting-women/

Huntemann, N. B. (2015). Working the Booth: Promotional Models and the Value of Affective Labor. In Banks, M., Conor, B., \& Mayer, V. (Eds.,) Production Studies, The Sequel! (pp. 59-65). Routledge.

Hutton, F., Griffin, C., Lyons, A., Niland, P., \& McCreanor, T. (2016). “Tragic girls” and "crack whores": Alcohol, femininity and Facebook. Feminism \& Psychology, 26(1), 73-93.

Illingworth, N. (2001). The Internet matters: Exploring the use of the Internet as a research tool. Sociological research online, 6(2), 1-12.

Jackson, T. L. (1991). A university athletic department's rape and assault experiences. Journal of College Student Development.

Jewkes, R. (2002). Intimate partner violence: causes and prevention. The lancet, 359(9315), 1423-1429.

Jewkes, R., Flood, M., \& Lang, J. (2015). From work with men and boys to changes of social norms and reduction of inequities in gender relations: a conceptual shift in prevention of violence against women and girls. The Lancet, 385(9977), 1580-1589.

Jewkes, R., Levin, J., \& Penn-Kekana, L. (2002). Risk factors for domestic violence: findings from a South African cross-sectional study. Social science \& 
medicine, 55(9), 1603-1617.

Johnson, A. (2005). The gender knot: Unraveling our patriarchal legacy. Philadelphia, PA: Temple University Press.

Jordan, C. E., Campbell, R., \& Follingstad, D. (2010). Violence and women's mental health: The impact of physical, sexual, and psychological aggression. Annual review of clinical psychology, 6, 607-628.

Jordan, J. (2004). Beyond belief? Police, rape and women's credibility. Criminal Justice, 4(1), 29-59.

Joseph, J., \& Falcous, M. (2017). Negotiating the 'Kiwi Bloke': accessing mosaic masculinities through Afro-Brazilian sport in New Zealand/Aotearoa. Qualitative Research in Sport, Exercise and Health, 1-15.

Kavanaugh, P. R. (2013). The continuum of sexual violence: Women's accounts of victimization in urban nightlife. Feminist Criminology, 8(1), 20-39.

Keene, S. M. (2015). Risky residences: An exploratory study of sexual violence in university halls of residence. (Masters thesis, Victoria university of Wellington, New Zealand). Retrieved from: http://researcharchive.vuw.ac.nz/xmlui/bitstream/handle/10063/4251/thesis.p df? sequence $=2$

Kelly, L. (1988). Surviving sexual violence. Minneapolis: University of Minnesota Press.

Kelly, L., \& Radford, J. (1990). 'Nothing really happened': the invalidation of women's experiences of sexual violence. Critical Social Policy, 10(30), 39-53.

Kensbock, S., Bailey, J., Jennings, G., \& Patiar, A. (2015). Sexual harassment of women working as room attendants within 5-star hotels. Gender, Work \& Organization, 22(1), 36-50.

Kift, S. (2005). Sport and the Law: Sex and the Team Player: When a Team Becomes a Gang. Alternative Law Journal, 30(3), 136-145.

Kimmel, M. S. (1994) Masculinity as homophobia: fear, shame, and silence in the construction of gender identity. Sage Publications: Thousand Oaks.

Kimmel, M. S., Hearn, J., \& Connell, R. W. (2004). Handbook of studies on men and masculinities. Sage Publications.

Kinnell, H. (2008). Violence and sex work in Britain. Cullompton: Willan.

Koss, M. P., \& Gaines, J. A. (1993). The prediction of sexual aggression by alcohol 
use, athletic participation, and fraternity affiliation. Journal of Interpersonal Violence, 8(1), 94-108.

Kyriacou, D. N., Anglin, D., Taliaferro, E., Stone, S., Tubb, T., Linden, J. A., ... \& Kraus, J. F. (1999). Risk factors for injury to women from domestic violence. New England journal of medicine, 341(25), 1892-1898.

Lamont, M. \& White, P. (2005). Workshop on Interdisciplinary Standards for Systematic Qualitative Research: Cultural Anthropology, Law and Social Science, Political Science, and Sociology Programs. National Science Foundation. 1-180. Retrieved from: http://www.nsf.gov/sbe/ses/soc/ISSQR_rpt.pdf\#page=70

Leichliter, J. S., Meilman, P. W., Presley, C. A., \& Cashin, J. R. (1998). Alcohol use and related consequences among students with varying levels of involvement in college athletics. Journal of American College Health, 46(6), 257-262.

Lemle, R., \& Mishkind, M. E. (1989). Alcohol and masculinity. Journal of substance abuse treatment, 6(4), 213-222.

Letherby, G. (2003). Feminist research in theory and practice. Buckingham: Open University Press.

Liamputtong, P. (2007). Researching the vulnerable: A guide to sensitive research methods. Sage.

Littleton, H. L., Rhatigan, D. L., \& Axsom, D. (2007). Unacknowledged rape: How much do we know about the hidden rape victim?. Journal of Aggression, Maltreatment \& Trauma, 14(4), 57-74.

MacKinnon, C. (1982) 'Feminism, Marxism, Method and the State: An agenda for theory.' Signs:Journal of women in culture and society, 7(3), 515-544.

Madigan, T., \& Delaney, T. (2009). Sports: Why people love them! University Press of America.

Mallett, R. K., Ford, T. E., \& Woodzicka, J. A. (2016). What did he mean by that? Humor decreases attributions of sexism and confrontation of sexist jokes. Sex Roles, 75(5-6), 272-284.

Manthei, R. J., \& Gilmore, A. (2005). The effect of paid employment on university students' lives. Education and Training, 47(3), 202-215.

Martin, S. L., Tsui, A. O., Maitra, K., \& Marinshaw, R. (1999). Domestic violence in northern India. American journal of epidemiology, 150(4), 417-426. 
Mayhew, P., \& Reilly, J. (2007). Community Safety: Findings from the New Zealand Crime \& Safety Survey 2006: Ministry of Justice Wellington.

McCabe, J. L., \& Holmes, D. (2009). Reflexivity, critical qualitative research and emancipation: A Foucauldian perspective. Journal of advanced nursing, 65(7), 1518-1526.

McCray, K. L. (2015). Intercollegiate athletes and sexual violence: A review of literature and recommendations for future study. Trauma, Violence, \& Abuse, 16(4), 438-443.

McEwan, B. J., Campbell, M. M., \& Swain, D. (2010). New Zealand culture of intoxication: Local and global influences. New Zealand Sociology, 25 (2), 15 37

McLeod, J. (2001). Qualitative research in counselling and psychotherapy. London: Sage.

Melnick, M. (1992). Male athletes and sexual assault. Journal of Physical Education, Recreation \& Dance, 63(5), 32-36.

Merriam, S. B., \& Tisdell, E. J. (2015). Qualitative research: A guide to design and implementation: John Wiley \& Sons.

Messner, M. A. (1990). When bodies are weapons: Masculinity and violence in sport. International review for the sociology of sport, 25(3), 203-220

Messner, M. A. (2002). Taking the field: Women, men, and sports: University of Minnesota Press

Messner, M. A., \& Sabo, D. F. (1994). Sex, violence \& power in sports: Rethinking masculinity. Freedom, CA: The Crossing Press.

Miller, T., \& Boulton, M. (2007). Changing constructions of informed consent: Qualitative research and complex social worlds. Social science \& medicine, 65(11), 2199-2211.

Moore, S. C., Shepherd, J. P., Eden, S., \& Sivarajasingam, V. (2007). The effect of rugby match outcome on spectator aggression and intention to drink alcohol. Criminal Behaviour and Mental Health, 17(2), 118-127.

Morin, K. M., Longhurst, R., \& Johnston, L. (2001). (Troubling) spaces of mountains and men: New Zealand's Mount Cook and Hermitage Lodge. Social \& Cultural Geography, 2(2), 117-139. 
Morris, R. C. (1995). All made up: Performance theory and the new anthropology of sex and gender. Annual review of anthropology, 24(1), 567-592.

Muir, K. B., \& Seitz, T. (2004). Machismo, misogyny, and homophobia in a male athletic subculture: A participant-observation study of deviant rituals in collegiate rugby. Deviant Behavior, 25(4), 303-32

Murnen, S. K., \& Kohlman, M. H. (2007). Athletic participation, fraternity membership, and sexual aggression among college men: A meta-analytic review. Sex Roles, 57(1-2), 145-157.

Nauright, J., \& Chandler, T. J. L. (1996). Making men: Rugby and masculine identity. London: Frank Cass \& Co

Nazneen, S., Darkwah, A., \& Sultan, M. (2014). Researching women's empowerment: Reflections on methodology by southern feminists. In Women's Studies International Forum, 45(1), 55-62.

Nelson, T. F., \& Wechsler, H. (2003). School spirits: Alcohol and collegiate sports fans. Addictive behaviors, 28(1), 1-11.

Olesen, V. (2011). Feminist qualitative research in the millennium's first decade: Developments, challenges, prospects. In N.K. Denzin, \& Y.S. Lincoln (Eds.), The SAGE-Handbook-of-Qualitative-Research (pp. 129-146). Thousand Oaks, CA: Sage

Ostrowsky, M. K. (2018). Sports-fans, alcohol-use, and-violent-behavior: Asociological-review. Trauma, Violence, \& Abuse, 19(4), 406-419.

O'Sullivan, C. (1991). Acquaintance gang rape on campus. In A. Parrot, \& L. Bechhofer (Eds.), Acquaintance rape: The hidden crime. New York: John Wdey \& Sons.

Palmer, C. (2011). Key themes and research agendas in the sport-alcohol nexus. Journal of sport and social issues, 35(2), 168-185.

Parks K, Miller B, Collins R and Zetes-Zanatta L (1998) 'Women's descriptions of drinkingin bars: reasons and risks.' Sex Roles 38(9/10), 701-17

Pasko, L. (2002). Naked power: The practice of stripping as a confidence game. Sexualities, 5, 49-66

Patton M.Q. (2002) Qualitative Research and Evaluation Methods. Sage Publications, Thousand Oaks, CA

Peitersen, B. (2009). Supporter culture in Denmark: The legacy of the 'world's best 
supporters'. Soccer and Society, 10, 374-385.

Phillips, J. (1987). A man's country? The image of the pakeha male, a history. Penguin Group New Zealand, Limited.

Phillips, J. (1996). The hard man: Rugby and the formation of male identity in New Zealand. In J. Nauright \& T. Chandler (Eds.), Making men: Rugby and masculine identity (pp. 70-90). London: Frank Cass \& Co

Phipps, A., \& Young, I. (2013). That's what she said: women students' experiences of lad culture in higher education. Retrieved from University of Sussex website: http://sro.sussex.ac.uk/49011/1/That's_what_she_said_full_report_Final_web. pdf

Plummer, D. (1999). One of the boys: Masculinity, homophobia, and modern manhood: Psychology Press.

Plummer, M., \& Young, L. E. (2010). Grounded theory and feminist inquiry: Revitalizing links to the past. Western Journal of Nursing Research, 32(3), 305-321.

Posadas, J. (2017). Teaching the cause of rape culture: toxic masculinity. Journal of Feminist Studies in Religion, 33(1), 177-179.

Poulston, J. (2008). Metamorphosis in hospitality: A tradition of sexual harassment. International Journal of Hospitality Management, 27(2), 232-240.

Price, M., \& Parker, A. (2003). Sport, sexuality, and the gender order: Amateur rugby union, gay men, and social exclusion. Sociology of sport journal, 20(2), 108126.

Pringle, R. (2001). Competing discourses: Narratives of a fragmented self, manliness and rugby union. International Review for the Sociology of Sport, 36(4), 425439 .

Pringle, R. (2004). A social-history of the articulations between rugby union and masculinities within Aotearoa/New Zealand. New Zealand Sociology, 19(1), 102-128.

Pringle, R. (2008). 'No rugby, no fear': collective stories, masculinities and transformative possibilities in schools. Sport, Education and Society, 13(2), 215-237.

Pringle, R. G., \& Hickey, C. (2010). Negotiating masculinities via the moral problematization of sport. Sociology of sport journal, 27(2), 115-138. 
Pringle, R., \& Markula, P. (2005). No pain is sane after all: A Foucauldian analysis of masculinities and men's rugby experiences of fear, pain, and pleasure. Sociology of sport journal, 22(4), 472-497.

PS Services (2010) Alcohol and Sport: What Is the Nature of the Relationship and Is There a Problem? A Scoping Study Prepared for SPARC. Aotearoa. Wellington, New Zealand: PS Services

Punch, K. F. (2005). Introduction to social research: Quantitative and qualitative approaches. London, England: Sage.

Quarrie, K. L., Feehan, M., Waller, A. E., Cooke, K. R., Williams, S., \& McGee, R. (1996). The New Zealand rugby injury and performance project: alcohol use patterns within a cohort of rugby players. Addiction, 91(12), 1865-1868.

Ram, Y. (2018). Hostility or hospitality? A review on violence, bullying and sexual harassment in the tourism and hospitality industry. Current Issues in Tourism, 21(7), 760-774.

Reicher, S. D., Spears, R., \& Postmes, T. (1995). A social identity model of deindividuation phenomena. European review of social psychology, 6(1), 161-198.

Reinharz, S. (1992). Feminist Methods in Social Research. New York: Oxford University Press.

Ridgeway, C. L., \& Correll, S. J. (2004). Unpacking the gender system: A theoretical perspective on gender beliefs and social relations. Gender \& society, 18(4), $510-531$.

Robinson, K. (2000). "Great Tits, Miss!" The silencing of male students' sexual harassment of female teachers in secondary schools: A focus on gendered authority. Discourse: studies in the cultural politics of education, 21(1), 7590.

Robinson, K. H. (2005). Reinforcing hegemonic masculinities through sexual harassment: issues of identity, power and popularity in secondary schools. Gender and education, 17(1), 19-37.

Ruback, R. B., Clark, V. A., \& Warner, C. (2014). Why are crime victims at risk of being victimized again? Substance use, depression, and offending as mediators of the victimization-revictimization link. Journal of interpersonal violence, 29(1), 157-185. 
Russo, N. F., \& Pirlott, A. (2006). Gender-based violence. Annals of the new york academy of sciences, 1087(1), 178-205.

Sage, G. H., \& Eitzen, D. S. (2016). Sociology of North American Sport. New York, NY: Oxford University Press.

Sanday, P. R. (1981). The socio-cultural context of rape: A cross-cultural study. Journal of social issues, 37(4), 5-27.

Sanday, P. R. (2007). Fraternity gang rape: sex, brotherhood and privilege on campus (2nd Ed). New York: New York University.

Sanders, T. (2001). Female street sex workers, sexual violence, and protection strategies. Journal of Sexual Aggression, 7(1), 5 -18.

Schaap, D., Postma, M., Jansen, L., \& Tolsma, J. (2015). Combating hooliganism in the-Netherlands: An evaluation of measures to combat hooliganism with longitudinal registration data. European Journal on Criminal Policy and Research, 21(1), 83-97.

Schacht, S. P. (1996). MISOGYNY ON AND OFF THE "PITCH" The Gendered World of Male Rugby Players. Gender \& Society, 10(5), 550-565.

Scholes-Balog, K. E., Hemphill, S. A., Kremer, P. J., \& Toumbourou, J. W. (2016). Relationships between sport participation, problem alcohol use, and violence: a longitudinal study of young adults in Australia. Journal of interpersonal violence, 31(8), 1501-1530.

Schwartz, M. D., \& DeKeseredy, W. S. (1997). Sexual assault on the college campus: the role of male peer support. Thousand Oaks: Sage Publications, Ltd.

Schwartz, M. D., \& Nogrady, C. A. (1996). Fraternity membership, rape myths, and sexual aggression on a college campus. Violence Against Women, 2(2), 148162.

Searles, P., \& Berger, R. J. (1995). Rape and society. Oxford, UK: Westview Press.

Segrave, J. O., McDowell, K. L., \& King, J. G. (2006). Language, gender, and sport: A review of the research literature. In Sport, Rhetoric, and Gender (pp. 31-41). Palgrave Macmillan, New York.

Semyonov, M., \& Farbstein, M. (1989). Ecology of sports violence: The case of Israeli soccer. Sociology of Sport Journal, 6, 50-59

Shavers, T., Baghurst, T., \& Finkelstein, M. (2015). The Influence of Social Status and Power on the Sexual Behavior of Male Collegiate Football 
Athletes. Journal for the Study of Sports and Athletes in Education, 9(2), 86101.

Sheets, A. M. (2017). "This Was Locker Room Talk": A Content Analysis on the Preservation and Policing of Rape Culture on Twitter. (Masters Thesis, Clemson University, South Carolina, USA). Retrieved from: https://tigerprints.clemson.edu/cgi/viewcontent.cgi?referer=https://scholar.go ogle.co.nz/\&httpsredir=1\&article=3680\&context=all_theses

Sivarajasingam, V., Moore, S., \& Shepherd, J. P. (2005). Winning, losing, and violence. Injury Prevention, 11(2), 69-70.

Skipper Jr, J. K., \& McCaghy, C. H. (1970). Stripteasers: The anatomy and career contingencies of a deviant occupation. Social problems, 17(3), 391-405.

Smith, D., \& Stewart, S. (2003). Sexual aggression and sports participation. Journal of Sport Behavior, 26(4), 384-395.

Smolak, L., \& Murnen, S. K. (2011). The sexualization of girls and women as a primary antecedent of self-objectification. In R. M. Calogero, S. TantleffDunn, \& J. K. Thompson (Eds.), Self-objectification in women: Causes, consequences, and counteractions (pp.53-75). Washington: American Psychological Association.

Sønderlund, A. L., O’Brien, K., Kremer, P., Rowland, B., De Groot, F., Staiger, P., ... \& Miller, P. G. (2014). The association between sports participation, alcohol use and aggression and violence: A systematic review. Journal of science and medicine in sport, 17(1), 2-7.

Spivey, S. E. (2005). Distancing and solidarity as resistance to sexual objectification in a nude dancing bar. Deviant Behavior, 26(5), 417-437.

Sprague, J. (2005). Feminist methodologies for critical researchers: Bridging differences. Walnut Creek, California: Lanham.

Stanley, E. (2012). Interviewing Victims of State Violence. In D. Gadd., S. Karstedt., \& S.F. Messner (Eds.), The Sage Handbook of Criminological Research Methods. 231-243. London: Sage Publications.

Stanley, L., \& Wise, S. (1993). Breaking out again: Feminist epistemology and ontology. London: Routledge.

Star, L. (1994). Televised rugby and male violence. New Zealand Journal of Media Studies, 1(1), 33-45. 
Star, L. (1999). 'Blacks are back': ethnicity, male bodies, exhibitionary order. In R. Law, H. Campbell, \& J. Dolan (Eds.), Masculinities in Aotearoa/New Zealand (pp. 229-250). Palmerston North: Dunmore Press.

Strauss, A., \& Corbin, J. (1998). Basics of qualitative research. Thousand Oaks.

Strauss, A., \& Corbin, J. M. (1990). Basics of qualitative research: Grounded theory procedures and techniques. Sage Publications, Inc.

Suddaby, R. (2006). From the editors: What grounded theory is not. The Academy of Management Journal, 49, (4), 633-642

Sutton, B. (2011). Playful cards, serious talk: a qualitative research technique to elicit women's embodied experiences. Qualitative research, 11(2), 177-196.

Swahn, M. H., \& Donovan, J. E. (2005). Predictors of fighting attributed to alcohol use among adolescent drinkers. Addictive behaviors, 30(7), 1317-1334.

Tarnas, R. (2010). The passion of the Western mind: Understanding the ideas that have shaped our world view. Random House.

Tate, C. C. (2012). Considering Lesbian Identity from a Social-Psychological Perspective: Two Different Models of "Being a Lesbian". Journal of lesbian studies, 16(1), 17-29.

Thompson Jr, E. H., \& Cracco, E. J. (2008). Sexual aggression in bars: What college men can normalize. The Journal of Men's Studies, 16(1), 82-96.

Thompson, S. (1988). Challenging the hegemony: New Zealand's women's opposition to rugby and the reproduction of capitalist patriarchy. International Review for the Sociology of Sport, 23(2), 205-223.

Thomson, R. (1993). Point of view: Rugby into the twenty-first century. Journal of Physical Education New Zealand, 26(3), 1.

Tierney, J., \& Hobbs, D. (2003). Alcohol-related crime and disorder data: guidance for local partnerships. London: Home Office.

Tovia, K.(2014). Making Sense of the Everyday Women Rugby Player. (Masters Thesis, Victoria University, Wellington, New Zealand) Retrieved from https://viewer.waireto.victoria.ac.nz/client/viewer/IE171184/details?dps_dvs= 1548573652450 99

Town, S. (1999) Queer(y)ing masculinities in schools: faggots, fairies and the first XV, in: R. Law, H. Campbell \& J. Dolan (Eds) Masculinities in Aotearoa/New Zealand (Palmerston North, NZ, Dunmore Press), 135152. 
Trevelyan, M., \& Jackson, S. (1999). Clash of the codes: A comparative analysis of media representations of violence in rugby union and rugby league. In $\mathrm{J}$. Nauright (Ed.), Sport, power and society in New Zealand: Historical and contemporary perspectives. ASSH Studies in Sport History, 11, 113-138.

Trippany, R. L., Kress, V. E. W., \& Wilcoxon, S. A. (2004). Preventing vicarious trauma: What counselors should know when working with trauma survivors. Journal of Counseling \& development, 82(1), 31-37.

Tutenges, S., Bøgkjær, T., Witte, M., \& Hesse, M. (2013). Drunken environments: a survey of bartenders working in pubs, bars and nightclubs. International journal of environmental research and public health, 10(10), 4896-4906.

Ullman, S. E., Relyea, M., Peter-Hagene, L., \& Vasquez, A. L. (2013). Trauma histories, substance use coping, PTSD, and problem substance use among sexual assault victims. Addictive behaviors, 38(6), 2219-2223.

Vaes, J., Paladino, P., \& Puvia, E. (2011). Are sexualized women complete human beings? Why men and women dehumanize sexually objectified women. European Journal of Social Psychology, 41(6), 774-785.

Van Manen, M. (1990). Researching lived experiences. State University of New York Press, Albany.

Varela, S. (2014). "Drunk and proud," from the streets to the stands: America Football Club fans, aguante and alcohol consumption in Mexican football fandom. International Review for the Sociology of Sport, 49, 435-450

Veliz, P., Schulenberg, J., Patrick, M., Kloska, D., McCabe, S. E., \& Zarrett, N. (2017). Competitive sports participation in high school and subsequent substance use in young adulthood: Assessing differences based on level of contact. International review for the sociology of sport, 52(2), 240-259.

Watson J (2000) The right to party safely: a report on young women, sexual violence and licensed premises, CASA House, Melbourne

Watson, L. B., Marszalek, J. M., Dispenza, F., \& Davids, C. M. (2015). Understanding the relationships among White and African American women's sexual objectification experiences, physical safety anxiety, and psychological distress. Sex roles, 72(3-4), 91-104.

Watts, C., \& Zimmerman, C. (2002). Violence against women: global scope and magnitude. The lancet, 359(9313), 1232-1237. 
Weiss, K. G. (2009). "Boys will be boys" and other gendered accounts: An exploration of victims' excuses and justifications for unwanted sexual contact and coercion. Violence Against Women, 15(7), 810-834.

Weitzer, R. (2018). Resistance to sex work stigma. Sexualities, 21(5-6), 717-729.

Welch, M. (1997). Violence against women by professional football players: A gender analysis of hypermasculinity, positional status, narcissism, and entitlement. Journal of Sport and Social Issues, 21(4), 392-411.

Wenner, L. A., \& Jackson, S. (2009). Sport, beer, and gender in promotional culture: On the dynamics of a holy trinity. New York, NY: Peter Lang.

West, C., \& Zimmerman, D. H. (1987). Doing gender. Gender \& society, 1(2), $125-$ 151.

Whannel, G. (2005). Media sport stars: Masculinities and moralities. Routledge.

Willness, C. R., Steel, P., \& Lee, K. (2007). A meta-analysis of the antecedents and consequences of workplace sexual harassment. Personnel psychology, 60(1), 127-162.

Wood, J. (2009). Feminist standpoint theory. In S. Littlejohn and K. Foss (Eds.), Encyclopedia of communication theory (pp. 397-399). Thousand Oaks: Sage Publications, Inc.

Woolley, S. R., Butler, M. H., \& Wampler, K. S. (2000). Unraveling change in therapy: Three different process research methodologies. American Journal of Family Therapy, 28(4), 311-327.

World Health Organization. (2013). Global and regional estimates of violence against women: prevalence and health effects of intimate partner violence and nonpartner sexual violence. Switzerland: WHO. Retrieved from: https://apps.who.int/iris/bitstream/handle/10665/85239/?sequence=1

Yagil, D. (2008). When the customer is wrong: A review of research on aggression and sexual harassment in service encounters. Aggression and Violent Behavior, 13(2), 141-152.

Yllö, K. (1984). The status of women, marital equality, and violence against wives: A contextual analysis. Journal of family Issues, 5(3), 307-320.

Young, B. R., Desmarais, S. L., Baldwin, J. A., \& Chandler, R. (2017). Sexual coercion practices among undergraduate male recreational athletes, intercollegiate athletes, and non-athletes. Violence against women, 23(7), 795- 
812.

Young, K. (2012). Sport, violence and society. London, England: Routledge. 